\title{
Antioxidant Activity of Oat Peptides in Hepatic HepG2 Cells
}

\section{By}

\section{Yichen Du}

A thesis submitted to the Faculty of Graduate and Postdoctoral Affairs in partial fulfillment of the requirements for the degree of

Masters of Science

In

Chemistry

(Specialization in Food Science and Nutrition)

Carleton University

Ottawa, Ontario, Canada

(C) 2015

Yichen Du 


\begin{abstract}
The health benefits of oats have long been established, with their protective activities against cardiovascular diseases and blood sugar being the most prevalent, although the protective effect against cancer has been demonstrated as well. In all these conditions, antioxidants and fibres present in oats are believed to be the most beneficial molecules. Recently however, it has been demonstrated that hydrolyzed proteins and their fractions have biological properties beyond their basic nutritional function. Many studies have been performed to demonstrate the antioxidant activities of hydrolyzed proteins and peptides from cereals such as corn, wheat, and barley using in vitro chemical assays. Two studies have also demonstrated the antioxidant properties of hydrolyzed oat proteins in chemical-based assays. Oat protein hydrolysates produced using different enzymes were analyzed. From the oat protein hydrolysate fraction with highest radical scavenging, which was produced using viscozyme and alcalase, four peptides were identified. These peptides include GQTVFNDRLRQGQLL (P4), YHNAPGLVYIL (P6), and DVNNNANQLEPR (P7), as well as their fragments GQTV (P3), FNDRLRQGQLL (P1), YHNAP (P5), and GLVYL (P2). The purpose of the current study was to establish the antioxidant activities of these peptides using chemical and cell culture based assays. The current research found that all seven peptides exhibited radical scavenging activity in ORAC assay, with P2 (0.67 $\mu \mathrm{M}$ Trolox equivalent (TE)/ $\mu \mathrm{M}$ peptide), P5 (0.61 $\mu \mathrm{M} \mathrm{TE} / \mu \mathrm{M}$ peptide), and $\mathrm{P} 3(0.52 \mu \mathrm{M} \mathrm{TE} / \mu \mathrm{M}$ peptide) having the highest activities, followed by P6, P4, P1, and P7 (0.14-0.37 $\mu \mathrm{M}$ TE/ $\mu \mathrm{M}$ peptide. The cytoprotective effect of the peptides was determined using the human hepatoma HepG2 cell model. Oxidative stress was induced in HepG2 cells by 2,2'-azobis (2-methylpropionamidine) dihydrochloride (AAPH), and
\end{abstract}


protective activities of peptides against AAPH including cell death, alteration of the antioxidant enzymes glutathione peroxidase (GPx), superoxide dismutase (SOD), and catalase (CAT), change in total glutathione and levels of reactive oxygen species (ROS). Two different concentrations, 50 and $100 \mu \mathrm{M}$ of each peptide were used to establish whether the effects were dosedependent. None of the peptides showed cytotoxicity. P2 increased cell viability by approximately 5-fold at both concentrations. However, P1 and P7 at $50 \mu \mathrm{M}$ as well as P3, P4, and P5 at both 50 and $100 \mu \mathrm{M}$ did not protect cells from AAPH-induced death. On the other hand, $\mathrm{P} 1$ and $\mathrm{P} 7$ at $100 \mu \mathrm{M}$, as well as $\mathrm{P} 2$ and $\mathrm{P} 6$ at both concentrations enhanced cell survival to between $65-143 \%$, with P2 increasing cell survival passed that of untreated cells. Treatment with AAPH decreased activities of GPx, SOD, and total glutathione by $18 \%, 29 \%$, and $48 \%$, respectively. Meanwhile AAPH treatment increased the CAT activity by almost 2-fold and ROS by $36.9 \%$. For both GPx and glutathione, treatments with P1, P2, and P6 at 50 and $100 \mu \mathrm{M}$ as well as P7 at $50 \mu \mathrm{M}$ only significantly inhibited the effect of AAPH. In the SOD assay, only P2 (50 and $100 \mu \mathrm{M})$, and P1 (100 $\mu \mathrm{M})$ attenuated the decrease of SOD activity by AAPH. P2 and P7 brought the activity of SOD back to that of untreated cells (negative control, NEG). The activity catalase, which increased after AAPH treatment, was further increased in the presence of P1, P2, P6, and P7 at both concentrations. The decrease SOD and GPx activities of HepG2 cells after treatment with AAPH were associated to the increase of intracellular ROS. The protection provided by peptides (P1, P2, P6, and P7) can then be attributed to their radical scavenging activity and to their potential to increase GSH levels. In most cases, the activity of the peptides correlated with their hydrophobicity. 


\section{DEDICATION}

This thesis is dedicated to my father, mother, and my sister Sylvia. For the completion of

this work would not have been possible without their unconditional love, support, and encouragement. 


\section{ACKNOWLEDGEMENTS}

My sincere thank you to my family. My loving parents, to whom I am forever indebted. My sister Sylvia, who has stood by me through thick and thin. I am also grateful to my caring aunt Huiling, grandma Guimei, and Cousin Kimberly for always believing in me.

I would like to express my utter gratitude to my supervisor, Dr. Apollinaire Tsopmo, for providing expertise, valuable guidance, patience and encouragement to me.

I am immensely grateful to Dr. William G. Willmore, for co-supervising my work and for sharing his pearl of wisdom with me as well as providing the necessary environment for the completion of the current research.

A special thanks to my significant other Zachary, for his continuous support and encouragement throughout my academic career. I would also like to thank my friends Sara, Morooj, Rowida, and Bianca, who have provided support and encouragement for my growth and learning, not only in the academic area, but also in life. 


\section{TABLE OF CONTENTS}

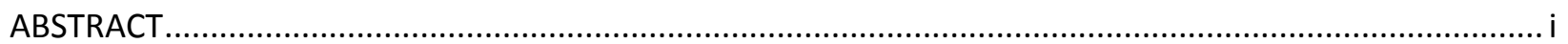

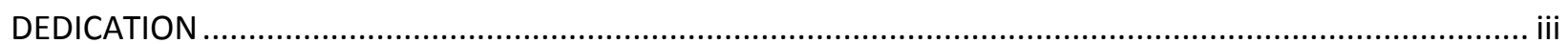

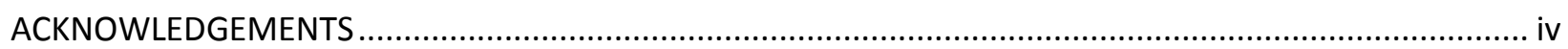

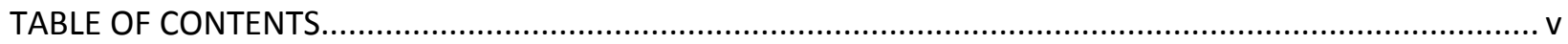

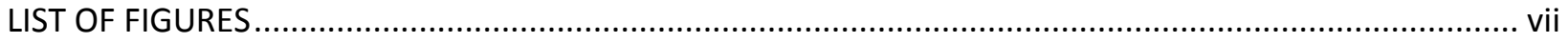

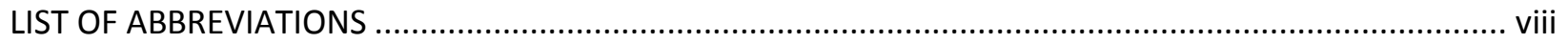

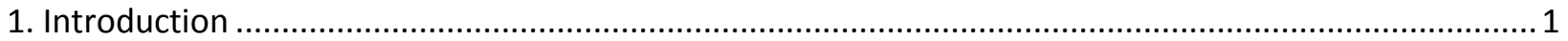

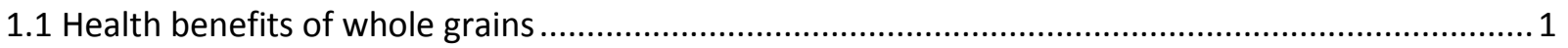

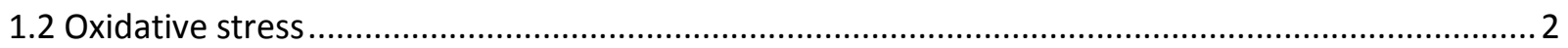

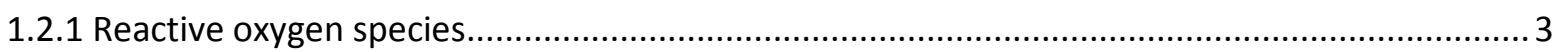

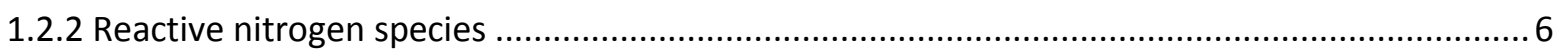

1.2.3 Oxidative stress and pathophysiological state.................................................................... 7

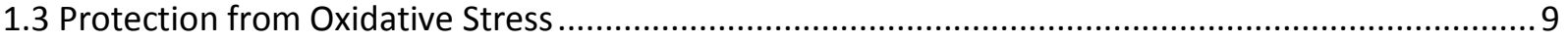

1.3.1. Endogenous Antioxidant Defense System ........................................................................ 9

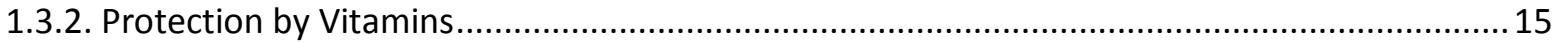

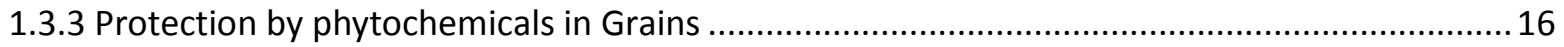

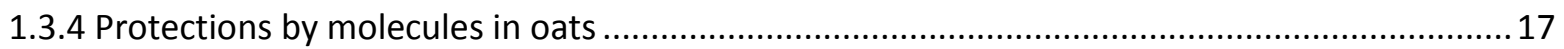

1.4 Oat and cereals derived antioxidative peptides and protein hydrolysates ................................... 19

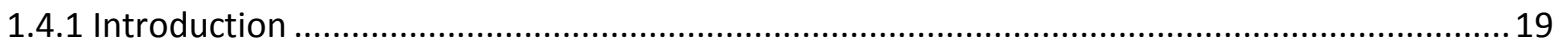

1.4.2 Activity of peptides and proteins in condition associated with oxidative stress ......................20

1.5 Methods for evaluation of food-derived compounds with antioxidant activity .............................22

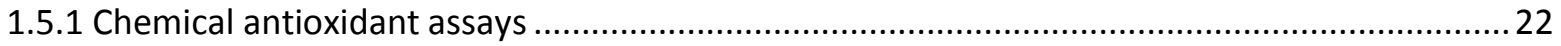

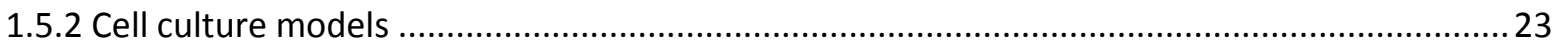

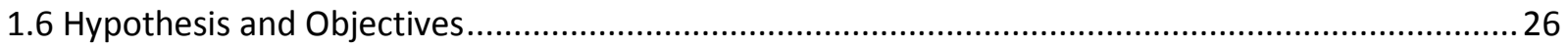

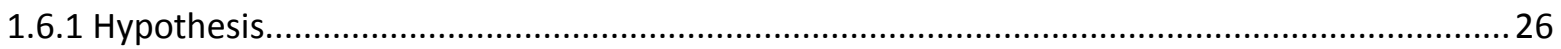

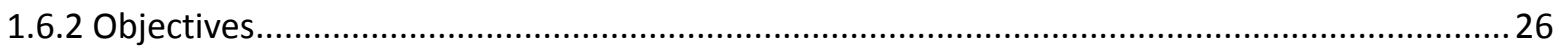

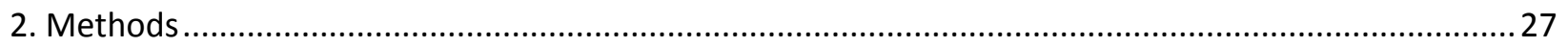

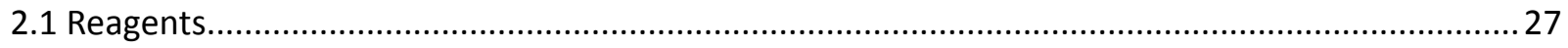

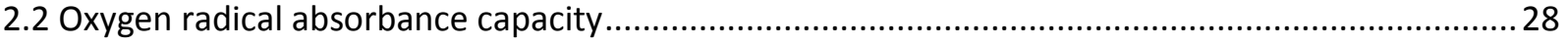

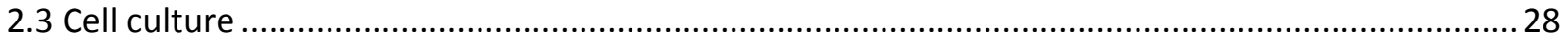




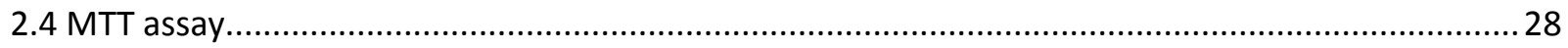

2.5 Measurement of antioxidant enzymes and total glutathione .........................................................29

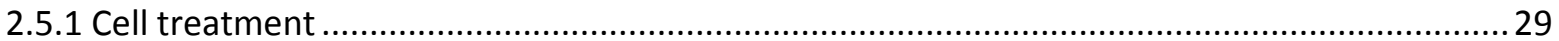

2.5.2 Determination of glutathione peroxidase activity ................................................................. 30

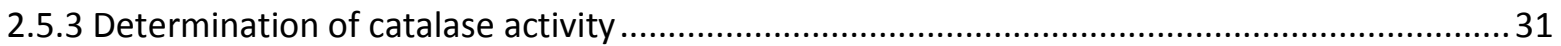

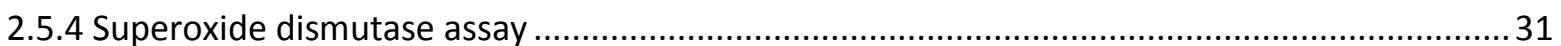

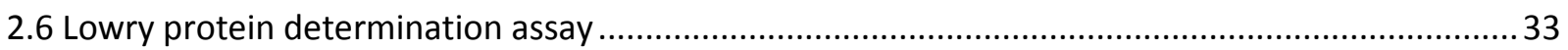

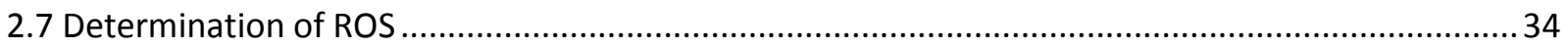

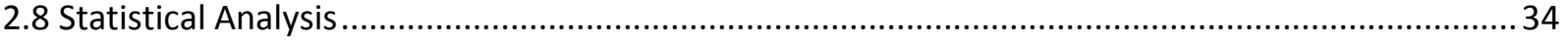

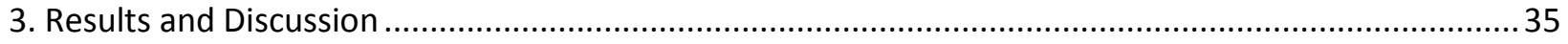

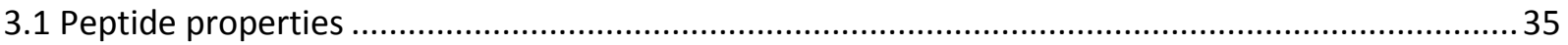

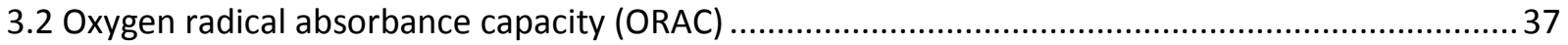

3.3 Cytotoxicity and cytoprotective effects of the peptides .............................................................. 40

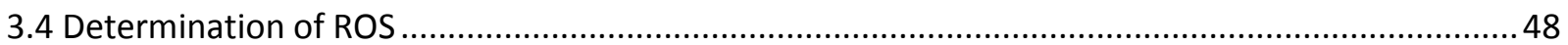

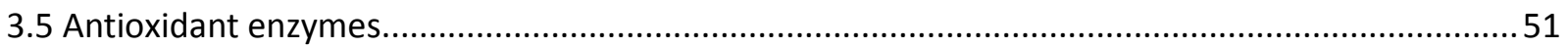

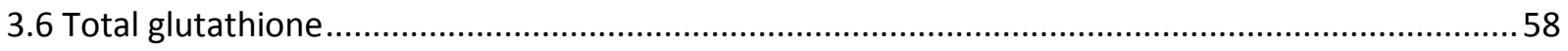

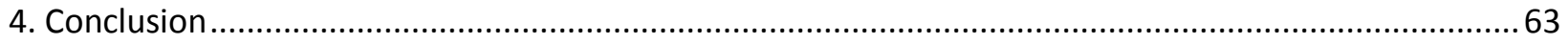

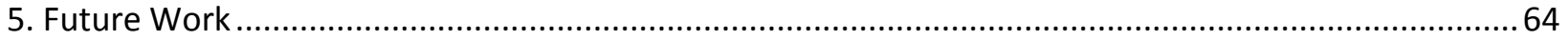

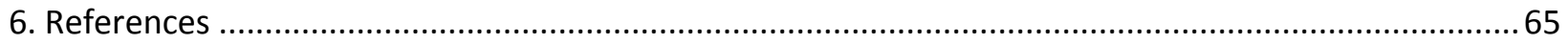




\section{LIST OF FIGURES}

Figure 1. Formation of reactive oxygen species ................................................................ 3

Figure 2. Reacion scheme of antioxidant enzymes GPx, SOD, and CAT............................... 10

Figure 3. Oxygen radical absorbance capacity (ORAC) values of the peptides. ........................ 38

Figure 4. Effect of peptides on the viability of HepG2 cells............................................. 41

Figure 5. Protective effects of peptides against AAPH - induced cell death .......................... 43

Figure 6. Effect of peptides on the generation of intracellular ROS....................................... 50

Figure 7. Effect of peptides on GPx level of HepG2 cells stressed with AAPH. ........................ 54

Figure 8. Effect of peptides on SOD levels of HepG2 cells treated with AAPH ........................ 56

Figure 9. Catalase levels of AAPH-stressed HepG2 cells pre-treated with peptides.................. 57

Figure 10. Effect of peptides on GSH levels of HepG2 cells treated with 20 mM AAPH ............. 59 


\section{LIST OF ABBREVIATIONS}

(P1)

(P2)

(P3)

(P4)

(P5)

(P6)

(P7)

(ROS)

(RNS)

(ORAC)

(AAPH)

$\left(\mathrm{O}_{2}^{-\bullet}\right)$

( $\left.\mathrm{HOO}^{\circ}\right)$

(LOO*)

$\left({ }^{\circ} \mathrm{OH}\right)$

$(\mathrm{LOOH})$

$\left({ }^{1} \mathrm{O}_{2}\right)$

$\left(\mathrm{O}_{3}\right)$

$\left(\mathrm{H}_{2} \mathrm{O}_{2}\right)$

( $\mathrm{HOCl})$

(०ON)

(ONOO-)

(ONOOH)

(t-OOH)

(NEG)

(POS)

(DCFH 2 - DA)

$\left(\mathrm{RhH}_{2}\right)$

(NADPH)

(Nox)

(8-OHdG)

(GPx)

(SOD)

(CAT)

(GSH)

(GSSG)

('GS)

(PUFA)

(DNA)

(RNA)

(HDL)
FNDRLRQGQLL

GLVYIL

GQTV

GQTVFNDRLRQGQLL

YHNAP

YHNAPGLVYIL

DVNNNANQLEPR

Reactive oxygen species

Reactive nitrogen species

Oxygen radical absorbance capacity

2, 2'-Azobis (2-methylpropionamidine) dihydrochloride Superoxide anion

Hydroperoxyl radical

Peroxyl radical

Hydroxyl radical

Alkyl hydroperoxides

Singlet oxygen

Ozone

Hydrogen peroxide

Hypochlorous acid

Nitric oxide

Peroxynitrite

Peroxynitrous acid

Tert-butyl-hydperoxide

Negative control

Positive control

Dicholorodihydrofluorescein diacetate

Dihydrorhodamine

Nicotinamide adenine dinucleotide phosphate

Nicotinamide adenine dinucleotide phosphate oxidase

8-hydroxy-2'-deoxyguanosine

Glutathione peroxidase

Superoxide dismutase

Catalase

Reduced glutathione

Oxidized glutathione

Glutathionyl radical

Polyunsaturated fatty acid

Deoxyribonucleic acid

Ribonucleic acid

High density lipoprotein 
(MDA)

(TRAP)

(FRAP)

(CHD)

(ASCVD)

(ALS)

(PD)

(AD)
Malondialdehyde

Total radical-trapping antioxidant parameter Ferric reducing/antioxidant power

Cardiovascular disease

Atherosclerotic cardiovascular disease

Amyotrophic lateral sclerosis

Parkinson's disease

Alzheimer's disease 


\section{Introduction}

\subsection{Health benefits of whole grains}

Cereal grain products are consumed as a staple food world-wide. The most commonlyconsumed ones include wheat, rice, corn, oats, rye, and barley. ${ }^{1}$ Whole grains are not only rich in dietary fibres and starch, they are also good sources of minerals, vitamins, phytoestrogens, and antioxidants whose amounts vary depending on the type of grain. ${ }^{1}$ Additionally, epidemiological studies have found relationships between the consumption of whole grains and the risks of cardiovascular disease, diabetes, and cancer..$^{2-4}$

Multiple studies have shown negative correlations between whole grain intakes and risk factors of atherosclerotic cardiovascular disease (ASCVD). ${ }^{2}$ Correlations have also been observed between the consumption of whole grains and the reduction in the incidence of type 2 diabetes, possibly due to alteration in insulin sensitivity and decrease in blood glucose. ${ }^{5}$ Increase in consumption of whole grains enhanced insulin sensitivity in non-diabetic hyperinsulinaemic subjects, while pre-prandial plasma glucose reduction was observed in diabetic individuals. ${ }^{3,6}$ As well, several studies on European and American populations have found that the reduction in risks of gastric and colorectal cancer was correlated with high consumption of whole grains. ${ }^{4,7-9}$

Protective effects of whole grains are often attributed to the abundance of dietary fibres. However, the protective effects of dietary fibres extracted from whole grains do not necessarily reflect that of direct consumption of whole grain. A Meta-analysis by Anderson et al. indicated that the consumption of whole grains was strongly protective against the 
incidence of ASCVD while cereal fibres only provide a modest protection. ${ }^{2}$ In many studies that reported beneficial effects, fibers are almost never $100 \%$ pure meaning other molecules like vitamins, minerals, polyphenols, amino acids, peptides or proteins may have contributed to the observed activity. Thus, the discovery of the beneficial property of these other compounds can provide a better understanding of the health effect associated with whole grain consumption. Amongst grains components, phytochemicals such as phenolic acids, vitamin $E$, and phytic acid have been investigated for their role in the prevention of chronic diseases. Phenolic acids are concentrated in the bran layer, with ferulic acid being the most abundant in wheat bran. Ferulic and caffeic acids are inhibitors of carcinogenesis and can not only prevent the formation of carcinogens, but also protect biological molecules from being attacked by carcinogens. ${ }^{10}$ Vitamin $\mathrm{E}$ is capable of protecting cellular membrane from oxidative damage as well as of promoting the reduced state of selenium, which can be utilized as cofactor for glutathione peroxidase. ${ }^{11}$ On the other hand, phytic acids can chelate metal ions capable of catalyzing oxidative chain reactions, hence protecting intestinal epithelium from oxidant molecules produced by colonic bacteria. ${ }^{12}$ There are several mechanisms by which oat and other grains reduce the risk of chronic diseases including immune system modulation, gene regulation, and regulation of the redox balance. This thesis focuses on factors, molecules or enzymes that the later (i.e. redox balance, oxidative stress).

\subsection{Oxidative stress}

Oxidative stress can be defined as the imbalance between oxidants and reductants present in the cell in which the previous outweighs the latter. Over-production of oxidants such as reactive oxygen species (ROS) and reactive nitrogen species (RNS) can lead to damage of 
cellular components including deoxyribonucleic acid (DNA), proteins, and lipid membranes. Oxidative stress has been correlated with many pathophysiological conditions and disease states such as neurological disorders, chronic inflammation, and atherosclerosis. ${ }^{13,14}$

There are various sources of ROS/RNS generation in a cell, including cytochrome P-450catalyzed metabolism and immunological response of phagocytes. ${ }^{15,16}$ However, the most important site of ROS/RNS generation is the mitochondria due to its function in the electron transport chain. Approximately $0.1-4 \%$ of oxygen consumed by the mitochondria is converted into ROS, with $2 \%$ being $\mathrm{O}_{2} \cdot{ }^{\cdot}{ }^{17}$ Oxygen is readily reduced into $\mathrm{O}_{2} \cdot{ }^{\cdot}$ in the intra mitochondrial space, due to the high reducing environment and the presence of respiratory complexes such as iron-sulfur clusters, ubisemiquionone, and flavoproteins, which are capable of single electron transfer. As well, single electron reactions are prevalent in the electron transport chain. ${ }^{18}$

\subsubsection{Reactive oxygen species}

Reactive oxygen species (ROS) is a term used to describe chemically reactive molecules derived from oxygen, including radicals and non-radicals. Free radicals are independently existing atoms/molecules that contain one or more unpaired electrons. Free radical ROS includes superoxide $\left(\mathrm{O}_{2}{ }^{\circ}\right)$, hydroperoxyl radical $(\mathrm{HOO})$, peroxyl radical (LOO'), and hydroxyl radical ('OH); whereas non-radical consists of hydrogen peroxide $\left(\mathrm{H}_{2} \mathrm{O}_{2}\right)$, alkyl hydroperoxides (LOOH), singlet oxygen $\left({ }^{1} \mathrm{O}_{2}\right)$, ozone $\left(\mathrm{O}_{3}\right)$, as well as hypochlorous acid $(\mathrm{HOCl}) \cdot{ }^{19}$

Singlet oxygen and superoxide anion are ROS species which can be formed directly from oxygen (Figure 1). Ground state oxygen $\left(\mathrm{O}_{2}\right)$ exists in a diatomic form with two unpaired electrons at parallel spin. When energy is transferred from a triplet excited molecule, the spin 
of one of these electrons can be reversed and singlet oxygen $\left({ }^{1} \mathrm{O}_{2}\right)$ is formed, and the spin restriction rule no longer applies ${ }^{20}$ Hence, ${ }^{1} \mathrm{O}_{2}$ can receive one pair of electron, making it highly reactive. As a result, ${ }^{1} \mathrm{O}_{2}$ readily attacks cell components such as proteins, DNA, and cell membrane ${ }^{21}$. The generation of singlet oxygen can be caused by photosensitizing agents such as porphyrins and riboflavin absorbing sunlight, transferring energy to $\mathrm{O}_{2} \cdot{ }^{22}$ For example, skin damage in several forms of skin porphyria is believed to be caused by accumulated porphyrins absorbing sunlight and producing singlet oxygen. ${ }^{22}$ When an electron is donated to ${ }^{1} \mathrm{O}_{2}$ by substances capable of single electron transfer, superoxide anion is formed.

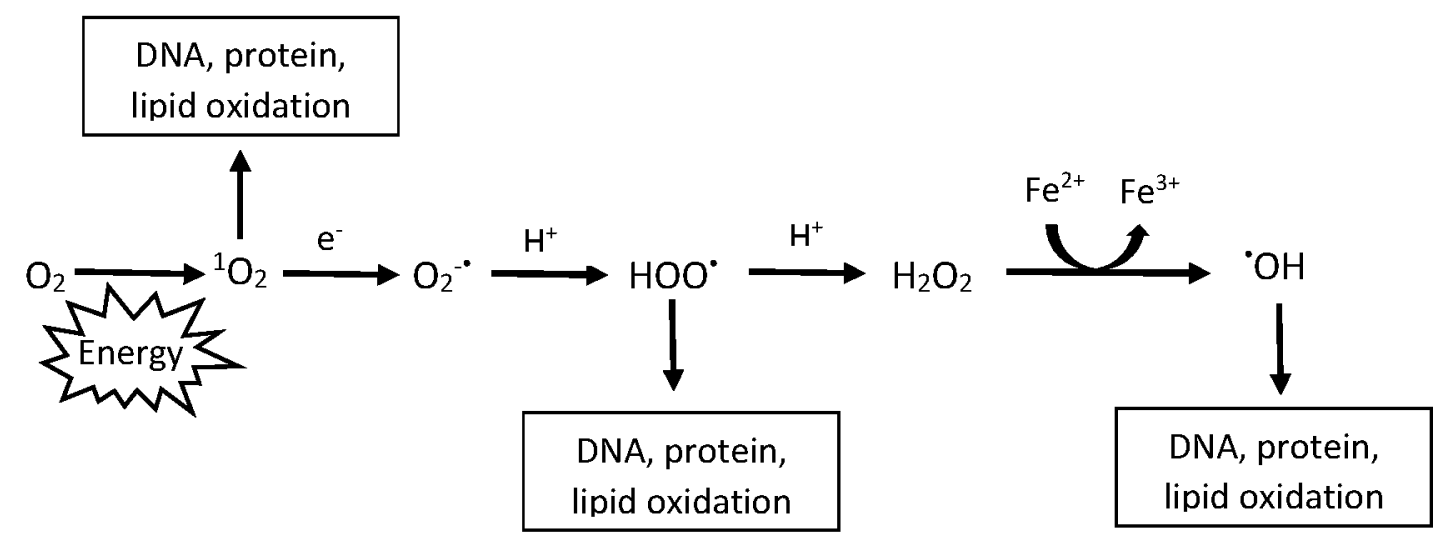

Figure 1. Formation of reactive oxygen species (adapted from Cadenas and Davies). ${ }^{19}$

Superoxide anion is a special free radical that can be either an oxidant or a reductant, with its reductive potential being biologically relevant. ${ }^{23}$ Unlike singlet oxygen, the reaction between superoxide anion and biological components such as proteins, lipids, and DNA is not significant due to the low rate of reaction. ${ }^{23}$ However, the intermediate produced during 
protonation of $\mathrm{O}_{2}^{-}$, hydroperoxyl radical $\left(\mathrm{HOO}^{\circ}\right)$, is capable of damaging biological membranes by reacting with polyunsaturated fatty acids (PUFA). ${ }^{24}$ Moreover, $\mathrm{O}_{2}{ }^{-}$can be converted to $\mathrm{H}_{2} \mathrm{O}_{2}$ through spontaneous dismutation or catalyzed by superoxide dismutase (SOD). ${ }^{23}$

Although $\mathrm{H}_{2} \mathrm{O}_{2}$ is a poor oxidizing agent, it has the ability to move freely throughout intracellular and extracellular space. ${ }^{25}$ More importantly, $\mathrm{H}_{2} \mathrm{O}_{2}$ can interact with transition metals, mainly $\mathrm{Fe}^{2+}$ and $\mathrm{Cu}^{+}$, to produce ${ }^{\circ} \mathrm{OH}$ through Fenton reaction, which is believed to be the most important source of ${ }^{\circ} \mathrm{OH}^{25}$ Besides production of $\mathrm{H}_{2} \mathrm{O}_{2}, \mathrm{O}_{2}{ }^{-}$can also promote formation of ${ }^{\circ} \mathrm{OH}$ by reduction of ferric ion $\left(\mathrm{Fe}^{3+}\right)$ to ferrous ion $\left(\mathrm{Fe}^{2+}\right)$ and $\mathrm{Cu}^{2+}$ to $\mathrm{Cu}^{+}$, which is essential for Fenton reaction (Figure 1).

'OH is believed to be the most damaging of all reactive species, due to its capability to react with a wide range of molecules as well as the high rate of reaction. ${ }^{14}{ }^{\circ} \mathrm{OH}$ readily reacts with deoxyribonucleic acid (DNA), proteins, carbohydrates, and ribonucleic acid (RNA), and is implicated in various diseases such as atherosclerosis, neurological disorders, and cancer. ${ }^{14}$

Lipid peroxidation, a free radical chain reaction commonly studied, yields three types of ROS: alkyl radicals (LO), alkyl peroxyl radicals (LOO'), and alkyl hydroperoxides (LOOH). ${ }^{26}$ The initiation of lipid peroxidation involves free radicals such as ${ }^{\circ} \mathrm{OH}$ or ${ }^{\circ} \mathrm{OOH}$ attacking an unsaturated fatty acid, producing LO and LOO; which are capable of attacking membrane proteins or other fatty acids. ${ }^{26}$ As a result, more peroxyl radicals are produced, causing damage to a large amount of fatty acids, all due to a single event of initiation. ${ }^{26}$ Lipid peroxidation generates a wide variety of products such as aldehydes and hydroperoxides which have been shown to exert genotoxic and cytotoxic effects. ${ }^{27}$ Abnormally high levels of lipid peroxidation 
products 4-hydroxylnonenal and malonaldehyde have been found in human atherosclerotic lesions. ${ }^{27}$

\subsubsection{Reactive nitrogen species}

Reactive nitrogen species include the free radicals nitric oxide ('ON), nitrogen dioxide $\left({ }^{\circ} \mathrm{NO}_{2}\right)$, and the non-radical peroxynitrite (ONOO$)$ and peroxynitrous acid $(\mathrm{ONOOH}) \cdot{ }^{28}$ By itself, 'NO is a non-toxic radical that is rapidly converted to nitrate by oxyhemoglobin present in red blood cells. However, in the presence of $\mathrm{O}_{2}^{-\bullet}$ at close proximity, "NO quickly reacts with it, forming the highly toxic ${ }^{-} \mathrm{ONOO} .^{29}$ The toxicity of ${ }^{-} \mathrm{ONOO}$ is contributed by its high stability and reactivity. Moreover, approximately $20 \%$ of peroxynitrite at physiological pH exists as $\mathrm{ONOOH}$, which is also a strong oxidizing agent. ${ }^{29}$ Both ${ }^{-} \mathrm{ONOO}$ and $\mathrm{ONOOH}$ can oxidize most biological molecules such as proteins, lipids, DNA, and RNA.

ROS/RNS was thought to be an undesired by-product of cellular respiration. However, new evidence emerged indicating the important role of ROS in cell signalling, including maintenance of redox homeostasis, vascular tone regulation, and control of ventilation. For example, "NO is a signalling molecule produced by oxidation of arginine, catalyzed by nitric oxide synthase. ${ }^{30}$ Due to its small size, ${ }^{*} \mathrm{NO}$ is a non-specific signalling molecule that has activity in virtually all organs. NO stimulates the production of cyclic guanylate monophosphate (cGMP) and cGMP- dependent kinases by activation of guanylate cyclase. ${ }^{31}$ Hence, $\bullet \mathrm{NO}$ is a messenger that plays a diverse role in intercellular as well as intracellular signal transduction, and as a result regulates various physiological activities such as mitochondrial respiration, vascular homeostasis, and possibly apoptosis. ${ }^{32-34}$ NO is an inhibitor of the enzyme NOS, which acts as the feedback inhibition of ${ }^{\circ O}$ production. ${ }^{35}$ In addition, studies suggest that in low 
concentrations, ROS activates genes involved in the production of catalase. ${ }^{36}$ In addition, $\mathrm{O}_{2}{ }^{-}$, and $\mathrm{H}_{2} \mathrm{O}_{2}$ may also promote the activation of guanylate cyclase. ${ }^{37,38}$ As well, ROS plays a role in regulating ventilation, possibly through controlling potassium influx of type I chemoreceptor cells, which is involved in the transduction of the sinus nerve signal. ${ }^{39,40}$ One of the proposed mechanisms of ROS as signalling molecules is the formation of protein disulfide bonds. For example, $\mathrm{H}_{2} \mathrm{O}_{2}$ promotes the formation of disulfide bonds in a variety of proteins including molecular chaperones, glycolytic, cell growth, cytoskeletal and antioxidant proteins. ${ }^{41}$ Through formation of disulfide bond, ROS can promote the activation and inactivation of proteins. ${ }^{41}$

\subsubsection{Oxidative stress and pathophysiological state}

Evidence of free radical damage has been demonstrated in neurodegenerative diseases, CVD, diabetes, and certain types of cancer.

Neurodegenerative diseases such as amyotrophic lateral sclerosis (ALS), Parkinson's disease (PD) and Alzheimer's disease (AD) are correlated with oxidative stress. A mutation of CuZn-SOD can be found in approximately $20 \%$ of familial ALS, which is positively correlated to neuronal degeneration, an increase in products of 'ONOO attack such as carbonyl protein, nitrotyrosine and 8-hydroxy-2'-deoxyguanosine. ${ }^{42}$ Unlike normal SOD, mutant CuZn-SOD induce free radical production and causes damage to neurons. ${ }^{42}$ As well, there exists strong correlation between brain damage in PD and elevated lipid peroxidation, DNA oxidation, iron accumulation, and GSH depletion. ${ }^{43}$ Additionally, increase in iron levels and 8-hydroxy-2'deoxyguanosine as well as decrease in PUFA, selenium-independent GPx, and cytochrome oxidase was found in the AD brain. ${ }^{44-47}$ 
Oxidative stress is also implicated in heart disease and stroke, which are responsible for $45-50 \%$ deaths worldwide. It is also related to the main factors that lead to CVD, including thrombosis, hypertension, hyperlipidemia, and hypercholesterolemia. ${ }^{48}$ Evidence suggests that the excess of free radicals such as $\mathrm{O}_{2}^{-}$and $\mathrm{ONOO}^{-}$as well as free metal ions promotes the oxidation of LDL. Oxidized LDL (ox-LDL) can lead to the production of arterial pro-inflammatory cytokines and other protein factors. These cytokines can activate phagocytes, and leads to the accumulation of macrophages, which are transformed into lipid-filled foam cells by protein factors. The accumulated macrophages produce ${ }^{\circ} \mathrm{ON}$ and $\mathrm{O}_{2}^{-}$, leading to further oxidative damage. As well, deposition of lipids and apoptotic death of foam cells causes plaque formation, leading to thrombosis, which can cause severe hypertension and stroke. In addition, increase in ROS by the harmful angiotensin II produces $\mathrm{O}_{2}^{-\cdot}$ and ${ }^{\circ} \mathrm{OH}$ through activation of a membrane oxidase, which can lead to heart failure. ${ }^{49-51}$ Increase in lipid peroxidation, which was suggested to be associated with hyperlipidemia in humans, has also been shown to favor the onset of arteriosclerosis. ${ }^{52,53}$ On the other hand, it has been shown that the increase of superoxide and peroxynitrite in hypercholesteraemic mice was responsible for the induction of cardiac dysfunction. ${ }^{54}$ Some studies have found that antioxidant-based therapies have therapeutic impacts in rats and humans with angiotensin II-associated CVD..$^{55}$ On the other hand, certain antioxidants can decrease lipid peroxidation and reduce blood pressure in patients with hypertension disease. ${ }^{52,56}$ As well, the antioxidant vitamin $\mathrm{E}$ has been shown to reduce hypercholesterolemia-induced oxidative stress in the heart of hypercholesteraemic rabbits. $^{57}$ 
In diabetic state, chronic exposure to high glucose concentration leads to increase in ROS, which has been correlated with decrease in insulin gene expression caused by reduction in DNA binding activities and in expression of the transcription factor homeobox-1 (PDX-1), crucial for the differentiation of $\beta$-cells and for the maintenance of the function of mature $\beta$-cells. ${ }^{58}$ Hence, increase in ROS can lead to $\beta$-cell dysfunction, which aggravates type 2 diabetes. Moreover, increase in ROS promotes the abnormal activation of the c-Jun N-terminal (JNK) pathway, which has been shown to be involved in development of insulin resistance and pancreatic $\beta$-cell dysfunction. ${ }^{59}$

Oxidative stress has been implicated in all three stages of the carcinogenesis process including initiation, promotion, and progression. Evidence has shown that free radicals can cause DNA damage in the form of single and double-stranded breaks and formation of crosslinked DNA adducts. ${ }^{60}$ All four DNA bases can be modified by ROS, with guanine to thymine transversions being the most common. ${ }^{60}$ It is believed that the ROS promotes carcinogenesis due to its potential in damaging crucial genes such as oncogenes and tumor suppressor genes 61. Evidence suggests that oxygen radicals can act as DNA mutagens in bacterial and cell culture models, as well as induce cancer in animal models. ${ }^{58,62-64}$ Moreover, lipid and DNA oxidation, which are implicated in carcinogenesis, can be reduced by antioxidants. ${ }^{65}$

\subsection{Protection from Oxidative Stress}

\subsubsection{Endogenous Antioxidant Defense System}

Considering the potential damage caused by ROS/RNS, the ability of aerobic organisms to defend against oxidative stress is essential for maintaining physiological health. In humans, 
the antioxidant defense system consists of a primary system, which prevents or blocks oxidative chain reaction, and a secondary system responsible for repairs. ${ }^{66}$ Primary antioxidant defense system includes enzymatic antioxidants such as superoxide dismutase (SOD), glutathione peroxidase (GPx), and catalase (CAT), as well as non-enzymatic antioxidants. Amongst nonenzymatic antioxidants, compounds such as glutathione, uric acid, and co-enzyme $Q$ are endogenously synthesized, while exogenous antioxidants include vitamins $C$ and $E$, carotenoids, and polyphenols. As shown in Figure 2, the three main antioxidant enzymes GPx, CAT and SOD function concertedly to reduce oxidative stress. For example, SOD converts $\mathrm{O}_{2}^{-}$to $\mathrm{H}_{2} \mathrm{O}_{2}$, followed by the conversion of $\mathrm{H}_{2} \mathrm{O}_{2}$ into water by GPx and/or CAT.
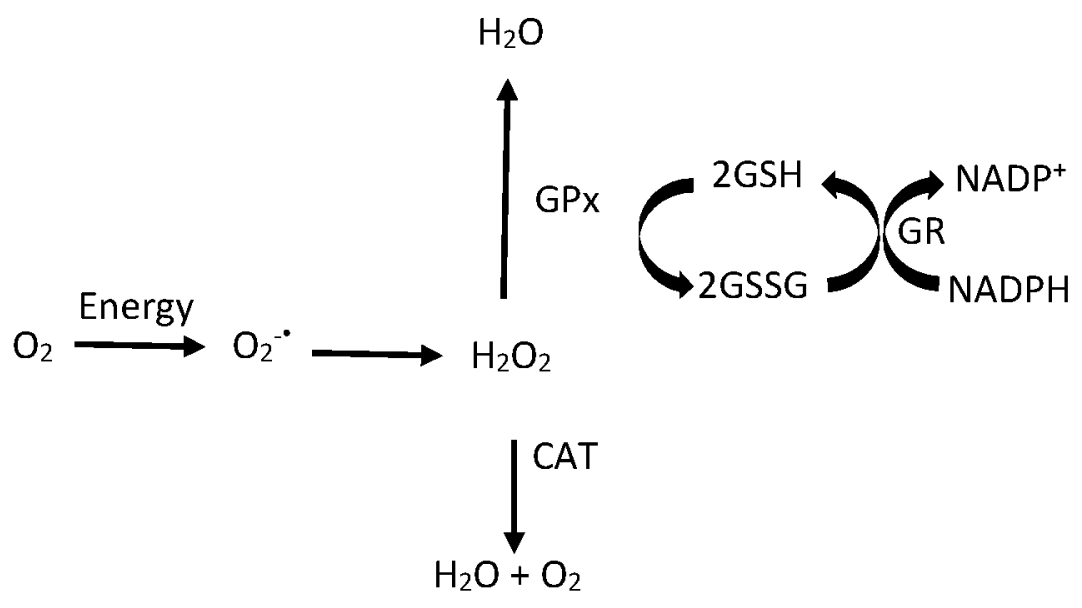

Figure 2. Reaction scheme of antioxidant enzymes GPx, SOD, and CAT (adapted from Pigeolet et al. ${ }^{218}$ ).

\subsubsection{Glutathione Peroxidase}

Glutathione peroxidase is responsible for catalyzing the decomposition of various peroxide molecules into oxygen and water, at the expense of two reduced glutathione 
molecules (GSH) being oxidized into glutathione disulfide. GPx can be found in most animals as well as certain plants and yeast. The active site of GPx contains a cysteine residue with or without a selenium attached. ${ }^{67}$ There are three types of selenium dependent GPx - classical GPx (cGPx), phospholipid hydroperoxide GPx (PHGPx), plasma GPx (pGPx), and gastrointestinal GPx (GI-GPx).

CGPx not only reacts with $\mathrm{H}_{2} \mathrm{O}_{2}$, but also with some organic hydroperoxides such as LOOH. Recently, it has been proposed that cGPx also catalyzes the decomposition of the very toxic ${ }^{-} \mathrm{ONOO}$ into $\mathrm{NO}_{2}$. CGPx is especially active in organs with high metabolic rate such as the kidney, lung, and liver, with the exception of the brain. ${ }^{67}$

PHGPx specializes in reducing hydroperoxide groups of lipophilic substrates due to its lipophilic active site. ${ }^{68}$ The reduction of hydroperoxides formed from the oxidation of cholesterol esters, lipoproteins, and thymine can be catalyzed by PHGPx. Unlike cGPx, PHGPx is sufficient in reducing lipid hydroperoxides on membrane without phospholipase. ${ }^{68}$ Most mammal tissues contain PHGPx, however, the activity of PHGPx is generally much lower than that of cGPx. ${ }^{68}$ On the other hand, $\mathrm{pGPx}$ is also capable of reducing phospholipid hydroperoxides. Evidence suggests that pGPx is exported to blood plasma from the kidney, where it is synthesized. However, pGPx mRNA has been found in other organs such as muscle, liver, and pancreas. ${ }^{69}$

GI-GPx is localized in the epithelial lining of the gastrointestinal track, and is responsible for the degradation of soluble hydroperoxides from food ingestion. ${ }^{70}$ As a result, GI-GPX protects the gastrointestinal track against damage by hydroperoxides. 
Selenium-independent GPx is not as well studied as the selenium-dependent GPx. It is believed that selenium-independent GPx serves as a backup to the selenium-dependent GPx. ${ }^{71}$ A study by Vernet et al. indicated that selenium-deficient mice had increased levels of mRNA coded for selenium-independent GPx, and hence did not experience a significant increase in lipid peroxides. ${ }^{67}$

\subsubsection{Catalase}

Catalase was so named due to its ability to catalyze the decomposition of $\mathrm{H}_{2} \mathrm{O}_{2}$ into oxygen $\left(\mathrm{O}_{2}\right)$ and water $\left(\mathrm{H}_{2} \mathrm{O}\right) .{ }^{72}$ Catalase has a wide range of existence in living organisms, with activity in plants, animals, fungi, and bacteria. Amongst vertebrates, virtually all tissues contain catalase, with high activity in adipose tissue, liver, kidney, and erythrocytes. ${ }^{72}$ It is believed that in insects, the activity of catalase compensates for the lack of Se-dependent GPx. On the other hand, certain parasitic worms do not produce catalase, but instead relies on cytochrome c peroxidase to control the concentration of $\mathrm{H}_{2} \mathrm{O}_{2} \cdot{ }^{73}$.

Interestingly, evidence suggests that the lack of catalase might not have a fatal consequence. Although catalase gene deletion in bacteria and yeast increased their sensitivity to high concentrations of $\mathrm{H}_{2} \mathrm{O}_{2}$, no significant effect was observed on growth. ${ }^{74}$ As well, mutation of catalase gene in humans with Takahara's disease increases susceptibility to $\mathrm{H}_{2} \mathrm{O}_{2}$ produced by Streptocccus bacteria, but had no effect on life span. ${ }^{75}$ Moreover, Bagnyukova et al. reported that a decrease in liver catalase in fish by $80-90 \%$ for 12 hours did not result in increase of protein or lipid oxidation. ${ }^{76}$ This suggests that the lack of catalase might be compensated by the action of other antioxidants. ${ }^{74}$ 


\subsubsection{Superoxide dismutase}

Superoxide dismutase (SOD, EC 1.15.1.1) catalyzes the dismutation of superoxide anion into $\mathrm{H}_{2} \mathrm{O}_{2}$. The mechanism of SOD is often referred to as "ping-pong" mechanism, as the metal centres are oxidized or reduced concurrently with the spontaneous dismutation of superoxide anion $\left(\mathrm{O}_{2}^{-\bullet}\right)$ into $\mathrm{O}_{2}$ and $\mathrm{H}_{2} \mathrm{O}_{2} \cdot{ }^{77}$ SOD can be categorized according to their metal cofactor. CuZnSOD and Mn-SOD are the most abundant amongst organisms, and are the most studied. Fe-SOD has been detected in the cytosol of certain bacteria and plants, and the recently discovered $\mathrm{Ni}$ SOD has only been found in Streptomyces species and cyanobacteria. ${ }^{77-79}$

In most animal cells, CuZn-SOD is the most prevalent, located mainly in cytoplasm, nuclei, and lysosomes, with a small amount in the mitochondrial intermembrane space. ${ }^{80,81}$ Extracellular SOD (EC-SOD) is another type of CuZn-SOD often bound to cell surfaces, which functions in scavenging $\mathrm{O}_{2}^{-\bullet}$ in extracellular space, preventing interaction between $\mathrm{O}_{2}^{-\bullet}$ and ${ }^{-} \mathrm{NO}$ to form -ONOO. ${ }^{82}$ As well, EC-SOD was thought to indirectly affect nitric oxide signalling pathways by interfering with the reaction between superoxide and nitric oxide. ${ }^{82}$

Mn-SOD can be detected in a variety of living organisms such as bacteria, yeast, plants, and animals. While Mn-SOD is found in the cytoplasm of prokaryotes, it is mainly located in the mitochondrial matrix of a eukaryotic cell. Since superoxide can be generated by the electron transport chain, $\mathrm{Mn}-\mathrm{SOD}$ is essential in protection of the mitochondria from oxidative damage. It has been shown that while the absence of CuZn-SOD in animals can lead to complications such as loss of hearing and muscle atrophy, the lack of Mn-SOD was fatal without antioxidant supplements. $^{83-85}$ 


\subsubsection{Glutathione and thioredoxin}

GSH is a tripeptide synthesized in cells through the activity of $\gamma$-glutamylcysteine synthetase and GSH synthetase, with cysteine, glutamine, and glycine as substrates. Once synthesized, GSH can be exported into blood plasma, with the liver being the main exporter of GSH ${ }^{86}$. Reduced glutathione (GSH) is not only used by GPx as substrate, but also capable of direct reaction with free radicals such as ${ }^{\circ} \mathrm{OH}, \cdot \mathrm{NO}$, and ${ }^{1} \mathrm{O}_{2}$, producing glutathionyl radicals ('GS). As well, GSH aides in the detoxification of xenobiotics by contributing sulfhydryl group in phase II metabolism, which leads to the elimination and excretion of toxins. ${ }^{87}$

When GSH is oxidized by free radicals, GSSG is formed. Proteins with sulfhydryl groups (SH) can be attacked by GSSG, producing protein disulfide, and therefore increasing their susceptibility to proteolytic degradation. ${ }^{88}$ As well, the cross-linking of protein SH groups can inactivate or activate enzymes, and therefore aids in modulation of enzymatic activity. ${ }^{88}$ Protein disulfide groups can be repaired by thiol-disulfide oxidoreductase using thioredoxin. Thioredoxin can also act as a substrate for pGPx and for thioredoxin peroxidase, which is capable of decomposition of hydroperoxides. ${ }^{41}$ It is believed that thioredoxin peroxidase compensates for the lack of GPx and/or catalase in some microorganisms and parasites. Increasing levels of thioredoxin can be found in response to oxidative stress. ${ }^{41}$

Other endogenous antioxidants include coenzyme $Q$ (ubiquinol) and uric acid. As a key component of the respiratory chain, the efficiency of ubiquinol $\left(\mathrm{CoQH}_{2}\right)$ is still under debate. However, evidence suggests that $\mathrm{CoQH}_{2}$ protects mitochondria DNA, membrane protein and phospholipids from free radical damage ${ }^{89}$ On the other hand, the antioxidant capacity of uric 
acid, present as urate at physiological $\mathrm{pH}$, is well established. Urate can react with ${ }^{\circ} \mathrm{OH}$ and ONOO- to produce a stable urate radical, which can be reduced by ascorbate. ${ }^{90}$

\subsubsection{Protection by Vitamins}

Exogenous antioxidants include ascorbic acid (vitamin C), tocopherols (vitamin E), and carotenoids (vitamin A). These vitamins has synergistic effects on cellular redox, with the capacity to reduce each other from oxidized to reduced state, promoting antioxidant recycling. ${ }^{91}$ Hence, it is difficult to isolate the antioxidant effects of vitamin $C, E$, or A from each other.

Vitamin $\mathrm{C}$ is a soluble compound endogenously synthesized by plants and certain animals, but not produced by primates. In vitro evidence suggests that vitamin C is capable of scavenging ${ }^{\circ} \mathrm{OH},{ }^{\circ} \mathrm{OOH},{ }^{1} \mathrm{O}_{2}$, and $\mathrm{O}_{2}{ }^{-}$, producing the stable ascorbyl radical. ${ }^{92-94}$ Moreover, vitamin $\mathrm{C}$ can reduce ferric ion $\left(\mathrm{Fe}^{3+}\right)$ into ferrous $\left(\mathrm{Fe}^{2+}\right)$, promoting the initiation of Fenton reaction. However, the antioxidant effect of vitamin $C$ is under debate due to the highly varied outcome of experiments on epidemiological studies of vitamin C supplement, with results greatly influenced by genetics, age, and lifestyle. ${ }^{95}$

Vitamin $E$ is composed of eight different compounds, with $\alpha$-tocopherol being the most active antioxidant. Alpha-tocopherol mainly protects lipids from free radical attack due to its localization on the plasma membrane. Like vitamin C, clinical studies of the effect of vitamin E supplement on certain cancers and cardiovascular diseases was shown to be either positive in some individuals, while others do not respond to the treatment. It is possible that vitamin E supplements are beneficial only to those whose diets are extremely vitamin E deficient. 
Like vitamin $\mathrm{E}$, the majority of vitamin $\mathrm{A}$ in a human cell are attached to the membrane, and thus aides in protecting the plasma membrane from lipid peroxidation. Approximately 50 types of carotenoids have vitamin activities, with $\alpha$ - and $\beta$-carotene being the most commonly studied. The in vivo mechanism of carotenoids remain to be elucidated. However, it has been proposed that carotenoids scavenge free radicals by hydrogen abstraction, electron transfer, and conjugation with the radical.

\subsubsection{Protection by phytochemicals in Grains}

Most phytochemicals found in whole grains exert antioxidant activity, and whole grains were found to be protective towards CVD, type 2 diabetes, and some cancer, all of which correlated with increase in production of oxidants (e.g. ROS/RNS). Thus, decrease in oxidative stress might be one of the protective mechanisms of whole grains. Indeed, studies have reported the correlation between the increase in consumption of whole grains and a decrease in oxidative stress. For example, healthy rats fed red and black rice experienced less renal tubular damage induced by ferric nitrilotriacetate that was characterized by less oxidation of lipids in experimental group compared to the control. ${ }^{96}$ Moreover, epidemiological studies found that human male subjects with coronary artery disease fed whole grains including brown rice and barley experienced a decrease in plasma malondialdehyde (MDA) and homocysteine, which are markers of oxidative stress. ${ }^{97}$ Oats are of particular interest for antioxidative properties because in addition to phenolic acids present in all cereals, they contain unique phenols named avenanthramides that have been investigated for their ability to reduced oxidative stress. ${ }^{98}$ High quality proteins present in oats may also be digested to produce antioxidant peptides. ${ }^{99}$ 


\subsubsection{Protections by molecules in oats}

Oats (Avena sativa) have long been considered a healthy food due to its excellent protein content and abundance of fibre, vitamins, and minerals. Oat grains contain $55.5 \%$ carbohydrate, $11.3 \%$ protein, $10.9 \%$ fiber, $5.8 \%$ lipid, and $3.2 \%$ ash. ${ }^{100}$ Over the past three decades, the role of oats in lowering coronary heart disease (CHD) has received attention. ${ }^{101}$

Hypocholesterolemic and antihypertensive effects are the main contributors to the cardiovascular benefits of oats. When consumed as oatmeal, oat gum, and oat bran, oats have the capacity to decrease LDL-cholesterol by $2-23 \%$ in not only healthy but also hypercholesterolemic women and men between ages 20-70. ${ }^{102}$ As well, the excellent lipid profile of oats (high polyunsaturated and low saturated fatty acid contents) contributes to the reduction of cardiovascular diseases. ${ }^{103}$ Fasting blood glucose concentration of diabetic subjects was reduced by $4 \%$ when oat soup was incorporated into daily meal for 23 weeks. ${ }^{104}$

Oats are unique amongst whole grains due to the exceptionally high amount of dietary fibre beta-glucan, as well as antioxidant molecules such as avenanthramides, tocopherols, and flavonoids. ${ }^{105}$ Additionally, oats have higher amount of lipids than any other cereal crop, including high amounts of unsaturated fatty acids and essential fatty acid linoleic acid.

It is believed that the main contributor to health benefits of grains is the high amounts of dietary fibre present. Rolled oats contains approximately $4 \%$ of the soluble fibre $\beta$-glucan (dry weight basis). Consumption of oat bran rich in $\beta$-glucan has been shown to reduce postprandial plasma glucose and insulin levels in both type 2 diabetic and healthy individuals. ${ }^{106}$ As well, Anderson et al. reported that the consumption of oat bran by hypercholesterolemic 
subjects led to a $23 \%$ reduction of total serum cholesterol but had no effect on high density lipoprotein (HDL). ${ }^{107-109}$

Since it has been established that viscous polysaccharides such as fibre are capable of lowering serum cholesterol, $\beta$-glucan alone was thought to be responsible for the cholesterol reducing activity of oat bran. ${ }^{110}$ However, dose dependent response studies of $\beta$-glucan were most commonly carried out using different amounts of oat bran and oatmeal. ${ }^{106,111,112}$ Since $\beta$ glucan is not commercially available, the very few studies that attempted to establish dose dependent effects of isolated $\beta$-glucan utilized 'oat gum', which was enzymatically extracted from oat bran and contained $80 \% \beta$-glucan. ${ }^{113-115}$ Hence, the lack of studies that utilize pure $\beta$ glucan suggests there might be other compounds in oat bran or the $\beta$-glucan extract that also exerted protective effects towards CVD.

Since reactive oxygen species is implicated in CVD, one of the protective mechanisms of oats against CVD might be the reduction of oxidative stress. To date, very few studies investigated the direct relationship between consumption of oats and oxidative stress using biologically relevant models. However, Furlan and colleagues reported an increase in antioxidant capacity of blood and plasma of rats fed diet with $30 \%$ oat grain compared to those on normal diet. ${ }^{116}$ In addition, the consumption of oats attenuated oxidative stress induced by exercise. ${ }^{116}$ Although $\beta$-glucan might exert weak antioxidant activity, $\beta$-glucan extracted from oats had much lower antioxidant capacity than that of barley. ${ }^{117}$ Hence, it is worthwhile to investigate other antioxidant compounds present in oats. 
Oats are rich in antioxidants such as tocopherols and phenolic acids, especially avenanthramides. The amount of vitamin E in 12 different genotypes of oats in the United States was found to be between $19.0-30.3 \mathrm{mg} / \mathrm{kg}$, with $86-91 \%$ being $\alpha$-tocopherol and $\alpha$ tocotrienol. ${ }^{118}$ Vitamin $E$ is capable of protecting the plasma membrane from lipid peroxidation. ${ }^{119}$ In addition, oats contain an abundance of phenolic acids, including ferulic acid, caffeic acid, syringic acid, protocatechuic acid, and vanillic acid. ${ }^{120}$ Evidence suggests that oat extracts with high amounts of phenolics are capable of inhibiting protein and lipid oxidation. ${ }^{99}$

Avenanthramides are a group of phenolic alkaloids found almost exclusively in oats that exert potent antioxidant activity both in vitro and in vivo. For example, consumption of avenanthramide capsules effectively reduced oxidative stress in healthy humans as evident by

increase in SOD and GSH as well as decrease in malondiadehyde (MDA) in blood serum. ${ }^{98}$ Chen et al. reported that avenanthramides showed good bioavailability and effectively increased plasma GSH in healthy individuals. ${ }^{121}$ As well, avenanthramides might act synergistically with vitamin E. ${ }^{121}$ Thus, reduction in oxidative stress might be implicated in the protective effects of oats against CVD. Although most of the protection provide by oats and other cereals have been attributed to the presence of glucans, vitamins, and polyphenols, recent studies have found hydrolyzed proteins, and peptides also contribute to the beneficial effects.

\subsection{Oat and cereals derived antioxidative peptides and protein hydrolysates}

\subsubsection{Introduction}

It is well established that dietary proteins are digested in the gastrointestinal tract system to provide amino acids that serve as the building blocks for important hormones and 
enzymes. However, dietary proteins can also become a source of peptides with positive impact on physiological functions. Proteins and peptides are also believed to play an important role in the stability of foods. Hence, the bioactivity of peptides and protein hydrolysates generated from food sources has received attention. Bioactive peptides and protein hydrolysate can be generated from food through microbial activity, $\mathrm{pH}$ changes, and heat, as well as through extraction in the laboratory. Moreover, sequences of peptides with potential bioactivity can be synthesized chemically and tested. Bioactive peptides and protein hydrolysates from various food sources are believed to have desirable properties such as antimicrobial, mineral binding, antihypertensive, hypolipidemic, hypocholesterolemic, and antioxidant activities. This work is more concerned about those that can reduce oxidative stress.

\subsubsection{Activity of peptides and proteins in condition associated with oxidative stress}

In addition to phytochemicals, the biologically activity of hydrolyzed food proteins, fractions and peptides to reduce oxidative stress under various conditions have been investigated. Proteins hydrolysates from oats, wheat, rice, and barley have been demonstrated to have antioxidant activity in vitro against common ROS in vitro and in food systems. ${ }^{99,122-124}$ Protective effects of antioxidant protein hydrolysates to control blood pressure are documented in the literature. ${ }^{125}$ Most studies have focused on the effects of these peptides on angiotensin-I converting enzyme, which increases blood pressure by promoting blood vessel constriction through converting it to angiotensin II. For example, peptides derived from plants such as soy protein hydrolysates with antioxidant activity have been demonstrated to exhibit antihypertensive activity through inhibition of angiotensin converting enzyme (ACE). ${ }^{126,127}$ In addition, peptides from wheat germ protein hydrolysate were found to possess not only free 
radical scavenging activity but also inhibits ACE activity. ${ }^{122,128}$ Soy protein hydrolysate have been found to lower cholesterol in the human hepatic Hep T9A4 cells as well as inhibit lipid peroxidation using in vitro chemical assay. ${ }^{127,129}$ In addition, oat protein hydrolysate fractions below 3 kDA demonstrated potent ACE-inhibitory activity. ${ }^{130}$

Even though oxidative stress is implicated in diabetes, few studies have investigated the anti-diabetic effects of antioxidant peptides from cereal. However, zein hydrolysate from corn has been shown to greatly inhibit lipid peroxidation, prevent hyperglycemia and enhance insulin secretion in rats, all of which might protect against development of diabetes. ${ }^{131,132}$

Bioactive peptides have great potential for cancer treatment due to their small size, strong target selectivity, and low toxicity. Studies have demonstrated that peptides from rice bran and soy possess potential anticarinogenic activity, with one of the possible mechanism being related to their radical scavenging effects. ${ }^{123,133}$ Lunasin, a peptide originally discovered in soy and later found in oat, wheat, and barley, which has great radical scavenging activity, is a novel cancer-preventive peptide capable of protecting mammalian cells from carcinogens. ${ }^{134,135}$

The mechanism of bioactive peptides as antioxidants remain to be elucidated. However, it has been proposed that peptides exert antioxidant activities by chelating metal ions, scavenging free radicals, or forming a membrane around lipids. ${ }^{124}$ Food-derived peptides have high potential as antioxidants in foods since they are colorless and odorless. As well, the amphipathic nature of peptides makes them suitable for use in multicomponent food systems. ${ }^{124}$ Moreover, peptides isolated from foods are generally considered as safe, and thus makes them applicable as pharmaceutical agents. ${ }^{124}$ 
However, evaluation of antioxidant activity using in vitro chemical-based assays do not necessarily reflect in vivo activity. Thus, more biologically relevant data is needed to determine the potential use of bioactive peptides with antioxidant properties as nutraceutical as well as pharmaceutical agents.

\subsection{Methods for evaluation of food-derived compounds with antioxidant activity}

Since food-derived antioxidants have great potential for nutraceutical and pharmaceutical applications, there is a need to establish methods to screen for and evaluate compounds with antioxidant activity.

\subsubsection{Chemical antioxidant assays}

Chemical antioxidant assays are widely used to measure antioxidant capacity of potential antioxidants, including oxygen radical absorbance capacity (ORAC) and total radicaltrapping antioxidant parameter (TRAP), which measures direct radical scavenging ability of compounds. ${ }^{136,137}$ As well, ferric reducing/antioxidant power (FRAP) measures ferric ironreducing ability of an antioxidant. ${ }^{138}$ However, chemical-based antioxidant assays do not necessarily reflect in vivo activity since they are mostly performed at non-physiological conditions and thus fails to account for uptake, distribution, and metabolism of the potential antioxidants. ${ }^{139}$ Moreover, antioxidant activity is not limited to scavenging free radical, but also includes altering the activity of antioxidant and antioxidant enzymes as well as activation or repression of transcription factors in redox system. ${ }^{140}$ Although animal model and human studies provide the best measures, they can be very expensive and time consuming. Hence, cell culture provides an alternative measure to not only screen for antioxidant compounds in foods, 
but also provide clues regarding cellular uptake, membrane permeability, distribution and metabolism in a fast and cost-effective manner. ${ }^{141}$

\subsubsection{Cell culture models}

Cell culture models can be used to screen for toxic compounds including those that are generally cytotoxic to cells and those that exhibit toxicity to a specific type of cells. In addition, cell culture models are useful tools to predict the target compound's mechanism of action. For example, Foldbjerg et al. reported that silver nanoparticles are genotoxic to the human lung cancer A549 cells, with the formation of DNA adducts by action of ROS being the potential culprit. ${ }^{142}$ Using rat pheochromocytoma neurosecretory PC12 cells, Maduh et al. deduced that cyanide causes neurotoxicity by significantly depleting cell adenylate energy pool. ${ }^{143}$ On the other hand, cytoprotective effects can also be analyzed. For example, olive phenolic compounds have been shown to protect Caco- 2 cells from $\mathrm{H}_{2} \mathrm{O}_{2}$ induced oxidative stress. ${ }^{144}$

In addition, cell culture models have been used to study mechanism of potential drugs including cellular uptake, distribution, and metabolism. For example, the rat brain endothelial cells RBE4 has been used to study permeability of drugs through the blood brain barrier, while lung airway cell lines 16HBE140- and Calu-3 has been used to mimic delivery of inhaled medicinal aerosols to the lungs. ${ }^{145,146}$ The intestinal epithelial Caco-2 cell model has been widely used to study intestinal transport of drug across the epithelial barrier. Hence, the Caco-2 cells can be used to predict bioavailability of a compound as well as its route of transport through intestinal epithelial cells including transcytosis, endocytosis, and diffusion. ${ }^{147}$ In addition, the Caco-2 model provide valuable clues in understanding the function of the tight junctions. ${ }^{147}$ Liver-derived cell lines such as $\mathrm{HepG} 2$ and $\mathrm{FaO}$ are commonly used to study drug metabolism. ${ }^{148}$ 
Cellular models have been widely used to study the protective effects of a potential antioxidant against oxidative stress. Oxidative stress can be measured by directly quantifying ROS or detecting biomarkers of oxidative stress. Broadly, direct quantification of ROS involves the use of dyes such as dicholorodihydrofluorescein diacetate (DCFH $-D A)$, dihydrorhodamine $\left(\mathrm{RhH}_{2}\right)$, and hydroethidine, which reacts with ROS and can be quantified by measuring fluorescence intensity. ${ }^{149}$ A cellular antioxidant assay utilizing $\mathrm{DCFH}_{2}-\mathrm{DA}$, which is the most commonly used method, was developed by Wolfe and Rui. ${ }^{141}$ This assay measures the oxidation of probe dihydrodichlorofluorescein $\left(\mathrm{DCFH}_{2}\right)$ into the fluorescent DCF by AAPH generated peroxyl radical in the human hepatocarcinoma HepG2 cells. ${ }^{141}$ Other cell lines can also be used in the $\mathrm{DCFH}_{2}$-DA assay such as human lung fibroblasts (W138, IMR-90), ${ }^{150}$ human macrophage cell line U937, ${ }^{151}$ matured differentiated intestinal cells CaCo-2,152 human gastric adenocarcinoma cell line AGS, ${ }^{48}$ and vascular endothelial cells EA.hy926. ${ }^{153}$ In addition, products of oxidation such as 8-hydroxy-2'-deoxyguanosine (8-OHdG) and malondialdehyde (MDA), which are generated by oxidation of DNA and plasma membrane, respectively, are commonly used as biomarkers of oxidative stress. ${ }^{154,155}$

Measurement of components of the antioxidant defense system such as GSH, GPx, SOD, and CAT not only indicates the redox state of cells, but also provides clues to the mechanism of action of cytoprotective agents. For example, various polyphenolic compounds and their metabolites were found to decrease endogenous ROS production in vascular endothelial cells by inhibiting NADPH oxidase (Nox), an enzyme that produces $\mathrm{O}_{2}^{-\cdot} .^{156}$ As well, curcumin and quercetin, which are food-derived polyphenols, exert antioxidant activity by activation of $\mathrm{Nrf}-2$, 
which is a transcription factor that induce the expression of antioxidant enzymes such as selenium independent GPx, SOD, and NADPH quinone oxidase. ${ }^{157-159}$

\subsubsection{The human hepatoma HepG2 cellular model}

HepG2 cells are commonly used to detect cytoprotective and cytotoxic agents due to their capability to express endogenous xenobiotic metabolizing enzymes. Liver-derived cell lines are able to reflect in vivo metabolism of xenobiotics since the liver is the main site of biotransformation. HepG2 cells were isolated from primary hepatoblastoma of an 11-year-old Argentine boy, and are the most versatile type of liver-derived cells. ${ }^{160}$ Various functions, such as secretion of plasma proteins, which are lost in cultured primary hepatocytes, are retained by HepG2 cells. ${ }^{161}$ Moreover, a wide range of metabolic enzymes are expressed by HepG2 cells such as the phase I cytochrome P450 1A1, 1A2, 2B, 2C, 3A and 2E1, nitroreductase, catalase, peroxidase, as well as phase II enzymes such as sulfotransferase and epoxide hydrolase. ${ }^{162}$

Most compounds exert cytoprotective effects on HepG2 cells through antioxidant activity. HepG2 cells express antioxidant defense enzymes such as GPx, SOD, and CAT at levels equivalent or exceeding primary hepatocytes, making it a suitable model for measuring not radical scavenging activity of the test compound but also its effects on expression of antioxidant enzymes. ${ }^{163}$ Hence, HepG2 cells can be used to reflect in vivo pro-oxidant and antioxidant effects of a substance tested. For example, studies have shown that tea catechins reduced lipid peroxidation in HepG2 cells by scavenging free radicals as well as inducing expression of heme oxygenase. ${ }^{164,165}$ Additionally, Bak et al. demonstrated that red ginseng essential oil exerted hepatoprotective effect on HepG2 treated with $\mathrm{H}_{2} \mathrm{O}_{2}$ by inducing the expression of GPx, SOD, and catalase. ${ }^{166}$ 


\subsection{Hypothesis and Objectives}

Oats have relatively better protein quality than other cereal grains, with high PDCAAS (protein digestibility-corrected amino acid score). A recent study, proteins extracted from oat brans with the aid of various concentrations of a cell-wall degrading polysaccharide enzyme were digested with the alcalase. ${ }^{167}$ Comparison of antioxidant activities showed that the alcalase hydrolysate of proteins from brans treated with viscozyme (1.5 unit/g)had the highest peroxyl radical scavenging activity. ${ }^{167}$ Three peptides were subsequently identified after tandem mass spectrometry analysis. ${ }^{167}$ Although antioxidant activities of oat hydrolysates were demonstrated, the biologically activity of the pure peptides has not been investigated.

\subsubsection{Hypothesis}

Radical scavenging peptides from oats will regulate markers of oxidative stress in a cellular model.

\subsubsection{Objectives}

1. Determine the radical scavenging activity of peptides using the oxygen radical absorbance capacity assay.

2. Determine the cytotoxicity or cytoprotection in hepatic HepG2 cells.

3. Evaluate the effects of peptides on the activity of antioxidative enzymes in cells stressed with a peroxyl radical.

4. Quantify the amount of intracellular reactive species, oxidised and reduced glutathione. 


\section{Methods}

\subsection{Reagents}

HepG2 cells were purchased from the American Type Culture Collection (ATCC). Peptides FNDRLRQGQLL (P1), GLVYIL (P2), GQTV (P3), GQTVFNDRLRQGQLL (P4), YHNAP (P5), YHNAPGLVYIL (P6), and DVNNNANQLEPR (P7) were synthesized by Genscript (Piscataway, NJ, USA). Sodium hydroxide $\mathrm{NaOH}$ reagent grade $>98 \%$, Sodium carbonate $\mathrm{Na}_{2} \mathrm{CO}_{3}$, copper (II) sulfate pentahydrate minimum $98 \% \mathrm{CuSO}_{4} .5 \mathrm{H}_{2} \mathrm{O}$, L-glutathione reduced (GSH), Folin-Ciocalteu's phenol reagent $(2 \mathrm{M})$, fatty acid free bovine serum albumin (BSA), mono- and dibasic potassium phosphates, 2, 2'-azobis(2-methylpropionamidine) dihydrochloride (AAPH), rutin trihydrate, 6hydroxy-2,5,7,8-tetramethylchroman-2-carboxylic acid (Trolox), diethylenetriaminepentaacetic acid (DETAPAC), 3-(4,5-dimethylthiazol-2-yl)-2,5-diphenyltetrazolium bromide (MTT), 96-well and $60-\mathrm{mm}$ tissue culture plates, dimethylsulfoxide $\geq 95 \%$ (DMSO), sodium azide $\left(\mathrm{NaN}_{3}\right)$, glutathione reductase (GR), nicotinamide adenine dinucleotide phosphate (NADPH), cumene hydroperoxide, catalase, nitroblue tetrazolium chloride (NBT), xanthine oxidase, 5,5'-dithiobis(2-nitrobenzoic acid) (DTNB), and 5-sulfosalicylic acid dehydrate were purchased from Sigma Aldrich (Oakville, ON, Canada). Sodium dodecyl sulfate (SDS), hydrogen peroxide $\left(\mathrm{H}_{2} \mathrm{O}_{2}\right)$ and fluorescein were from Fisher Scientific Co (Nepean, ON, Canada). Ethylene diamine tetra acetic acid (EDTA) was obtained from Bioshop (Burlington, ON, Canada). Bathocuproine disulfonic acid (BCS) and xanthine were purchased from MP Biomedical (Solon, OH, USA). 


\subsection{Oxygen radical absorbance capacity}

The ORAC assay was performed as described by Huang et al. ${ }^{168}$ The decay of fluorescein $(0.082 \mu \mathrm{M})$ by $\mathrm{AAPH}(153 \mathrm{mM})$ at $37^{\circ} \mathrm{C}$ was tracked using a microplate fluorescence reader (FLx800, Biotek Instruments Inc.) with fluorescence filters (excitation 485/20 nm, emission $528 / 20 \mathrm{~nm})$. Potassium phosphate buffer $(\mathrm{pH} 7.4,75 \mathrm{mM})$ was used to dissolve peptides and standards. Trolox $(6.25,12.5,25,50$, and $100 \mu \mathrm{M})$ were used to construct a standard curve while rutin trihydrate was used as control (20 and $100 \mu \mathrm{M})$. Peptides (P1-P7) were analysed at $100 \mu \mathrm{M}$ and $200 \mu \mathrm{M}$. In each 96-well plate, $120 \mu \mathrm{L}$ of fluorescein dye was mixed with $20 \mu \mathrm{L}$ solution of Trolox, rutin, or peptide and incubated for 20 minutes at $37^{\circ} \mathrm{C}$. Then, $60 \mu \mathrm{L}$ of AAPH solution was added to each well, and the change in fluorescent intensity was tracked by reading at 1 minute intervals over a total of 50 minutes. Data analysis was done through Gen5 $5^{\mathrm{TM}}$ software, and ORAC values were expressed as $\mu$ mole Trolox Equivalents (TE) using the standard curve established by Trolox solutions.

\subsection{Cell culture}

HepG2 (human hepatocellular carcinoma) cells were purchased from the American Type Culture Collection (ATCC). The cells were cultured at $37{ }^{\circ} \mathrm{C}$ in a humidified incubator with $5 \%$ $\mathrm{CO}_{2}-95 \%$ air, and maintained in DMEM media supplemented with $10 \%(\mathrm{v} / \mathrm{v}) \mathrm{FBS}$.

\subsection{MTT assay}

Cytotoxicity and cytoprotective effects of the peptides were measured using the MTT (3-(4,5-dimethylthiazol-2-yl)-2,5-diphenyltetrazolium bromide) assay as described by Liu and Nair. ${ }^{169}$ HepG2 cells were plated at $2 \times 10^{4}$ cells/well in a 96-well tissue culture plate and 
incubated for 24 hours. Cells were washed once with $200 \mu \mathrm{L}$ PBS (phosphate buffer saline solution, $\mathrm{pH} 7.2$ ) and treated with peptide samples (50 and $100 \mu \mathrm{M})$. After 24 hours, cells were washed twice with $200 \mu \mathrm{L}$ of PBS, and $200 \mu \mathrm{L}$ of media with or without $20 \mathrm{mM}$ of AAPH $\left(2,2^{\prime}-\right.$ azobis(2-amidinopropand) dihydrochloride) was added to wells intended for cytoprotection and cytotoxicity evaluation, respectively. Following 24 hour incubation, cells were washed twice with $200 \mu \mathrm{L}$ of PBS. Ten $\mu \mathrm{L}$ of MTT solution $(5 \mathrm{mg} / \mathrm{mL}$ in PBS) and $100 \mu \mathrm{L}$ of media was added to each well. After 1 hour, MTT solution was removed, and $50 \mu \mathrm{L}$ dimethyl sulfoxide (DMSO) was added to each well. Absorbance was read at $570 \mathrm{~nm}$ with 630 background subtraction using a microplate reader (Epoch, Biotek Instruments Inc.). Untreated cells were used as negative control (NEG), and cells treated with only AAPH were used as positive control (POS).

\subsection{Measurement of antioxidant enzymes and total glutathione}

\subsubsection{Cell treatment}

Cells were seeded at $10^{6}$ cells/plate in $60 \mathrm{~mm}$ tissue culture plates and allowed to grow for 24 hours. In each plate, the cells were washed twice with $4 \mathrm{~mL}$ of PBS (pH 7.2), and treated with $4 \mathrm{~mL}$ peptide samples (P1, P2, P6, P7) dissolved in culture media at 50 or $100 \mu \mathrm{M}$ for 24 hours. After removal of peptide samples, the cells were washed twice with $4 \mathrm{~mL}$ PBS/plate and treated with $4 \mathrm{~mL}$ of $20 \mu \mathrm{M} \mathrm{AAPH}$ dissolved in culture media for 24 hours. Controls were not treated with AAPH or peptide samples.

Cells in each culture plate were harvested by incubation with $0.5 \mathrm{~mL}$ trypsin solution $(0.25 \%)$, and after five minutes, $1 \mathrm{~mL}$ of cell culture media was added to inhibit the activity of trypsin. Cell pellets were obtained by centrifugation in Eppendorf tubes at $1000 \mathrm{xg}$ for 5 
minutes. The cells in each tube were washed by removing the supernatant and re-suspension in $500 \mu \mathrm{L}$ ice cold PBS until no pink color can be observed. The cell pellet in each tube was then re-suspended in ice cold PBS (300 $\mu \mathrm{L}$ for SOD assay, $500 \mu \mathrm{L}$ for GPx and CAT assays), except for total glutathione assay, which utilized $300 \mu \mathrm{L}$ of $5 \%$ ice cold sulfosalicylic acid bubbled with $100 \%$ nitrogen. Then, the cells were lysed by sonication on ice for 1 minute using a probe-type sonicator (Vibra-Cell, Sonics \& Materials Inc.) pulsing at 15 seconds on, 10 seconds off cycles. Following centrifugation of cell lysate at $13,000 \times g\left(4{ }^{\circ} \mathrm{C}\right)$, the pellet containing cell debris was discarded, and the supernatant was used for protein determination as well as antioxidant enzyme assays. The negative control (NEG) consists of cells that were untreated, and cells treated only with AAPH were utilized as positive control (POS).

\subsubsection{Determination of glutathione peroxidase activity}

Activity of glutathione peroxidase was determined using an enzyme coupling assay described by Paglia and Valentine, with slight modifications. ${ }^{170} \mathrm{~A}$ potassium phosphate stock buffer (55.6 mM, pH 7.0) was made to contain $1.1 \mathrm{mM}$ EDTA and $1.1 \mathrm{mM} \mathrm{NaN}_{3}$. As well, a working buffer was prepared with $1.33 \mathrm{mM}$ reduced glutathione (GSH) and 1.33 E.U./mL glutathione reductase (GR) using stock buffer as solvent. In addition, 4 mM NADPH solution dissolved in stock buffer was obtained. The assay was carried out in a 96-well plate. In each well, $187.5 \mu \mathrm{L}$ of working buffer was mixed with $12.5 \mu \mathrm{L}$ NADPH solution and $25 \mu \mathrm{L}$ of sample or buffer (blank), and incubated at $30{ }^{\circ} \mathrm{C}$ for 5 minutes. Then, $100 \mu \mathrm{L}$ of $0.15 \%$ cumene hydroperoxide was added in each well to begin the reaction. The rate of disappearance of NADPH was followed at 340nm for five minutes using a microplate spectrophotometer (Epoch, Biotek Instruments Inc.) with Gen5 $5^{\mathrm{TM}}$ software. The amount of enzyme required to oxidize 
$\mathrm{NADPH}$ at $1 \mu \mathrm{mole} / \mathrm{minute}$ was defined as 1 unit. Unit of GPx/mg protein was calculated using the following formula, which takes into account the extinction coefficient of NADPH oxidation $\left(\varepsilon=6.22 \mathrm{mmol}^{-1} \mathrm{~cm}^{-1}\right)$.

UGPx/mg protein $=($ Absorbance change/6.22) $\times$ Dilution faction $\times 2 \times(1 / \mathrm{mg}$ protein $)$

\subsubsection{Determination of catalase activity}

Catalase activity was measured as described by Beers and Sizer. ${ }^{171}$ Briefly, $1790 \mu \mathrm{L}$ potassium phosphate buffer (50 mM, pH 7.0) was mixed with $200 \mu \mathrm{L}$ cell lysate in a cuvette. Ten $\mu \mathrm{L} \mathrm{H}_{2} \mathrm{O}_{2}(30 \%)$ was added, and removal of $\mathrm{H}_{2} \mathrm{O}_{2}$ by catalase was followed at 240nm using a spectrophotometer (Cary 50 Bio UV-Vis, Varian Inc.) with CaryWinUV Bio Pack Software. One unit of catalase was defined as the amount of enzyme capable of decomposing $1.0 \mu \mathrm{M} \mathrm{H}_{2} \mathrm{O}_{2}$ per minute. Unit of catalase can be calculated using the following formula with extinction coefficient of $\mathrm{H}_{2} \mathrm{O}_{2}$ disappearance $39.4 \mathrm{~mol}^{-1} \mathrm{~cm}^{-1}$.

Unit catalase $=($ Absorbance change $/ \mathrm{min}) / 39.4 * 10 * 1000$

Catalase activity per milligram protein can then be calculated using protein content determined by Lowry method. For the ease of comparison, catalase activity was expressed as percent control.

\subsubsection{Superoxide dismutase assay}

Superoxide dismutase (SOD) activity was measured using the BCS-NBT assay described by Spitz and Oberley, with slight modifications ${ }^{172}$. An assay solution was prepared with $0.05 \mathrm{M}$ potassium phosphate buffer $(\mathrm{pH} 7.8)$ containing $1.34 \mathrm{mM}$ diethylenetriaminepentaacetic acid (DETAPAC), $0.13 \mathrm{mg} / \mathrm{mL}$ bovine serum albumin (BSA), 1.0 unit CAT, $0.056 \mathrm{mM}$ nitroblue 
tetrazolium chloride (NBT), $0.1 \mathrm{mM}$ xanthine, and $50 \mu \mathrm{M}$ bathocuproine disulfonic acid (BCS). In addition, a xanthine oxidase solution was prepared in ice cold potassium phosphate buffer (0.05 M, pH 7.8) containing $1.34 \mathrm{mM}$ DETAPAC. The xanthine oxidase solution was prepared such that there will be sufficient amount of enzyme in the final reaction mix to achieve a blank rate of $0.021 \pm 0.04$ absorbance/minute. Briefly, $100 \mu \mathrm{L}$ of sample, standard, or buffer (blank) was mixed with $800 \mu \mathrm{L}$ of assay solution, and $100 \mu \mathrm{L}$ of xanthine oxidase solution was added to initiate the reaction. The reduction of nitroblue tetrazolium to blue formazan by $\mathrm{O}_{2}^{-}$was followed at $560 \mathrm{~nm}$ using a microplate spectrophotometer (Epoch, Biotek Instruments Inc.) with Gen5 $5^{\mathrm{TM}}$ software. The blank rate was measured in the absence of cell lysate. Percent inhibition of NBT reduction for different concentrations of cell lysate can be calculated as follows:

Percent inhibition $=[($ blank rate - sample rate $) /$ blank rate $] * 100 \%$

One unit of SOD can be defined as the amount of protein that caused $50 \%$ maximum inhibition of NBT reduction, and unit SOD/mg protein can be calculated. For the purpose of this experiment, SOD activity was expressed as percent control.

\subsubsection{Determination of total glutathione}

Total glutathione was measured using the enzymatic recycling method as described by Tietze, with slight modifications to adjust for the use of 96 -well plates ${ }^{173}$. Sodium phosphate buffer (125 mM, pH 7.5) was prepared with $6.3 \mathrm{mM}$ sodium EDTA (ethylenediamintetraacetic acid), and all solutions in this assay were prepared with the buffer solution. Broadly, in each well, a mix of $60 \mu \mathrm{L}$ of $0.35 \mathrm{mM}$ NADPH, $10 \mu \mathrm{L}$ of $6 \mathrm{mM}$ DTNB (5,5'-dithiobis-(2-nitrobenzoic 
acid)), and $20 \mu \mathrm{L}$ of cell lysate or GSH standard was prepared. Then, $10 \mu \mathrm{L}$ of glutathione reductase at $5 \mathrm{IU} / \mathrm{mL}$ was added to initiate the reaction. The rate of reaction between GSH from cell lysate and DTNB was measured at $412 \mathrm{~nm}$ following the formation of the yellow 2nitrobenzoic acid using a microplate reader (Epoch, Biotek Instruments Inc.). Untreated cells were used as negative control (NEG), whereas cells treated with only AAPH were used as positive control (POS). Pure GSH standards at known concentrations were used to establish a standard curve, and total glutathione of cell lysates can then be calculated using the standard curve, and expressed as percent of negative control.

\subsection{Lowry protein determination assay}

Protein determination was performed using a modified Lowry procedure as described by Markwell et al ${ }^{174}$. Reagent $A$ was produced with $2.0 \% \mathrm{Na}_{2} \mathrm{CO}_{3}, 0.4 \% \mathrm{NaOH}, 0.16 \%$ sodium tartrate, and $1 \%$ SDS; while reagent $\mathrm{B}$ consisted of $4 \% \mathrm{CuSO}_{4}$. Preparation of reagent $\mathrm{C}$ was achieved by combining reagents $A$ and $B$ in a 100:1 ratio. In a micro-centrifuge tube, $200 \mu \mathrm{L}$ of reagent $C$ was mixed with $66.7 \mu \mathrm{L}$ of cell lysate, and the resulting mixture was incubated at room temperature for 25 minutes. Then, $20 \mu \mathrm{L}$ of Folin-Ciocalteu phenol reagent diluted at 1:1 ratio with Milli-Q water was added and allowed to react at room temperature for 45 minutes. The resulting blue color was measured at $660 \mathrm{~nm}$ using a microplate reader (Epoch, Biotek Instruments Inc.). A standard curve was generated using bovine serum albumin (BSA) and used to calculate the protein content of cell lysate. The protein concentrations of cell lysates were used in the calculation of antioxidant enzyme activities in order to express them as Unit of enzyme/mg protein. 


\subsection{Determination of ROS}

The measurement of ROS was determined using method described by Wolfe and Rui, with modifications ${ }^{141}$ HepG2 cells were seeded at $4 \times 10^{4}$ cells/well in a 96-well tissue culture plate. After 24 hours, cells were treated with $200 \mu \mathrm{L}$ peptide samples dissolved in media, with the exception of AAPH control cells and untreated cells. After two hours, media was removed, and cells were washed twice with $200 \mu \mathrm{L}$ PBS/well. Then, cells were incubated with $40 \mathrm{mM}$ AAPH dissolved in media at $200 \mu \mathrm{L} /$ well. After 45 minutes, AAPH was removed, and cells were again washed twice with $200 \mu \mathrm{L}$ PBS/well. Two hundred $\mu \mathrm{L}$ of $40 \mu \mathrm{M}$ dichlorohydrofluorescein diacetate $\left(\mathrm{DCFH}_{2}-\mathrm{DA}\right)$ dissolved in buffer was added, and fluorescent intensity reading was immediately started, and measurement was carried out at two- minute intervals for a total of 60 minutes. Negative control (NEG) involved untreated cells, whereas positive control (POS) consists of cells treated only with AAPH. Percent increase in fluorescent intensity was calculated using the following formula:

Percent increase in fluorescent $=($ final reading-initial reading $) /$ initial reading

In order to emphasize the cytoprotective effect of the peptide samples, amount of ROS was indicated as \%NEG.

\subsection{Statistical Analysis}

All data was expressed as mean \pm standard error of mean (S.E.M.), and comparison between groups carried out by one way ANOVA with post-hoc Tukey's honest significant differences (HSD) using SPSS software (SPSS, Chicago). 


\section{Results and Discussion}

\subsection{Peptide properties}

Seven peptides (Table 1) were analyzed in this study, three of which (P4, P6, and P7) were identified from oat protein alcalase digest. These peptides were fragments of oat $12 \mathrm{~S}$ globulin, a storage protein located mostly in the endosperm. It is digested during germination of oat seeds and used as a source of amino acids. ${ }^{173}$ The role or the function of $12 \mathrm{~S}$ globulin found in oat bran remains unknown. Although the functional properties of oat $12 \mathrm{~S}$ globulins have not been studied, it was found that enzymatic digestion of $11 \mathrm{~S}$ globulin, which is homologous to $12 \mathrm{~S}$ globulin, produced oligopeptides that were more readily absorbed by adult humans than amino acid mixtures or undigested proteins. ${ }^{175}$ According to the amino acid sequence and previous bioactive peptides identified from various sources, Cavazos and Mejia predicted that enzymatic digestion of oat $12 \mathrm{~S}$ globulin can produce bioactive peptides with ACE inhibiting, antithrombotic, antioxidant, hypotensive, and regulating activities, most of which were dipeptides. ${ }^{176}$

In this experiment, besides the peptides P4, P6, and P7, fragments of P4 and P6 were also analyzed. P5 consisted of the five amino acids at the N-terminal of P6, whereas P2 consisted of the six amino acids found at the C-terminal of P6. P3 was made up of the four amino acids at the N-terminal of P4, and P1 was made up of the 12 amino acids at the C-terminal of P4. Testing of these extra peptides from the $\mathrm{N}$ or C-terminal of P6 or P4 was to examine whether they can play a role in the activity of P6 or P4. 
Table 1. Hydrophobicity, charges, and hydropathy plots of peptide samples analyzed in the present study.

\begin{tabular}{|c|c|c|c|c|}
\hline Sequence & Abbreviation & Hydrophobic residues (\%) & Charge & Hydropathy plots \\
\hline FNDRLRQGQLL & P1 & 42 & +1 & \\
\hline$\overline{\text { GLVYIL }}$ & $\mathrm{P} 2$ & 67 & 0 & \\
\hline GQTV & P3 & 25 & 0 & 4 \\
\hline $\begin{array}{l}\text { GQTVFNDLRLRQ } \\
\text { GQLL }\end{array}$ & P4 & 38 & +1 & \\
\hline YHNAP & P5 & 40 & +1 & 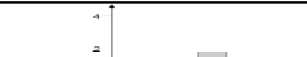 \\
\hline YHNAPGLVYIL & P6 & 55 & +1 & \\
\hline $\begin{array}{l}\text { DVNNNANAVQLE } \\
\text { PR }\end{array}$ & P7 & 33 & -1 & \\
\hline
\end{tabular}

$\mathrm{D}$ : aspartic acid; $\mathrm{V}$ : valine; $\mathrm{N}$ : asparagines; A: alanine; Q: glutamine; L: leucine; E: glutamic acid; $\mathrm{P}$ : proline; R: arginine; F: phenylalanine; G: glycine; $\mathrm{Y}$ : tyrosine; $\mathrm{T}$ : threonine; $\mathrm{H}$ : histidine. Hydropathy plots were obtained through website http://haubergs.com/peptide, which indicates hydrophobicity of peptide sequences by plotting hydrophobicity versus amino acid number. The different bars represent the amino acids in the same order as that which makes up the peptide. Bar heights above and below $x$-axis represent the degree of hydrophobicity and hydrophilicity of the amino acids, respectively. 


\subsection{Oxygen radical absorbance capacity (ORAC)}

In a previous study, four cell wall carbohydrases degrading enzymes viscozyme $L, \alpha$ amylase, amyloglucosidase, and cellulose were used to optimize the extraction of proteins from oat bran followed by hydrolysis with alacase. ${ }^{177}$ The biological evaluation of the digested proteins then identified the hydrolysate with the highest antioxidant activity from which a number of peptides were sequenced by LC-MS/MS. ${ }^{178}$ In order to evaluate the radical scavenging activity of these peptides in vitro, the ORAC assay was used in the present work. In this assay, the water-soluble AAPH was used to generate peroxyl radicals, and the ability of the peptide samples to scavenge peroxyl radicals and attenuate the oxidation of fluorescein was measured. The peptides analysed were P1 (FNDRLRQGQLL), P2 (GLVYIL), P3 (GQTV), P4 (GQTVFNDRLRQGQLL), P5 (YHNAP), P6 (YHNAPGLVYIL), and P7 (DVNNANQLEPR). According to ORAC data as shown in Figure 1, P1 $(0.27 \mu \mathrm{mol} \mathrm{TE} / \mu \mathrm{mol}), \mathrm{P} 4(0.35 \mu \mathrm{mol}$ TE/ $\mu \mathrm{mol}), \mathrm{P} 6(0.37$ $\mu \mathrm{mol} \mathrm{TE} / \mu \mathrm{mol})$, and P7 $(0.14 \mu \mathrm{mol} \mathrm{TE} / \mu \mathrm{mol})$ had much lower activity than P2 $(0.67 \mu \mathrm{mol} \mathrm{TE} /$ $\mu \mathrm{mol})$, P3 $(0.52 \mu \mathrm{mol} \mathrm{TE} / \mu \mathrm{mol})$, and P5 $(0.61 \mu \mathrm{mol} \mathrm{TE} / \mu \mathrm{mol})$. P1 (1359.54 g/mol), P4 (1744.95 g/mol), P6 (1259.46 g/mole), and P7 (1366.44 g/mol) had significantly larger molecular weights than P2 $(676.85 \mathrm{~g} / \mathrm{mol})$, P3 $(403.43 \mathrm{~g} / \mathrm{mol})$, and P5 $(600.64 \mathrm{~g} / \mathrm{mol})$. Ranathunga et al. reported that low molecular weight peptides exhibit greater antioxidant potential, possibly due to their ease of access to peroxyl radicals. ${ }^{179}$ As well, P1, P4, P6, and P7 had chain lengths of between 11 and 14 amino acids, at least two times longer than those of P2, P3, and P5. As demonstrated by many researchers, short-chain peptides containing 2-10 amino acids demonstrated more potent antioxidant activities than their parent polypeptides, which had chain lengths of $10-50$ amino acids. ${ }^{179-181}$ 


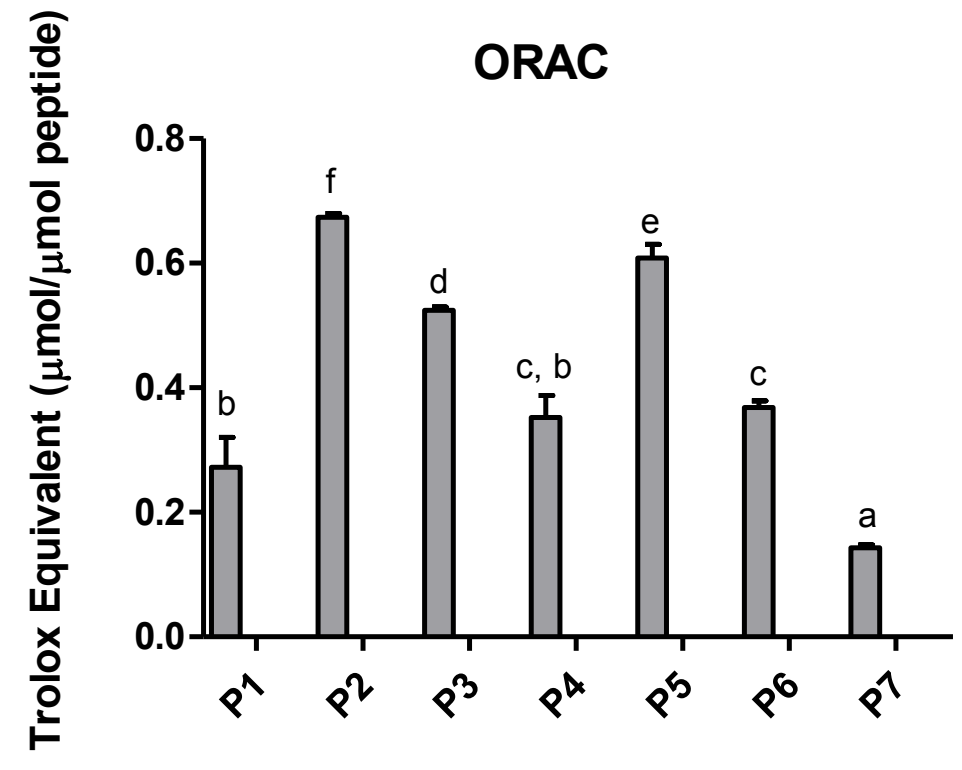

Figure 3. Oxygen radical absorbance capacity (ORAC) values of the peptides. These peptides include: FNDRLRQGQLL (P1), GLVYIL (P2), GQTV(P3), GQTVFNDRLRQGQLL (P4), YHNAP (P5), YHNAPGLVYIL (P6), and DVNNNANQLEPR (P7). Each peptide was tested in triplicate with ORAC values expressed as $\mu \mathrm{mol}$ Trolox equivalent $/ \mu \mathrm{mol}$ peptide, and shown as mean $\pm \mathrm{SEM}$. Different letters indicate significant difference post-hoc Tukey's Honest Significant Differences (HSD) test $(p<0.05)$.

Amongst the peptides with relatively long chain lengths, including P1, P4, P6, and P7, P6 had the highest activity, which can be explained by its hydrophobicity (55\% hydrophobic residues). On the other hand, there is no significant difference between activities of $\mathrm{P} 1$ and $\mathrm{P} 4$, possibly due to their similarity in amino acid composition, since P1 consists of the 12 amino acids at the C-terminal of P4. Additionally, amongst the peptides with relatively high antioxidant activities, the activities of P6, P5, and P3 correlated with their percentage of hydrophobic residues, which are $67 \%, 40 \%$, and $25 \%$, respectively. Analysis of mackerel protein hydrolysate by Wu et al. found that high amount of hydrophobic amino acid positively correlated with antioxidant activity. ${ }^{182}$ 
Besides size and hydrophobicity, amino acid composition is also essential for radical scavenging activities of peptides. Amino acids with sulfhydryl groups and aromatic rings are believed to be capable of scavenging radicals by donating protons. ${ }^{183}$ Aromatic amino acids histidine, threonine, tyrosine and phenylalanine are believed to be great radical scavengers due to the presence of benzene ring, which stabilizes the amino acid after proton donation. ${ }^{183}$ Threonine in P3, tyrosine in P2, and histidine/tyrosine in P5, might have contributed to their radical scavenging capacity. As well, it was speculated that the enhancement in antioxidant activity through increasing hydrolysis time might be contributed by increase in free amino acid leucine. ${ }^{182}$ In addition, Byun et al. reported that leucine-rich peptides from marine rotifer that exhibited high antioxidant activity. ${ }^{184}$ This corresponds to the current experiment, in which the leucine-rich hydrophobic peptide P2 exhibited the highest radical scavenging activity. In addition, studies have shown that the presence of certain hydrophobic amino acids such as glycine, leucine, isoleucine, valine, and tyrosine enhanced radical scavenging activity of peptides.

Besides amino acid composition, the sequence of amino acids is also important in the antioxidant activity of peptides. Amino acids positioned near the $\mathrm{N}$ or C-terminals tend to affect the activity of peptides more than those located far from both ends. ${ }^{185}$ In this experiment, P2 and P5 were fragments of P6 from $\mathrm{C}$ and $\mathrm{N}$-terminals, respectively, and each molecule of P6 contained more radical scavenging amino acids such as tyrosine than P2 or P5. However, P2 and P5 had greater radical scavenging activities than P6. This could be due to the fragmentation of P6 exposing antioxidant activity-contributing amino acids such as glycine, leucine and isoleucine at positions close to the terminals, leading to higher activities observed in P2 and P5. Similarly, 
P1 and P3 are fragments of P4. Whereas P3 had higher activity than P4, that of P1 was equivalent to P4. This could be due to the change in position of amino acids threonine and valine, from third and fourth position at $\mathrm{N}$-terminal to first and second position at $\mathrm{C}$-terminal.

The ORAC activities of P1, P4, and P6 were similarto that of the peptide MHIRL found in hydrolysate of the protein $\beta$-lactoglobulin $\left(0.306 \mu \mathrm{mol}\right.$ Trolox $/ \mu \mathrm{mol}$ of peptide) ${ }^{186}$ On the other hand, peptide YAEERYPIL from egg white protein hydrolysate exhibited $3.5 \mu \mathrm{mol}$ TE/ $\mu \mathrm{mol}$ peptide. ${ }^{53}$ Peptides produced from the most commonly studied protein hydrolysates, including those from $\beta$-lactoglobulin and ovotransferrin, demonstrated highly varied ORAC values, with $0.306-7.67 \mu \mathrm{mol} \mathrm{TE} / \mu \mathrm{mol}$ peptide from $\beta$-lactoglobulin and $0.43-15.4767 \mu \mathrm{mol} \mathrm{TE} / \mu \mathrm{mol}$ peptide from ovotransferrin. ${ }^{187}$

\subsection{Cytotoxicity and cytoprotective effects of the peptides}

The cytotoxicity of each peptide was determined by measuring the viability of HepG2 cells. The assay was initially optimized using P2 at concentrations between 50-500 $\mu \mathrm{M}$. It was only cytotoxic above $450 \mu \mathrm{M}$. These tests were then performed using 50 or $100 \mu \mathrm{M}$ only. As shown in Figure 2, treatment with P1, P3, P4, P5, P6, and P7 did not significantly affect HepG2 cells viability as compared to that of the negative control (NEG) at both concentrations. Interestingly, P2 at 50 or $100 \mu \mathrm{M}$ greatly promoted the growth of HepG2 cells as evident by the nearly six-fold increase in cell viability. It has been demonstrated that treatment with yeast, soy, and broadbean hydrolysates enhanced the cell viability of Chinese hamster ovary cells, although no suggestion of mechanism was provided. ${ }^{188}$ In addition, Kuzuya et al. reported that treatment with $\alpha$-tocopherol enhanced growth of cultured endothelial cells, and the 
mechanism was possibly not due to radical scavenging activity, but rather related to antioxidant uptake. ${ }^{189}$

\section{Cytotoxicity}

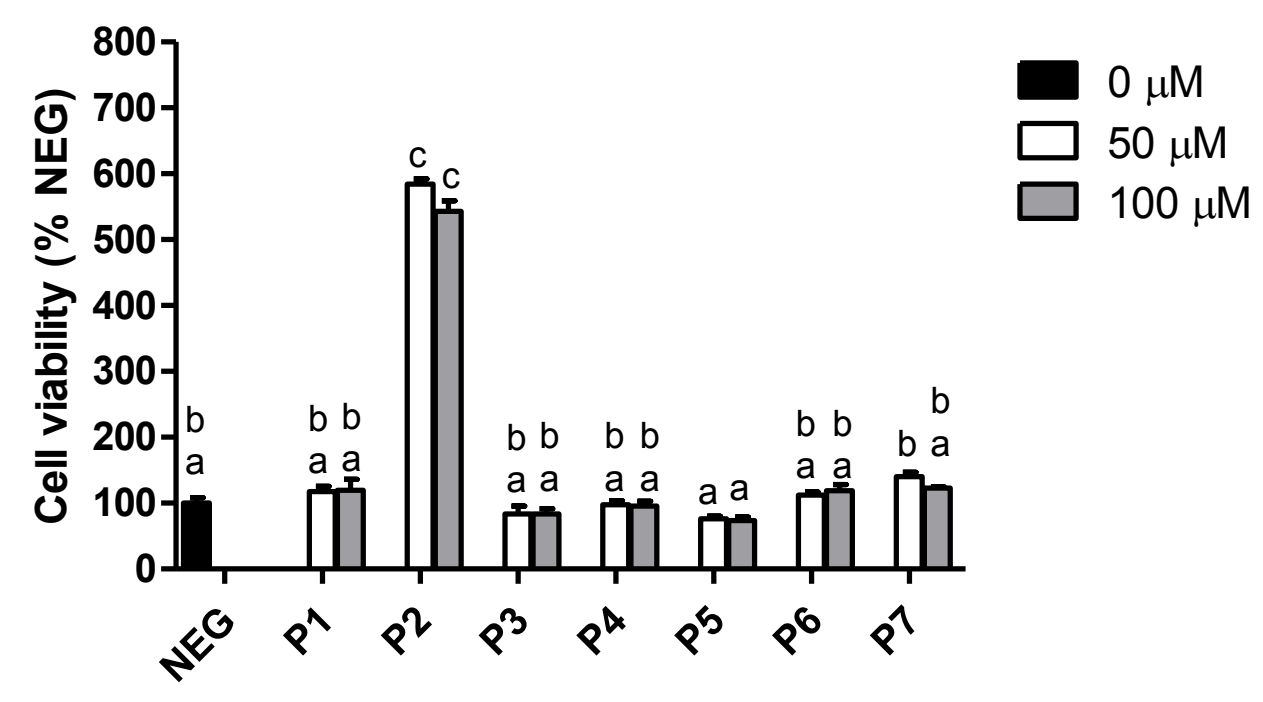

Figure 4. Effect of peptides on the viability of HepG2 cells. NEG (negative control), FNDRLRQGQLL (P1), GLVYIL (P2), GQTV(P3), GQTVFNDRLRQGQLL (P4), YHNAP (P5), YHNAPGLVYIL (P6), and DVNNNANQLEPR (P7). Cells were treated with peptides (except for NEG) for 24 hours and cell viability expressed as percent of NEG are means \pm SEM. Data marked with different letters are significantly different $(p<0.05)$ on post-hoc Tukey's Honest Significant Differences (HSD) test.

Cytoprotective effects of the peptides against oxidative stress was also measured. Oxidative stress was induced using $\mathrm{AAPH}$, a small azo molecule that undergoes thermal decomposition to produce carbon centered radicals that react with oxygen to produce peroxyl radicals in solution at a constant rate. ${ }^{190}$ In the present experiment, HepG2 treated with APPH only experienced a $40 \%$ decrease in viability compared to NEG (not treated with APPH). Although each peptide was analyzed at two different concentrations (50 and $100 \mu \mathrm{M}$ ), no significant differences in cytoprotective activities was observed between the two 
concentrations, except for P1. Treatment with $50 \mu \mathrm{M}$ P1 and P7 did not result in effective protection against AAPH induced damage, whereas $100 \mu \mathrm{M}$ of P1 and P7 increased the viability by $13 \%$ and $15 \%$, respectively. On the other hand, P6 at both $50 \mu \mathrm{M}$ and $100 \mu \mathrm{M}$ completely eliminated the effect of AAPH. P2 not only prevented AAPH damage, but also significantly increased the viability of HepG2 cells as compared to the negative control (NEG).

The results demonstrated that hydrophobicity of the peptides was essential for their cytoprotective activities. Amongst peptides that demonstrated cytoprotective effects, the cytoprotective activities from highest to lowest are: P2 > P6 > P7 > P1, which was in the same order as their hydrophobicity from highest to lowest. Studies have demonstrated that hydrophobicity of peptides promotes their cellular uptake due to ease of interaction with the cell membrane ${ }^{191}$. It has been proposed that hydrophobic peptides can anchor themselves to the lipid membrane and create transient membrane voids that eventually leads to their internalization. ${ }^{191}$ In this experiment, the peptides P3 and P4, which had low hydrophobicity, did not exert cytoprotection. Low hydrophobicity of P3 and P4 might have limited their interaction with the lipid membrane, leading to difficulty in cellular uptake. On the other hand, at $100 \mu \mathrm{M}$, cytoprotective activities of P1, P2, P6, and P7 correlated greatly with their hydrophobicity, with P2 having the highest activity, followed by P6 and P7. P1 was the lowest in both hydrophobicity and cytoprotective activity. According to the hydropathy plots of the peptides, as indicated in Table 1, P1, P6, and P7 had no cluster of hydrophobic residues, and were likely internalized by the cells and exerted protective activity through intracellular mechanisms. On the other hand, P2 contained concentrated hydrophobic residues at the Cterminal, and could be lodged in the hydrophobic region of the membrane. Since the main 
mechanism of AAPH-induced cell damage is through membrane peroxidation, the presence of P2 in the cell membrane might have contributed to its potent cytoprotective activity against AAPH-induced cell damage.

\section{Cytoprotection}

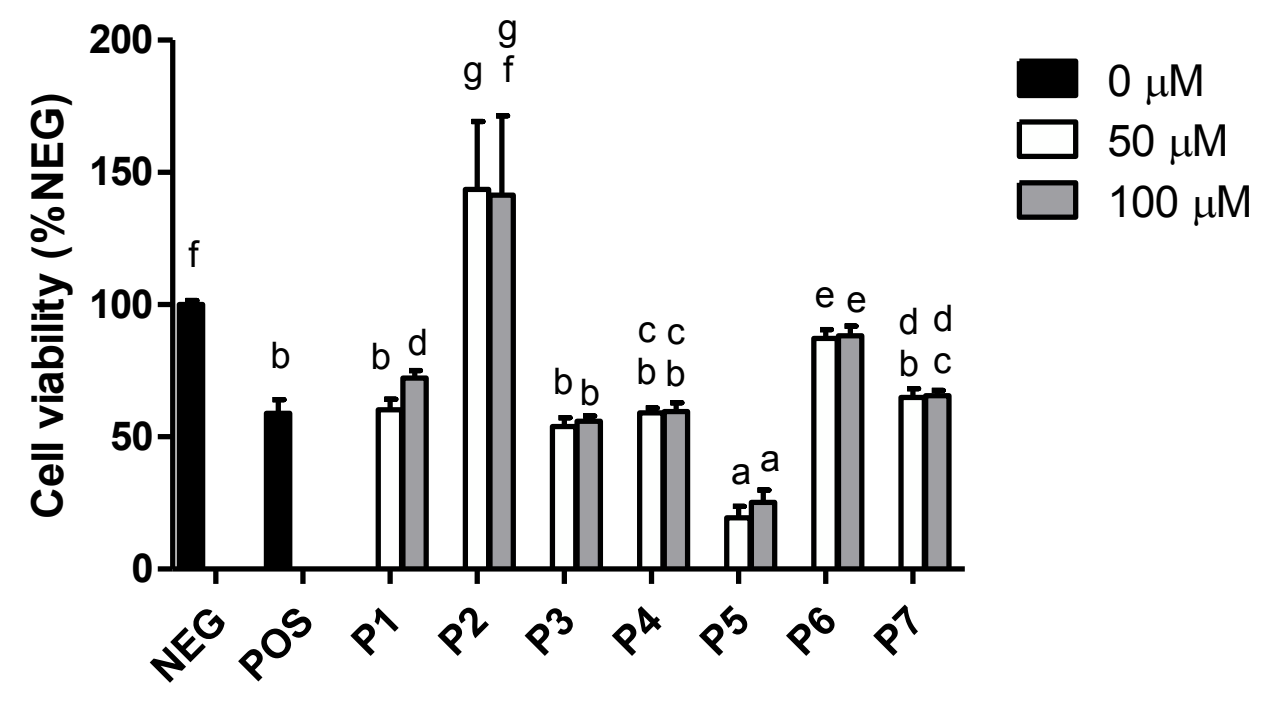

Figure 5. Protective effects of peptides against AAPH - induced cell death. These peptides include: FNDRLRQGQLL (P1), GLVYIL (P2), GQTV(P3), GQTVFNDRLRQGQLL (P4), YHNAP (P5), YHNAPGLVYIL (P6), and DVNNNANQLEPR (P7). HepG2 cells were pretreated with the peptides for 24 hours, followed by 24-hour incubation with $20 \mathrm{mM}$ AAPH. NEG group represents HepG2 cells that were untreated. Cell viability was calculated as percent of control. Data are means \pm $\mathrm{SEM}, \mathrm{n}=3$. Different letters indicate significant differences on post-hoc Tukey's Honest Significant Differences (HSD) test.

Although cellular internalization mechanism of peptides has not been fully elucidated, it has been suggested that a weak cationic charge promotes endocytosis of peptides. Studies showed that even at low concentrations, positively charged peptides can be up-taken by mammalian cells through binding with the negatively charged sulfated glycosaminoglycans located on membrane surface. ${ }^{192}$ In the present experiment, although P1 had low 
hydrophobicity compared to $\mathrm{P} 2, \mathrm{P} 6$, and $\mathrm{P} 7$, it is positively charged at $\mathrm{pH} 7$. As well, $\mathrm{P} 1$ is rich in amino acids arginine, which has been shown to induce cytoskeleton rearrangement in HeLa cells, promoting endocytosis. ${ }^{193}$ Hence, at $100 \mu \mathrm{M}$, P1 exerted cytoprotective activity against AAPH-induced cell death.

Free radical scavenging activity due to presence of proton-donors in a peptide such as aromatic amino acids and sulfhydryl side chains is important for protection against AAPH insult. Hence, the presence of phenylalanine in P1, tyrosine in $\mathrm{P} 2$, tyrosine/histidine in $\mathrm{P} 6$ might have contributed to their cytoprotective activities. The lack of aromatic amino acids in P7 might have contributed to its relatively low activity compared to P2 and P6. Studies of hydrolysates of various protein sources such as whey, smooth hound muscle and giant squid muscle found that antioxidant peptides are usually rich in glycine, valine, isoleucine, and leucine, suggesting that these amino acids play a role in antioxidant activity of peptides via in vitro chemical assays. ${ }^{194-}$ 196 Hence, besides aromatic amino acids, presence of valine and leucine in P7 as well as valine, isoleucine and leucine might have contributed to their cytoprotective activities. Interestingly, the hydrophobic peptide P2 is consists of glycine, leucine, isoleucine, valine, and tyrosine, all of which has been suggested to enhance antioxidant activity of peptides. This corresponds to the high cytoprotective activity of $\mathrm{P} 2$, which not only enhanced cell survival compared to cells not treated with peptides, but also increased cell viability by 2 -fold higher than the NEG cells.

In addition, metal chelation is important for reduction of free radical formation since $\mathrm{Fe}^{2+}$ and $\mathrm{Cu}^{2+}$ can promote formation of ${ }^{\circ} \mathrm{OH}$ and $\mathrm{O}_{2}{ }^{-\bullet}$, accelerating lipid peroxidation. ${ }^{197}$ Studies have found that peptides with metal chelating activities such as bean protein hydrolysates and caseinophosphopeptides protected Caco-2 cells from 2,2'-azobis (2-amidinopropane) 
dihydrochloride (ABAP) and $\mathrm{H}_{2} \mathrm{O}_{2}$ - induced oxidative damage. ${ }^{197,198}$ It has been proposed that histidine as well as other basic or acidic amino acids including arginine, lysine, aspartate, and glutamate have metal chelating properties. ${ }^{197}$ Hence, aspartate and glutamate in P7, aspartate in P1, and histidine in P6 might have contributed to their cytoprotective activities. Interestingly, Rajapakse et al. reported that the position of favorable amino acids in a peptide affects its antioxidant activity. ${ }^{199}$ For example, evidence suggests that histidine and phenylalanine at penultimate positions of $\mathrm{N}$ and $\mathrm{C}$-terminals greatly increased their antioxidant activity compared to other positions. ${ }^{185}$ As well, the insertion of proline and/or leucine at the Cterminal greatly reduces the antioxidant activity of the metal chelating amino acid histidine. In this experiment, the penultimate position of histidine at the $\mathrm{N}$-terminal P6 might have contributed to its cytoprotective activity through metal chelation. On the other hand, the metal chelating activity of P7 might have been reduced by the presence of proline and leucine consecutively with the metal chelating glutamate at the C-terminal.

Interestingly, pre-treatment with P5 seemed to have weakened the cells' defense against AAPH, with approximately $80 \%$ decrease in cell viability as compared to NEG Compared to POS, cells pre-treated with P5 at 50 and $100 \mu \mathrm{M}$ further decreased cell viability by 40 and $34 \%$, respectively, with no significant difference between the two concentrations. This contradicts with ORAC data, which indicated that P5 had high radical scavenging activity. Indeed, under certain conditions, compounds that were established as having antioxidant activity using in vitro chemical assays can act as a pro-oxidant in cellular or animal models. Many phenolic acids, such as ferulic acid, caffeic acid, vanillic, and gallic acid, which were commonly studied antioxidants, has been shown to exhibit pro-oxidant activity under certain 
conditions such as high dosage or presence of metal ions. ${ }^{200}$ The exact pro-oxidant mechanism of polyphenols is unclear. However, unlike their antioxidant properties, the pro-oxidant properties of polyphenols demonstrated specified cellular target preference. ${ }^{201}$ Galati and O'Brien speculated that certain dietary polyphenols can cause apoptotic death of cells by inducing mitochondrial dysfunction. ${ }^{202}$ On the other hand, Azmi et al. demonstrated that polyphenols promote the mobilization of endogenous copper in humans, which causes consequent DNA damage. ${ }^{203}$ Hence, in this experiment, P5 might have acted synergistically with AAPH to enhance oxidative stress and induce cell death. P5 contains a phenol (tyrosine residue) which coupled with its specific sequence may have allowed the localisation of P5 in target were it acted at a pro-oxidant or regulate genes or enzymes involved in cell death.

Antioxidant peptides found in hoki frame protein hydrolysate was found to protect human embryonic lung fibroblasts MRC-5 cells against t- $\mathrm{OOH}$ induced injury. ${ }^{204}$ The oxidative stressor used in this experiment, AAPH, is a relatively new and less commonly used free radical generator. While t-OOH produces the both alkoxyl and peroxyl radicals, AAPH is known to produce peroxyl radicals. In addition, $\mathrm{t}-\mathrm{OOH}$ has been shown to cause extensive DNA oxidation. ${ }^{205}$ The mechanism of interaction between AAPH and cells is unclear. However, it is believed that AAPH causes cell damage mainly through oxidation of plasma membrane phospholipid and proteins. ${ }^{206}$ Studies suggested that while a small amount of protein hyroperoxides are formed during interaction between AAPH and cells are lipid hydroperoxides, most of the hydroperoxides produced were lipid hydroperoxides. AAPH is a good oxidation inducer since the generation of free radicals by thermal decomposition takes place at a constant and measurable rate and without biotransformation. ${ }^{207}$ In addition, AAPH causes 
various pathologies which can be clearly seen and suppressed by antioxidants such as uric acid, vitamin E, and glutathione, making it a suitable candidate as oxidative stressor to study cytoprotective effects of potential antioxidants. ${ }^{207}$ Other food-derived substances have been found to protect cells against damage by oxidative stress. For example, Martin et al. reported that cocoa phenolic extract at $0.5-50 \mu \mathrm{g} / \mathrm{mL}$ was effective in protecting cells against tert-butylhydroperoxide (t-OOH)-induced oxidative damage on HepG2 cells. ${ }^{208}$ As well, Kim et al. reported that at 10 and $100 \mu \mathrm{M}$, quercetin exerted cytoprotective activity against HepG2 cell damage by AAPH. ${ }^{209}$

The cytoprotective effects of the peptides on the HepG2 cells in this work correlated with ORAC data of peptides P2 and P6. However, P3, P4, and P5, which demonstrated radical scavenging activity in ORAC assay, did not show protective effects on HepG2 cells. In contrast, P1, and P7 with the lowest radical scavenging activity in ORAC assay, demonstrated considerable cytoprotection against AAPH induced damages on HepG2 cells. Hydrophobicity of the peptides played a small role in radical scavenging activity of ORAC assay, but correlated perfectly with the cytoprotective activities against AAPH. This could be due to the interaction of peptide with cell membrane and cellular uptake, a factor that is essential for cytoprotective activity, but not in the ORAC assay. Since metal ions are naturally present in cells as well as the cell culture media, metal chelating activity might have enhanced cytoprotective activity of the peptides. However, in the ORAC assay, metal chelating activity was not applicable due to the absence of metal ions. 


\subsection{Determination of ROS}

In order to elucidate the protective mechanism of peptides P1, P2, P6, and P7, it was of interest to investigate whether these peptides protected HepG2 cells from AAPH-induced damage by decreasing reactive oxygen species. DCFH $_{2}$-DA can be up-taken by cells and deacetylated by intracellular esterase to produce DCFH, which can be oxidized by a wide array of ROS including $\mathrm{ONOO}^{-}, \mathrm{NO}, \mathrm{H}_{2} \mathrm{O}_{2},{ }^{\circ} \mathrm{O}_{2},{ }^{\circ} \mathrm{OH}$, and peroxyl radicals to produce the fluorescent DCF 210,211 . ROS was calculated as percent increase in fluorescence, which is advantageous over mere calculation of net change in fluorescence because the previous eliminates the effect of background fluorescence in each well and controls for differences between wells by reflecting on the percent change of fluorescence intensity in the same well over time. ${ }^{210}$

As can be observed in Figure 4, when treated with AAPH (POS), ROS increased by 36.9 \%. On the other hand, pre-treatment with 50 or $100 \mu \mathrm{M}$ of P1, P2, P6, and P7 completely eliminated the effect of AAPH, with the exception of P6 at $50 \mu \mathrm{M}$. Amongst pre-treatments with peptides at $50 \mu \mathrm{M}, \mathrm{P} 2(107.5 \% \mathrm{NEG})$ and P7 (107.5\%) had the lowest levels of ROS, followed by P1 (112.9\%) and P6 (125.0\% NEG), all of which were significantly lower than that of POS (136.9\%). On the other hand, at $100 \mu \mathrm{M}$, pre-treatment with P2 (91.9\%) and P6 (97.2\%) had the lowest levels of ROS, followed by P1 (100.3\%) and P7 (102.9\%), with no significant differences between P2 and P6, as well as between P1 and P7. Even when stressed with AAPH, HepG2 cells pre-treated with $100 \mu \mathrm{M}$ of P2 had lower ROS than NEG cells, which were not stressed. This can be explained by the fact that P2 increased cell viability but also by the fact P2 and P6 are more hydrophobic compared to P1 and P7. Other factors that contribute to cytoprotective activity such as charge and amino acid composition also affected the amount of ROS after treatment 
with the peptide samples. For example, P1 had a weak positive charge, which might have enhanced its cellular uptake. As previously explained, the presence of amino acids such as the aromatic tyrosine, and other hydrophobic amino acids such as glycine, leucine, valine, and isoleucine might enhance the radical scavenging activity of the peptides, leading to a decrease in intracellular ROS. As well, the presence of metal chelating amino acids such as histidine, aspartate, and glutamate could decrease metal-induced ROS formation, leading to reduction of ROS.

Certain food-derived antioxidants have been shown to decrease $\mathrm{H}_{2} \mathrm{O}_{2}, t-\mathrm{OOH}$, and AAPH-induced damages in cellular models. The commonly studied antioxidants vitamins E and C has been shown to inhibit ROS production in myelomonocytic HL-60 cells dose-dependently. ${ }^{212}$ As well, antioxidant peptides from Nile tilapia scale gelatin and purified peptides from gastrointestinal digests of oyster has been found to decrease intracellular ROS induced by $\mathrm{H}_{2} \mathrm{O}_{2}$ in mouse macrophage RAW 264.7 cells. ${ }^{213,214}$ Ko et al. reported that two peptides from flounder fish protease digest, VCSV and CAAP, attenuated AAPH-induced increase in ROS in RAW 264.7 cells ${ }^{215}$. In addition, peptides from marine Chlorella ellipsoidea protein at 50 and $100 \mu \mathrm{M}$ decreased ROS formation in AAPH treated monkey kidney cells, although the effect of AAPH on ROS was not completely eliminated even with peptides at $100 \mu \mathrm{M} .^{216}$ In addition, Nile tilapia protein hydrolysate have been found to decrease ROS induced by either AAPH or $\mathrm{H}_{2} \mathrm{O}_{2}$ in HepG2 cells. ${ }^{217}$ 


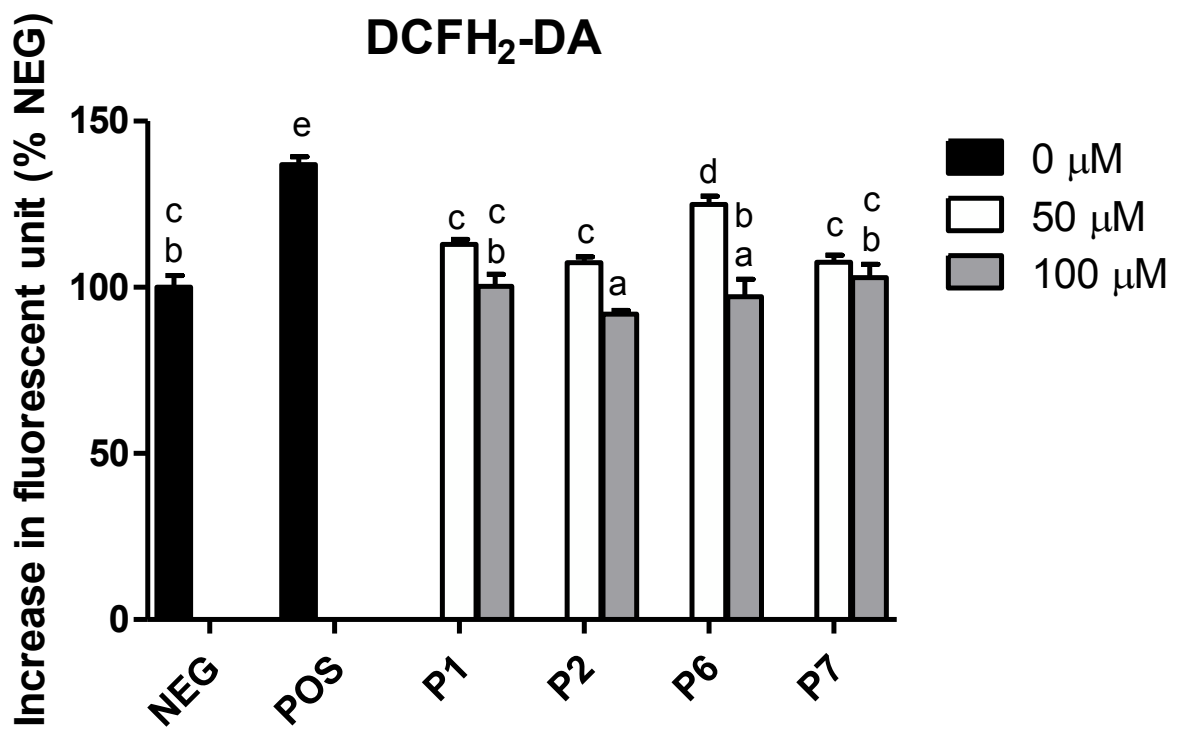

Figure 6. Effect of peptides on the generation of intracellular ROS. These peptides include: FNDRLRQGQLL (P1), GLVYL (P2), GQTV(P3), GQTVFNDRLRQGQLL (P4), YHNAP (P5), YHNAPGLVYIL (P6), and DVNNNANQLEPR (P7). After pre-treatment with peptides at 0, 50, or $100 \mu \mathrm{M}$ for 24 hours, HepG2 cells were incubated for 24 hours with 20 mM AAPH. NEG group represents HepG2 cells that were untreated. Increase in DCF-fluorescence was calculated as percent control (mean $\pm S E M, n=3$ ). Data marked with different letters are significantly different on post-hoc Tukey's Honest Significant Differences (HSD) test $(p<0.05)$.

In this experiment, $\mathrm{DCFH}_{2}-\mathrm{DA}$ data for peptides at $100 \mu \mathrm{M}$ was comparable to ORAC data, where peptides in the order from high to low ORAC activity, P2 > P6 > P1 > P7 was inversely related to amount of ROS from high to low, P7 > P1 > P6 > P2, although the difference between P1 and P7 was significant for ORAC assay, but was not significant for $\mathrm{DCFH}_{2}-\mathrm{DA}$ assay. Due to short AAPH incubation time (45 minutes) as the considerable correlation between results from ORAC and DCFH 2 - DA assay, it can be assumed that the decrease in ROS in HepG2 cells pre-treated with $\mathrm{P} 1, \mathrm{P} 2, \mathrm{P} 6$, and $\mathrm{P} 7$ was mainly caused by radical scavenging activity of these peptides. The result from $\mathrm{DCFH}_{2}-\mathrm{DA}$ correlates with that of cytoprotective activity of the 
peptides. At $100 \mu \mathrm{M}, \mathrm{P} 2$ and P6 had the highest cytoprotective activity as well as lowest ROS levels. In addition, at both 50 and $100 \mu \mathrm{M}$, cytoprotective activities and ROS levels of P1 and P7 were not significantly different. This suggests that decrease in ROS was possibly implicated in the cytoprotective activities of P1, P2, P6, and P7. However, cytoprotective activities of P1, P2, P6 and P7 were not found to be affected by concentration, as treatment with either 50 or 100 $\mu \mathrm{M}$ of the same peptide resulted in non-statistically different levels of cellular protection; whereas pre-treatment with P2 and P6 at $100 \mu \mathrm{M}$ resulted in significantly lower ROS levels than those pre-treated with $50 \mu \mathrm{M} P 2$ and P6. This suggests that there exists other mechanism of cytoprotection by the peptides such as regulation of antioxidant enzyme.

\subsection{Antioxidant enzymes}

As shown in Figure 5, incubation of HepG2 cells with AAPH decreased GPx to $81.8 \%$ NEG and pre-treatment with $\mathrm{P} 1, \mathrm{P} 2$, and $\mathrm{P} 6$ at $50 \mu \mathrm{M}$ increased $\mathrm{GPx}$ levels to those equivalent to NEG. On the other hand, pre-treatment with P7 at $50 \mu \mathrm{M}$ did not have an effect on GPx level. At $100 \mu \mathrm{M}$, pre-treatment with peptides further increased the GPx activity above that of normal cells (NEG), with the exception of P6, which did not affect SOD levels. The highest increase of GPx was associated with P6 (138.6\% of NEG), followed by P2 (130.2\% NEG), P1 (110.3\% NEG), and P7 (108.3\% NEG), with no significant difference between NEG and P1, P7. The current study demonstrated that, even when oxidative stress was induced with AAPH, HepG2 cells pretreated with P2 and P6 at $100 \mu \mathrm{M}$ maintained levels of GPx higher than non-treated cells. This correlated with the cytoprotective effects as shown in Figure 2, with P2 and P6 being more protective than P1 and P7. Although P1 at $50 \mu \mathrm{M}$ did not improve survivability of cells, it might improve the redox status of cells as indicated by the increase in GPx level. As shown in Figure 6, 
P1 and P7 at $50 \mu \mathrm{M}$ did not increase SOD activity as compared to POS, and P6 did not have an effect on SOD at any concentration. At both 50 and $100 \mu \mathrm{M}, \mathrm{P} 2$ was able to increase SOD to levels equivalent to that of NEG. Interestingly, P6, which had high activity in cytoprotection and elevation of GPx level, did not affect SOD activity.

In the current study, pre-treatment with 50 and $100 \mu \mathrm{M}$ of P2, P6, and P7 enhanced CAT activity. At $50 \mu \mathrm{M}, \mathrm{P} 7$ had the highest elevation of CAT (387\% NEG), followed by P2 (328\% NEG), P6 (232.6\% NEG), and P1 (231.4\% NEG). At $100 \mu \mathrm{M}$, the same trend follows with P2 (665.6\% NEG) having the highest activity, followed by P7, P6, and P1. As can be observed in Figure 7, treatment with AAPH (POS) increased CAT by almost 2-fold, which might be due to two reasons. First, compared to SOD and GPx, CAT is particularly resistant to inactivation by peroxyl radicals, possibly due to the narrowness of its active site leading to difficulty of access by peroxyl radicals. ${ }^{218}$ In addition, Meilhac et al. demonstrated that lipid peroxides, which are products of lipid peroxidation can induce CAT activity in rabbit femoral arterial smooth muscle cells, macrophage RAW cells, and HUVEC. ${ }^{219}$ Since lipid peroxidation is the main mechanism of cellular damage by AAPH, the increase in CAT in this experiment for APPH treated cells compared to normal cells might be due to induction by lipid peroxides, although in certain cell types treatment with $\mathrm{H}_{2} \mathrm{O}_{2}$ increased the CAT activity as well. ${ }^{220}$ Roig et al. where more than 2fold increase in catalase was found in rat hepatoma Fao cells after 21 hour treatment with 600 $\mu \mathrm{M} \mathrm{H}_{2} \mathrm{O}_{2}$, and treatment with epicatechin further induced increase of the CAT activity ( 3 times control). ${ }^{220}$

The effects of different peptides on levels of CAT correlated with those of GPx. For example, for both GPx and CAT assays, the effects of P2 and P6 were dose dependent whereas 
P1 and P7 were not. In addition, at $100 \mu \mathrm{M}, \mathrm{P} 2$ and P6 had significantly higher activities than P1 and P7 for both GPx and CAT, although at $50 \mu \mathrm{M}$, such different was significant only for CAT. The similarity between trends of results for GPx and CAT was probably due to the fact that both enzymes catalyzes the conversion of $\mathrm{H}_{2} \mathrm{O}_{2}$ into water and oxygen; whereas the discrepancy can be related to the differences in mechanism where GPx function requires the substrate GSH and CAT is a dismutase that does not require a substrate.

Studies have demonstrated that antioxidants can decrease oxidative stress by scavenging free radicals as well as by regulating levels of important antioxidant enzymes. Hence, the effects of P1, P2, P6, and P7 on the levels of main antioxidant enzymes GPx, SOD, and CAT in HepG2 cells under oxidative stress were investigated. As previously mentioned, these antioxidant enzymes work together to maintain the oxidation-reduction balance, hence they are rarely studied alone in establishing effects of potential antioxidant compounds. Both cellular and animal model are often used to evaluate the protective effect of antioxidant molecules. For example, significant decrease in levels of GPx, CAT, and SOD in the heart of adult rats receiving ethanol solution were found to be inhibited by pre-treatment with orally administered sardinelle protein hydrolysate. ${ }^{221}$ As well, rats administered Bacopa monniera extract was found to have increased levels of SOD, CAT, and GPx in the brain ${ }^{222}$ while the consumption of Korean red ginseng capsule for 8 weeks by human subjects was found increase plasma levels of SOD, CAT, and GPx. ${ }^{223}$

Cellular models are relatively low cost and can be easily scale up for high throughput screening. Peptides from fish skin gelatin hydrolysate were shown to elevate levels of SOD, GPx, and CAT in Hep3B cells by $92.8 \%, 60.78 \%$, and $35 \%$, respectively. ${ }^{224}$ Lee et al. demonstrated 
that certain plant root extracts induced elevation of GPx, CAT, and SOD in the Chinese hamster lung fibroblast V97-4 cells. ${ }^{225}$

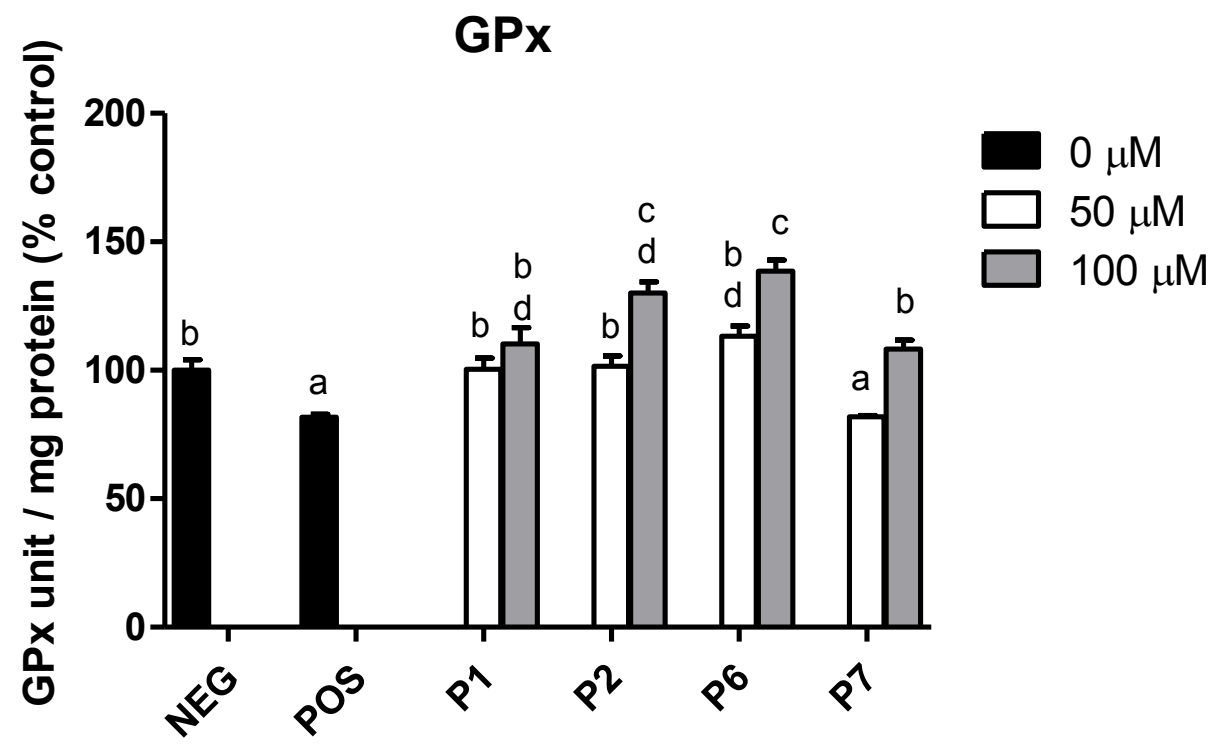

Figure 7. Effect of peptides on GPx level of HepG2 cells stressed with AAPH. These peptides include: FNDRLRQGQLL (P1), GLVYIL (P2), GQTV(P3), GQTVFNDRLRQGQLL (P4), YHNAP (P5), YHNAPGLVYIL (P6), and DVNNNANQLEPR (P7). Cells were pretreated with peptides at 0, 50, or $100 \mu \mathrm{M}$ for 24 hours. Then, cells were incubated with $20 \mathrm{mM} \mathrm{AAPH}$, and GPx unit/mg protein was calculated as percent of negative control (NEG), which consists of untreated cells. Data was expressed as mean \pm SEM, and significant difference ( $p<0.05$, One-way ANOVA) in post-hoc Tukey's Honest Significant Differences (HSD) test was indicated by different letters.

Studies like the ones mentioned above involved only the use of the potential antioxidant of interest without induced oxidative stress. However, in order to elucidate the mechanism of a cytoprotective compound against oxidative injury and better mimic pathological conditions related to oxidative stress, oxidative inducers can be used. The most common used oxidative stressor is $\mathrm{H}_{2} \mathrm{O}_{2}$. Subhashinee et al. tested the dose-response $(0-250 \mu \mathrm{M})$ effect of $\mathrm{H}_{2} \mathrm{O}_{2}$ on levels of antioxidant enzymes in Caco-2 cells, and it was found that above $50 \mu \mathrm{M} \mathrm{H} \mathrm{H}_{2}$, SOD 
activity was inversely related to concentration of $\mathrm{H}_{2} \mathrm{O}_{2} \cdot{ }^{226}$ On the other hand, CAT and GPX activity of cells treated with $\mathrm{H}_{2} \mathrm{O}_{2}$ increased up to $50 \mu \mathrm{M}$, and remained unchanged even at the maximum concentration tested. ${ }^{226}$

To date, there has been very little studies indicating the effects of AAPH on antioxidant enzyme levels. Liao et al. reported that incubation of erythrocytes with $200 \mathrm{mM}$ AAPH for 2 hours increased levels of CAT, SOD, and GPx, while studies by Park and Han as well as by Hwang reported a decrease in SOD and GPx in porcine kidney epithelial (LLC-PK1) cells after 24 hour treatment with $1 \mathrm{mM} \mathrm{AAPH} .{ }^{225,227,228}$ Therefore, the effect of AAPH on antioxidant enzymes depends on cell type and concentration of AAPH used. In the current study, treatment of HepG2 cells with 20 mM AAPH for 24 hours decreased GPx and SOD activities by $18.2 \%$ and 29.1\%, respectively, whereas it increased the activity of CAT by 2 -fold. Studies have demonstrated that isolated GPx and SOD can be inactivated by peroxyl radicals, and GPx is especially susceptible to such damage. ${ }^{218}$ While the susceptibility of GPx to peroxyl radicals has not been explained, it has been speculated that tryptophan residue at its active site is particularly sensitive to ROS damage. ${ }^{229}$ In addition, $\mathrm{H}_{2} \mathrm{O}_{2}$ inhibits $\mathrm{CuZnSOD}$ by reducing $\mathrm{Cu}^{2+}$ to $\mathrm{Cu}^{1+}$ as well as by oxidising histidine located at its active site. ${ }^{230,231}$ 


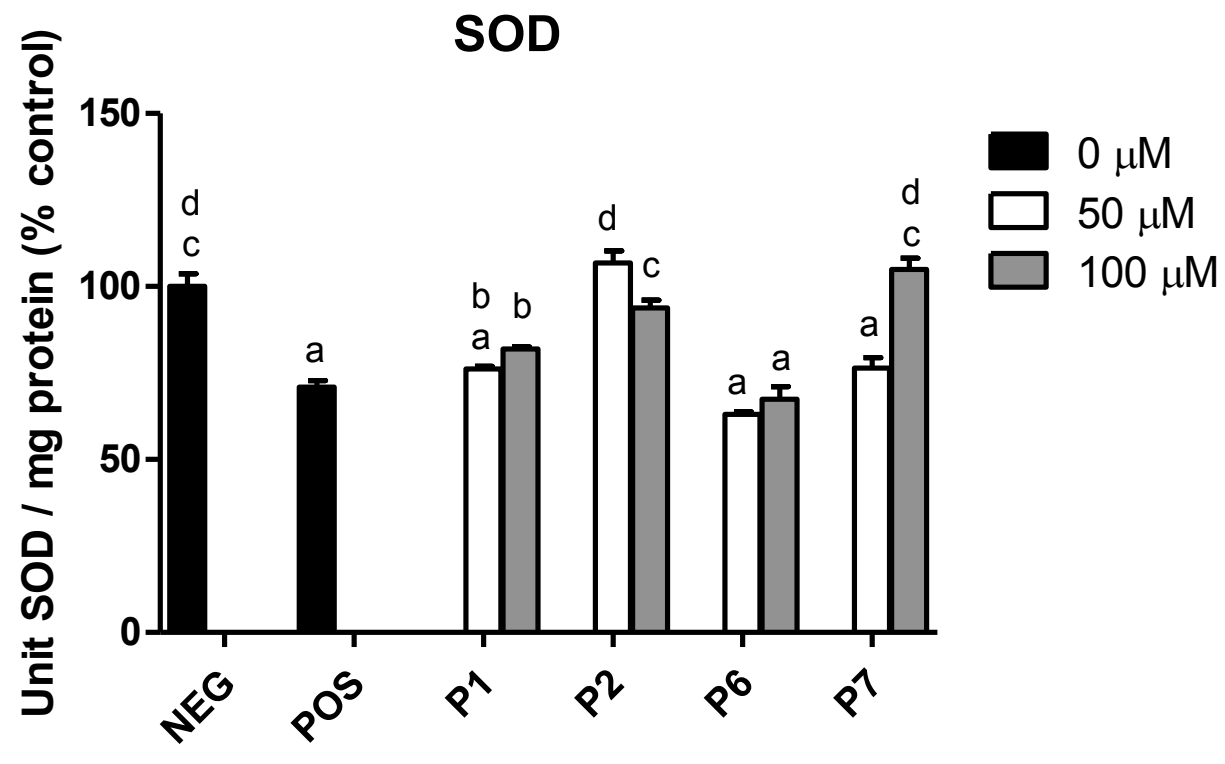

Figure 8. Effect of peptides on SOD levels of HepG2 cells treated with AAPH. These peptides include: FNDRLRQGQLL (P1), GLVYIL (P2), GQTV(P3), GQTVFNDRLRQGQLL (P4), YHNAP (P5), YHNAPGLVYIL (P6), and DVNNNANQLEPR (P7). After 24-hour treatment with 0,50 , or $100 \mu \mathrm{M}$ of peptides, HepG 2 cells were treated with AAPH for 24 hours, and unit SOD/mg protein was determined. Data was expressed as mean \pm SEM, and different letters represent significant difference via post-hoc Tukey's Honest Significant Differences (HSD) test $(p<0.05$, One-Way ANOVA).

Certain compounds with antioxidant activities have been shown to affect levels of antioxidant enzymes in cells under oxidative stress. For example, Shi et al. reported that peptides derived from eggshell membrane attenuated the decrease in GPx and GSH levels in Caco- 2 cells caused by $\mathrm{H}_{2} \mathrm{O}_{2} \cdot{ }^{232}$ Liao et al. reported that treatment with diosmetin, a flavonoid compound, attenuated the decrease in CAT, SOD, and GPx in erythrocytes treated with $200 \mathrm{mM}$ AAPH for 2 hours. As well, treatments with fucoidan and Sasa borealis leaf extract were found to inhibit the decrease in SOD and GPx caused by $1 \mathrm{mM} \mathrm{AAPH}$ in porcine kidney epithelial (LLCPK1) cells. ${ }^{225,227,228}$ 


\section{CAT}

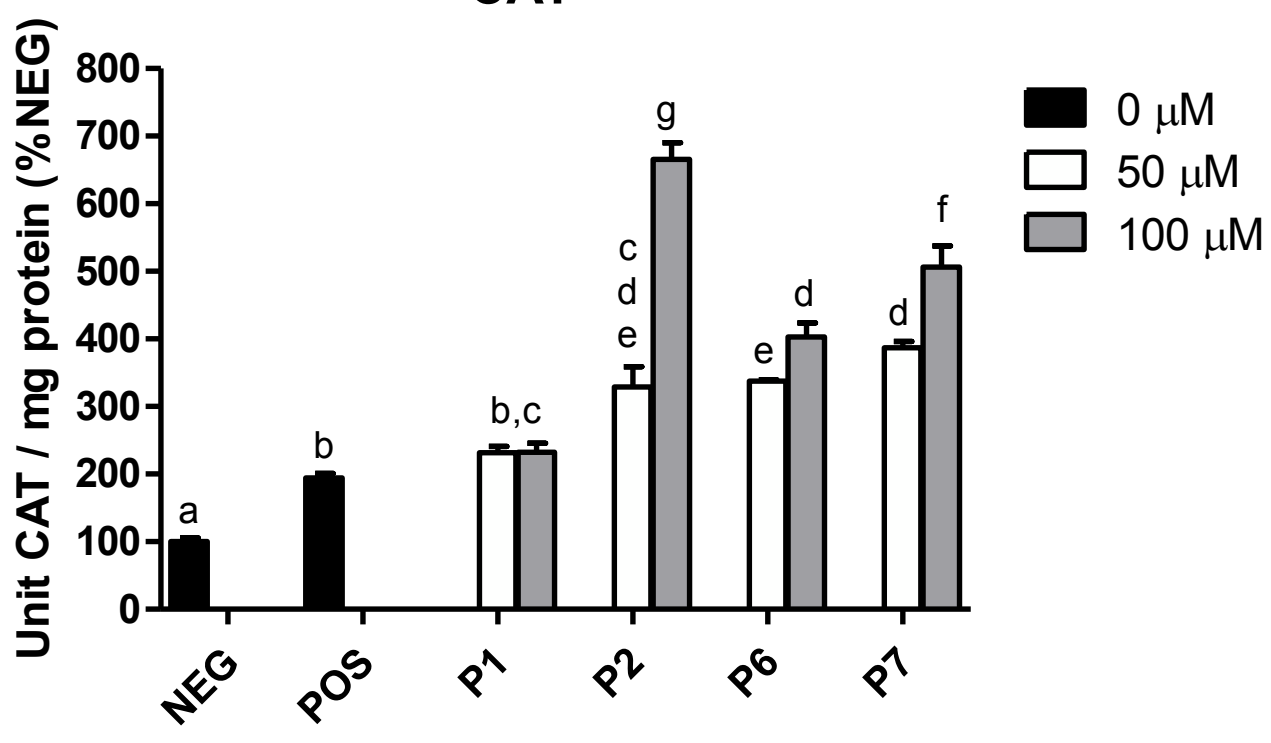

Figure 9. Catalase levels of AAPH-stressed HepG2 cells pre-treated with peptides. These peptides are: FNDRLRQGQLL (P1), GLVYIL (P2), GQTV(P3), GQTVFNDRLRQGQLL (P4), YHNAP (P5), YHNAPGLVYIL (P6), and DVNNNANQLEPR (P7). HepG2 cells were treated with 0, 50, or 100 $\mu \mathrm{M}$ of peptides for 24 hours, followed by incubation with $20 \mathrm{mM}$ AAPH. After 24 hours, catalase activity was measured and unit CAT/mg protein was expressed as percent NEG (mean \pm SEM). Statistical difference was indicated by different letters via post-hoc Tukey's Honest Significant Differences (HSD) test ( $p<0.05$, One-Way ANOVA).

It is unclear how antioxidant enzymes can be regulated by cytoprotective agents such as antioxidants. However, besides scavenging free radicals, it has been suggested that certain compounds can up-regulate the expression of genes that regulate enzymes such as GPx, SOD, and CAT. Shashoua et al. reported that peptides CMX-9236 (KKDGDFAIDAPE) and CMX-8933 (KKETLQFR) had neuro-protective effects and also increased activities of GPx, SOD, and CAT in rat primary cortical cell culture by upregulating the mRNA of these three enzymes, suggesting that the peptides might bind to a certain "defense receptor" and turning on genes for the enzymes. ${ }^{233}$ Evidence suggests that the antioxidant resveratrol increases GPx level of human 
umbilical vein endothelial cells (HUVEC) through up-regulating mRNA of GPx1, which is the most abundant selenoperoxidase in cells. ${ }^{234}$ As well, resveratrol has been shown to up-regulate mRNA expression of the mitochondrial SOD2. ${ }^{235}$ Hence, the peptides P1, P2, P6, and P7 might exert cytoprotective activity through regulation of antioxidant enzymes.

\subsection{Total glutathione}

The reduced form of glutathione, GSH, is a tripeptide consists of amino acids glutamate, cysteine, and glycine. The physiological roles of GSH has long been of interest, particularly its antioxidant function due to the unique redox chemistry of the cysteinyl thiol residues. ${ }^{88}$ The oxidation of sulfhydryl groups on amino acids by ROS can lead to the formation of protein disulfide bonds, which can be reduced by GSH into individual sulfhydryl groups again (Equation 1). Many proteins involved in normal cellular biochemistry, physiology, and pathophysiological processes such as glucose-6-phosphate dehydrogenase, pyruvate kinase, and aldehyde dehydrogenase in metabolism, guanylate cyclase in signal transduction, and collagenase and trypsin in protein catabolism, have been demonstrated to be sensitive to thiol disulphide formation. ${ }^{88}$ In addition, GSH is not only a radical scavenger, but also the substrate used by GPx in reduction of $\mathrm{H}_{2} \mathrm{O}_{2}$. Hence, it is believed that $\mathrm{GSH}$ level reflects oxidative status of cells.

In this experiment, the effect of pre-treatment of HepG2 cells with P1, P2, P6, and P7 on total glutathione was evaluated. As shown in Figure 8, treatment with AAPH decreased total glutathione by $58.1 \%$. Pre-incubation with P1, P2, P6, and P7 at $50 \mu \mathrm{M}$ completely inhibited the glutathione-decreasing effect of AAPH as demonstrated by the increase in glutathione levels to $115.5 \%, 145.0 \%, 105.7 \%$, and $92.9 \%$ of NEG, respectively, with P2 treatment being significantly 
higher than P1, P6, P7, and negative control. On the other hand, whereas the dose-dependent differences were not significant for P1 and P7, P2 and P6 had much higher glutathione levels at $100 \mu \mathrm{M}$ than at $50 \mu \mathrm{M}$. In addition, even when under AAPH-induced oxidative stress, HepG2 cells pretreated with P7 at $100 \mu \mathrm{M}$ and P2 at both 50 and $100 \mu \mathrm{M}$ brought the level of glutathione passed that of NEG.

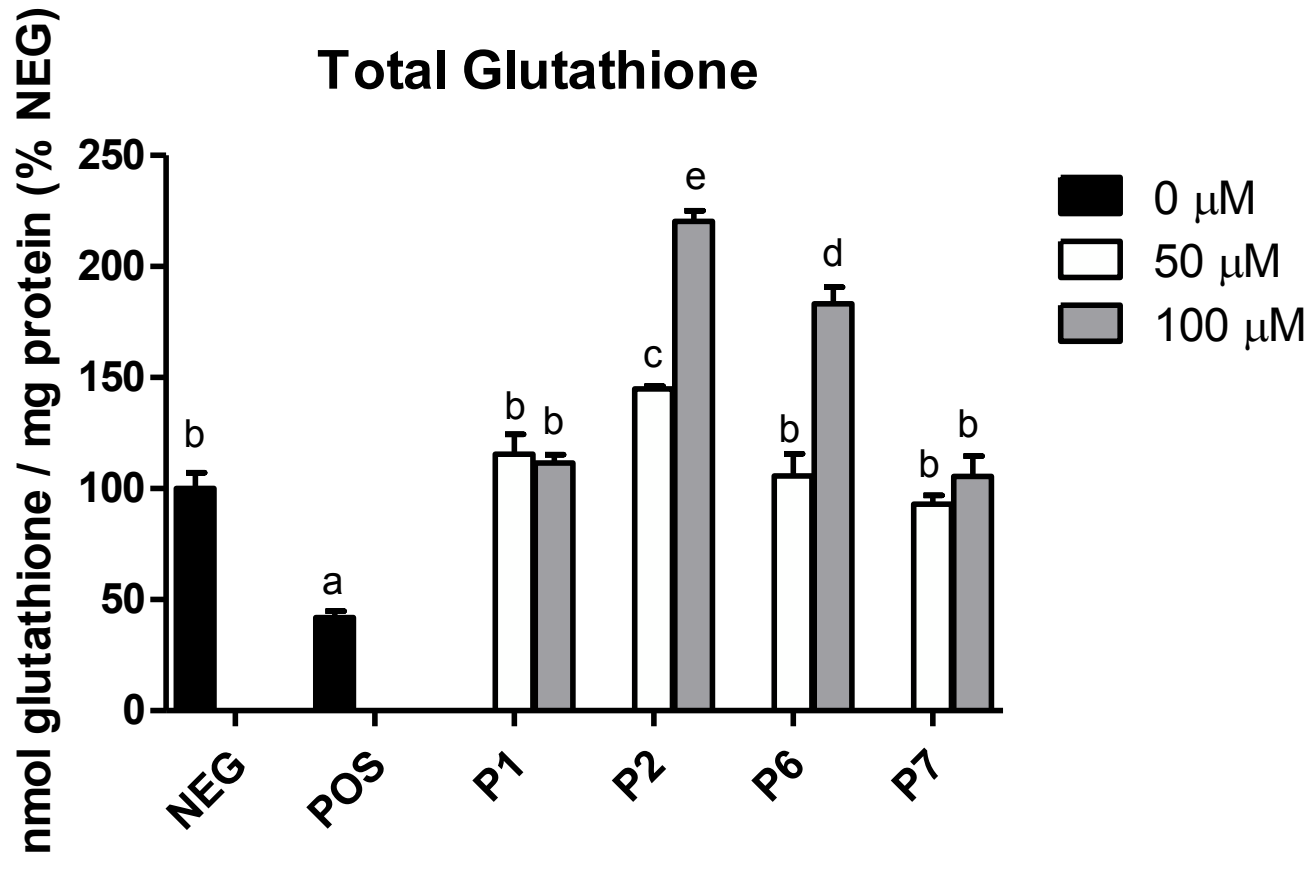

Figure 10. Effect of peptides on GSH levels of HepG2 cells treated with $20 \mathrm{mM} \mathrm{AAPH}$. These peptides are: FNDRLRQGQLL (P1), GLVYIL (P2), GQTV(P3), GQTVFNDRLRQGQLL (P4), YHNAP (P5), YHNAPGLVYIL (P6), and DVNNNANQLEPR (P7). After 24-hour treatment with peptides at 0, 50 , or $100 \mu \mathrm{M}, \mathrm{HepG} 2$ cells were incubated with AAPH for 24 hours, and GSH levels were expressed as percent NEG (mean \pm SEM). Significant differences in post-hoc Tukey's Honest Significant Differences (HSD) test were represented by different letters $(p<0.05$, One-Way ANOVA).

Previous studies have found that since the reduced form of GSH in HepG2 cells is approximately 30 -fold higher than that of the oxidized form GSSG, changes in total glutathione 
levels caused by oxidative stress-inducer such as $\mathrm{t}-\mathrm{OOH}$ and copper or antioxidants such as tea catechins is largely due to change in GSH, with changes in GSSG statistically significant but minor. ${ }^{165,236,237}$ Hence, changes in total glutathione level reflects change in GSH levels. In this experiment, it can be assumed that the decrease in total glutathione by treatment of AAPH or increase in glutathione with peptide pre-treatment is mainly due to changes in GSH levels. Since GSH is a good scavenger of $\mathrm{OH}, \cdot \mathrm{OOH}, \mathrm{H}_{2} \mathrm{O}_{2}$, and lipid peroxyl radicals, the decrease in glutathione levels after treatment with AAPH was due to decrease in GSH levels. ${ }^{238}$ As well, GSH is not only important in cellular antioxidant defense, but also in xenobiotic metabolism as well as regulation of cell proliferation, apoptosis, DNA and protein synthesis, and gene expression. Thus, the increase in GSH levels by P1, P2, P6, and P7 not only improves redox-status of cells, but also promote proper physiological function of cells. ${ }^{238}$

Food-derived antioxidants such as phenolic compounds have been found to increase GSH levels of HepG2 cells with or without addition of oxidative stressor. For example, caffeic acid and rosmarinic acid at 370 and $180 \mu \mathrm{M}$ were found to attenuate but not completely eliminate the GSH depletion caused by $\mathrm{t}-\mathrm{OOH}$ treatment. ${ }^{239}$ Cocoa phenolic extract at $0.05-50$ $\mu \mathrm{g} / \mathrm{mL}$ exhibited protective effect against the remarkable decrease in GSH levels of HepG2 cells treated with $200 \mu \mathrm{M} \mathrm{t}-\mathrm{OOH}$, although even at the maximum concentration, treatment with cocoa phenolic extract did not completely bring GSH level back to that equivalent to negative control. ${ }^{208}$ Although much less studied, antioxidant peptides such as those from microalgae protein hydrolysate have been found to attenuate the effect of oxidative stress on GSH levels. ${ }^{240}$ 
One of the protective effects of increase in GSH levels amongst HepG2 cells treated with P1, P2, P6, and P7 might have been due to its radical scavenging activities. First, results from GSH correlated with $\mathrm{DCFH}_{2}-\mathrm{DA}$ data, with the dose-dependent P2 and P6 having highest activity both in increasing GSH and decreasing ROS, and the non-dose-dependent P1 and P7 having relatively lower sufficient activities to bring GSH and ROS levels back to the norm (negative control). GSH could have protected antioxidant enzymes from free radical damage as explained previously. GSH results partially correlated with GPx data, with P2 and P6 at $100 \mu \mathrm{M}$ having highest activity and brining GSH and GPx levels passed the norm (NEG). In addition, P1, P7 brought both GSH and GPx levels back to those equivalent to NEG. The protective effect of GSH on CAT is not likely significant due to the previously explained resistance of CAT to AAPHinduced peroxyl radical, which was also indicated by the increase in CAT by AAPH treatment alone.

Besides radical scavenging activities, P1, P2, P6, and P7 could regulate GSH level by providing amino acids for synthesis of GSH, as well as regulating levels of $\gamma$-glutamylcysteine synthetase (GCS), the rate limiting enzyme for GSH synthesis. Under oxidative stress, the oxidation of cysteine to cystine and glycine to ammonia, carbon dioxide, and water makes these two amino acids the limiting factor for GSH synthesis. ${ }^{238}$ High levels of extracellular glutamate can reduce GSH levels by competitively inhibiting cysteine uptake. ${ }^{241}$ However, high intracellular glutamate concentration can enhance GSH synthesis by preventing GSH feedback inhibition of GCS. ${ }^{86}$ Since treatment with AAPH can led to decomposition of glycine, P1, P2, and P6 might have acted as a source of glycine for enhancement of GSH synthesis. On the other hand, studies have shown that certain food-derived compounds such as flavonoids can regulate 
the level of $\gamma$-glutamylcysteine synthetase, which is an essential catalyst for GSH synthesis. For example, flavonoids quercetin, kaempferol, and apigenin have been shown to increase GSH level by enhancing the transactivation of the promoter for the GCS heavy subunit with catalytic activity. ${ }^{242}$ Urata et al. demonstrated that treatment with melatonin elevates GSH level in human vascular endothelial cells through enhancing the binding of activator protein -1 to DNA binding sites of GCS promoter, thereby increasing GCS mRNA expression. ${ }^{243}$ 


\section{Conclusion}

From the results of this study, it can be concluded that P1, P2, P6, and P7 have cytoprotective activities against AAPH-induced oxidative stress in hepatic HepG2 cells. The protective mechanism of these peptides might involve direct radical scavenging activity, as indicated by ORAC activity and the reduction of cellular ROS. In addition, these peptides might up-regulate GPx, SOD, and CAT, as indicated by increase in the activities of these antioxidant enzymes. As well, an increase in GSH was observed after treatment with P1, P2, P6, and P7, which could have been due to their radical scavenging activities, and possibly through affecting GSH synthesis. In addition, amino acids such as histidine and glutamate might have protected cellular components through metal chelation. Interestingly, when HepG2 cells were treated with $20 \mathrm{mM} \mathrm{AAPH}$ overnight, CAT levels increased as part of the cellular response against increase in oxidative stress. The overall cytoprotective activity of these peptides, as shown by increase in cell survival under oxidative stress, with activities from high to low of P2 > P6 > P7 > P1, correlated with the hydrophobicity of the peptides. This is probably due to the ease of hydrophobic peptides to interact with cellular membrane to promote cell uptake, as well as the high radical scavenging activities of hydrophobic amino acids such as leucine, glycine, and tyrosine. The current study indicated that P1, P2, P6, and P7 exert cytoprotective activity against oxidative stress through radical scavenging as well as antioxidant enzyme regulating activities. Hence, the peptides $\mathrm{P} 1, \mathrm{P} 2, \mathrm{P} 6$, and $\mathrm{P} 7$ has the potential to be used in food products to prevent oxidative rancidity as well as pharmaceutical agents to protect cells against elevated oxidative stress and improve oxidative status. 


\section{Future Work}

The current study found that peptides derived from oat protein hydrolysate P1, P2, P6, and P7 possess cytoprotective activities against oxidative stress on HeG2 cells possibly through radicals scavenging activity, regulation of antioxidant enzymes GPx, SOD, and CAT and the endogenous glutathione. However, bioavailability as well as their exact mechanism of action remains to be elucidated. Therefore, future studies can explore how P1, P2, P6, and P7 regulate levels of GPx, SOD, and CAT by evaluating their potential effects on transcription, translation, post-translational modification, and degradation of these enzymes. In addition, the bioavailability of these peptides can be studied using Caco-2 cell model system. As well, the effects of P1, P2, P6, and P7 on oxidative status of healthy animals as well as those with conditions associated with oxidative stress can be analyzed. In addition, potential synergistic effects of these peptides can be studied. 


\section{References}

1. Slavin, J. Whole grains and human health. Nutr. Res. Rev. 17, 99-110 (2004).

2. Anderson, J. W. Whole grains protect against atherosclerotic cardiovascular disease. Proc. Nutr. Soc. 62, 135-142 (2003).

3. Pereira, M. A. et al. Effect of whole grains on insulin sensitivity in overweight hyperinsulinemic adults. Am. J. Clin. Nutr. 75, 848-855 (2002).

4. Hansson, L. E. et al. Diet and risk of gastric cancer. A population-based case-control study in Sweden. Int. J. Cancer 55, 181-189 (1993).

5. Murtaugh, M. A., Jacobs, D. R., Jacob, B., Steffen, L. M. \& Marquart, L. Epidemiological support for the protection of whole grains against diabetes. Proc. Nutr. Soc. 62, 143-149 (2003).

6. Chandalia, M. et al. Beneficial effects of high dietary fiber intake in patients with type 2 diabetes mellitus. N. Engl. J. Med. 342, (2000).

7. Tuyns, A. J., Kaaks, R., Haelterman, M. \& Riboli, E. Diet and gastric cancer. A case-control study in Belgium. Int. J. Cancer 51, 1-6 (1992).

8. Tuyns, A. J., Kaaks, R. \& Haelterman, M. Colorectal cancer and the consumption of foods: a case-control study in Belgium. Nutr. Cancer 11, 189-204 (1988).

9. Slattery, M. L. et al. Plant foods and colon cancer: an assessment of specific foods and their related nutrients (United States). Cancer Causes Control 8, 575-590 (1997).

10. Wattenberg, L. W. Chemoprevention of Cancer. Cancer Res. 45, 1-8 (1985).

11. Navarro, F. et al. Vitamin E and selenium deficiency induces expression of the ubiquinone-dependent antioxidant system at the plasma membrane. FASEB J. 12, 16651673 (1998).

12. Graf, E. \& Eaton, J. W. Suppression of colonic cancer by dietary phytic acid. Nutr. Cancer 19, 11-19 (1993).

13. Kriszbacher, I., Koppán, M. \& Bódis, J. Inflammation, atherosclerosis, and coronary artery disease. N. Engl. J. Med. 353, 429-430 (2005).

14. Uttara, B., Singh, A. V, Zamboni, P. \& Mahajan, R. T. Oxidative stress and neurodegenerative diseases: a review of upstream and downstream antioxidant therapeutic options. Curr. Neuropharmacol. 7, 65-74 (2009). 
15. Ahmed, S. S., Napoli, K. L. \& Strobel, H. W. Oxygen radical formation during cytochrome P450-catalyzed cyclosporine metabolism in rat and human liver microsomes at varying hydrogen ion concentrations. Mol. Cell. Biochem. 151, 131-140 (1995).

16. Rosen, G. M., Pou, S., Ramos, C. L., Cohen, M. S. \& Britigan, B. E. Free radicals and phagocytic cells. FASEB J. 9, 200-209 (1995).

17. Sanz, A. \& Stefanatos, R. K. A. The mitochondrial free radical theory of aging: a critical view. Curr. Aging Sci. 1, 10-21 (2008).

18. Turrens, J. F. Mitochondrial formation of reactive oxygen species. J. Physiol. 552, 335344 (2003).

19. Cadenas, E. \& Davies, K. J. Mitochondrial free radical generation, oxidative stress, and aging. Free Radic. Biol. Med. 29, 222-230 (2000).

20. Apel, K. \& Hirt, H. Reactive oxygen species: metabolism, oxidative stress, and signal transduction. Annu. Rev. Plant Biol. 55, 373-399 (2004).

21. Sharma, P., Jha, A. B., Dubey, R. S. \& Pessarakli, M. Reactive oxygen species, oxidative damage, and antioxidative defense mechanism in plants under stressful conditions. J. Bot. 2012, 1-26 (2012).

22. Dalle Carbonare, M. \& Pathak, M. A. Skin photosensitizing agents and the role of reactive oxygen species in photoaging. J. Photochem. Photobiol. B Biol. 14, 105-124 (1992).

23. Fridovich, I. Superoxide anion radical (O2-.), superoxide dismutases, and related matters. J. Biol. Chem. 272, 18515-18517 (1997).

24. Pryor, W. A. Oxy-radicals and related species: their formation, lifetimes, and reactions. Annu. Rev. Physiol. 48, 657-667 (1986).

25. Neyens, E. \& Baeyens, J. A review of classic Fenton's peroxidation as an advanced oxidation technique. J. Hazard Mater. 98, 33-50 (2003).

26. Niki, E., Yoshida, Y., Saito, Y. \& Noguchi, N. Lipid peroxidation: Mechanisms, inhibition, and biological effects. Biochem. Biophys. Res. Commun. 338, 668-676 (2005).

27. Esterbauer, H., Muskiet, F. \& Horrobin, D. F. Cytotoxicity and genotoxicity of lipidoxidation products. in Am. J. Clin. Nutr. 57, (1993).

28. Lim, C. H., Dedon, P. C. \& Deen, W. M. Kinetic analysis of intracellular concentrations of reactive nitrogen species. Chem. Res. Toxicol. 21, 2134-2147 (2008). 
29. Beckman, J. S. \& Koppenol, W. H. Nitric oxide, superoxide, and peroxynitrite: the good, the bad, and ugly. Am. J. Physiol. 271, 1424-1437 (1996).

30. Knowles, R. G. \& Moncada, S. Nitric oxide synthases in mammals. Biochem. J. 298, 249258 (1994).

31. Murad, F. Signal Transduction Using Nitric Oxide and Cyclic Guanosine Monophosphate. JAMA: The Journal of the American Medical Association 276, 1189-1192 (1996).

32. Tousoulis, D., Kampoli, A.-M., Tentolouris, C., Papageorgiou, N. \& Stefanadis, C. The role of nitric oxide on endothelial function. Curr. Vasc. Pharmacol. 10, 4-18 (2012).

33. Brown, G. C. Nitric oxide and mitochondrial respiration. Biochim. Biophys. Acta 1411, 351-369 (1999).

34. Brüne, B. Nitric oxide: NO apoptosis or turning it ON? Cell Death Differ. 10, 864-869 (2003).

35. Assreuy, J., Cunha, F. Q., Liew, F. Y. \& Moncada, S. Feedback inhibition of nitric oxide synthase activity by nitric oxide. Br. J. Pharmacol. 108, 833-837 (1993).

36. Dröge, W. Free radicals in the physiological control of cell function. Physiol. Rev. 82, 4795 (2002).

37. Burke, T. M. \& Wolin, M. S. Hydrogen peroxide elicits pulmonary arterial relaxation and guanylate cyclase activation. Am. J. Physiol. 252, H721-H732 (1987).

38. Mittal, C. K. \& Murad, F. Activation of guanylate cyclase by superoxide dismutase and hydroxyl radical: a physiological regulator of guanosine 3',5'-monophosphate formation. Proc. Natl. Acad. Sci. U. S. A. 74, 4360-4364 (1977).

39. López-Barneo, J. et al. $\mathrm{K}+$ and $\mathrm{Ca} 2+$ channel activity and cytosolic [Ca2+] in oxygensensing tissues. in Respiration Physiology 115, 215-227 (1999).

40. Peers, C., Wyatt, C. N. \& Evans, A. M. Mechanisms for acute oxygen sensing in the carotid body. Respir. Physiol. Neurobiol. 174, 292-298 (2010).

41. Cumming, R. C. et al. Protein disulfide bond formation in the cytoplasm during oxidative stress. J. Biol. Chem. 279, 21749-21758 (2004).

42. Barber, S. C., Mead, R. J. \& Shaw, P. J. Oxidative stress in ALS: A mechanism of neurodegeneration and a therapeutic target. BBA-Mol. Basis. Dis. 1762, 1051-1067 (2006). 
43. Dias, V., Junn, E. \& Mouradian, M. M. The role of oxidative stress in parkinson's disease. J. Parkinsons Dis. 3, 461-491 (2013).

44. Lyras, L., Cairns, N. J., Jenner, A., Jenner, P. \& Halliwell, B. An assessment of oxidative damage to proteins, lipids, and DNA in brain from patients with Alzheimer's disease. J. Neurochem. 68, 2061-2069 (1997).

45. Marcus, D. L. et al. Increased peroxidation and reduced antioxidant enzyme activity in Alzheimer's disease. Exp. Neurol. 150, 40-44 (1998).

46. Perry, T. L., Yong, V. W., Bergeron, C., Hansen, S. \& Jones, K. Amino acids, glutathione, and glutathione transferase activity in the brains of patients with Alzheimer's disease. Ann. Neurol. 21, 331-336 (1987).

47. Mutisya, E. M., Bowling, A. C. \& Beal, M. F. Cortical cytochrome oxidase activity is reduced in Alzheimer's disease. J. Neurochem. 63, 2179-2184 (1994).

48. Xu, B. \& Chang, S. K. C. Comparative study on antiproliferation properties and cellular antioxidant activities of commonly consumed food legumes against nine human cancer cell lines. Food Chem. 134, 1287-1296 (2012).

49. Laursen, J. B. et al. Role of superoxide in angiotensin II-induced but not catecholamineinduced hypertension. Circulation 95, 588-593 (1997).

50. Dzau, V. J. Theodore Cooper Lecture: Tissue angiotensin and pathobiology of vascular disease: a unifying hypothesis. Hypertension 37, 1047-1052 (2001).

51. Zablocki, D. \& Sadoshima, J. Angiotensin II and oxidative stress in the failing heart. Antioxid. Redox Signal. 19, 1095-1109 (2013).

52. Yang, R.-L., Shi, Y.-H., Hao, G., Li, W. \& Le, G.-W. Increasing Oxidative Stress with Progressive Hyperlipidemia in Human: Relation between Malondialdehyde and Atherogenic Index. J. Clin. Biochem. Nutr. 43, 154-158 (2008).

53. Dávalos, A., Miguel, M., Bartolomé, B. \& López-Fandiño, R. Antioxidant activity of peptides derived from egg white proteins by enzymatic hydrolysis. J. Food Prot. 67, 1939-1944 (2004).

54. Csont, T. et al. Hypercholesterolemia increases myocardial oxidative and nitrosative stress thereby leading to cardiac dysfunction in apoB-100 transgenic mice. Cardiovasc. Res. 76, 100-109 (2007). 
55. Rosenbaugh, E. G., Savalia, K. K., Manickam, D. S. \& Zimmerman, M. C. Antioxidant-based therapies for angiotensin II-associated cardiovascular diseases. Am. J. Physiol. Regul. Integr. Comp. Physiol. 304, R917-R928 (2013).

56. Baykal, Y. et al. Effects of antihypertensive agents, alpha receptor blockers, beta blockers, angiotensin-converting enzyme inhibitors, angiotensin receptor blockers and calcium channel blockers, on oxidative stress. J. hypertens. 21, (2003).

57. Prasad, K., Mantha, S. V., Kalra, J. \& Lee, P. Hypercholesterolemia-induced oxidative stress in heart and its prevention by vitamin E. Int. J. Angiol. 6, 13-17 (1997).

58. Kaneto, $\mathrm{H}$. et al. Activation of the hexosamine pathway leads to deterioration of pancreatic $\beta$-cell function through the induction of oxidative stress. J. Biol. Chem. 276, 31099-31104 (2001).

59. Nakatani, Y. et al. Modulation of the JNK pathway in liver affects insulin resistance status. J. Biol. Chem. 279, 45803-45809 (2004).

60. Waris, G. \& Ahsan, H. Reactive oxygen species: role in the development of cancer and various chronic conditions. J. Carcinog. 5, 14 (2006).

61. Shishiba, Y., Imai, Y., Odajima, R., Ozawa, Y. \& Shimizu, T. Immunoglobulin G of patients with circumscribed pretibial myxedema of Graves' disease stimulates proteoglycan synthesis in human skin fibroblasts in culture. Acta Endocrinol. (Copenh). 127, 44-51 (1992).

62. Moody, C. S. \& Hassan, H. M. Mutagenicity of oxygen free radicals. Proc. Natl. Acad. Sci. U. S. A. 79, 2855-2859 (1982).

63. Cunningham, M. L. \& Lokesh, B. R. Superoxide anion generated by potassium superoxide is cytotoxic and mutagenic to chinese hamster ovary cells. Mutat. Res. 121, 299-304 (1983).

64. Ito, A., Watanabe, H., Naito, M. \& Naito, Y. Induction of duodenal tumors in mice by oral administration of hydrogen peroxide. Gann 72, 174-175 (1981).

65. Bartsch, H. \& Nair, J. Oxidative stress and lipid peroxidation-derived DNA-lesions in inflammation driven carcinogenesis. Cancer Detect. Prev. 28, 385-391 (2004).

66. Davies, K. J. Intracellular proteolytic systems may function as secondary antioxidant defenses: an hypothesis. J. Free Radic. Biol. Med. 2, 155-173 (1986). 
67. Vernet, P. et al. Selenium-independent epididymis-restricted glutathione peroxidase 5 protein (GPX5) can back up failing Se-dependent GPXs in mice subjected to selenium deficiency. Mol. Reprod. Dev. 54, 362-370 (1999).

68. Ursini, F., Maiorino, M. \& Gregolin, C. The selenoenzyme phospholipid hydroperoxide glutathione peroxidase. Biochim. Biophys. Acta - Gen. Subj. 839, 62-70 (1985).

69. Brown, K. M. \& Arthur, J. R. Selenium, selenoproteins and human health: a review. Public Health Nutr. 4, 593-599 (2001).

70. Wingler, K. \& Brigelius-Flohé, R. Gastrointestinal glutathione peroxidase. Biofactors 10, 245-249 (1999).

71. Simmons, T. W., Jamall, I. S. \& Lockshin, R. A. Selenium-independent glutathione peroxidase activity associated with glutathione S-transferase from the housefly, Musca domestica. Comp. Biochem. Physiol. B. 94, 323-327 (1989).

72. James Kang, Y., Chen, Y. \& Epstein, P. N. Suppression of doxorubicin cardiotoxicity by overexpression of catalase in the heart of transgenic mice. J. Biol. Chem. 271, 1261012616 (1996).

73. Barrett, J. \& Beis, I. Catalase in free-living and parasitic platyhelminths. Experientia 38, 536 (1982).

74. Izawa, S., Inoue, Y. \& Kimura, A. Importance of catalase in the adaptive response to hydrogen peroxide: analysis of acatalasaemic Saccharomyces cerevisiae. Biochem. J. 320, 61-67 (1996).

75. Góth, L., Rass, P. \& Páy, A. Catalase enzyme mutations and their association with diseases. Molecular Diagnosis 8, 141-149 (2004).

76. Bagnyukova, T. V., Storey, K. B. \& Lushchak, V. I. Adaptive response of antioxidant enzymes to catalase inhibition by aminotriazole in goldfish liver and kidney. Comp. Biochem. Physiol. - B Biochem. Mol. Biol. 142, 335-341 (2005).

77. Abreu, I. A. \& Cabelli, D. E. Superoxide dismutases-a review of the metal-associated mechanistic variations. BBA-Proteins Proteom. 1804, 263-274 (2010).

78. Youn, H. D., Kim, E. J., Roe, J. H., Hah, Y. C. \& Kang, S. O. A novel nickel-containing superoxide dismutase from Streptomyces spp. Biochem. J. 318 ( Pt 3, 889-896 (1996).

79. Priya, B. et al. Comparative analysis of cyanobacterial superoxide dismutases to discriminate canonical forms. BMC Genomics 8, 435 (2007). 
80. Crapo, J. D., Oury, T., Rabouille, C., Slot, J. W. \& Chang, L. Y. Copper,zinc superoxide dismutase is primarily a cytosolic protein in human cells. Proc. Natl. Acad. Sci. U. S. A. 89, 10405-10409 (1992).

81. Goldsteins, G. et al. Deleterious role of superoxide dismutase in the mitochondrial intermembrane space. J. Biol. Chem. 283, 8446-8452 (2008).

82. Fattman, C. L., Schaefer, L. M. \& Oury, T. D. Extracellular superoxide dismutase in biology and medicine. Free Radic. Bio. Med. 35, 236-256 (2003).

83. Keithley, E. M. et al. Cu/Zn superoxide dismutase and age-related hearing loss. Hear. Res. 209, 76-85 (2005).

84. Watanabe, K. et al. Superoxide Dismutase 1 Loss Disturbs Intracellular Redox Signaling, Resulting in Global Age-Related Pathological Changes. Biomed Res. Int. 2014, 140165 (2014).

85. Hamilton, R. T. \& Van Remmen, M. E. W. and H. Mouse Models of Oxidative Stress Indicate a Role for Modulating Healthy Aging. J. Clin. Exp. Pathol. 4, 1-14 (2012).

86. Griffith, O. W. Biologic and pharmacologic regulation of mammalian glutathione synthesis. in Free Radical Biology and Medicine 27, 922-935 (1999).

87. Wallig, M. A. Xenobiotic Metabolism, Oxidant Stress and Chronic Pancreatitis. Digestion 59, 13-24 (1998).

88. Cotgreave, I. A. \& Gerdes, R. G. Recent trends in glutathione biochemistry--glutathioneprotein interactions: a molecular link between oxidative stress and cell proliferation? Biochem. Biophys. Res. Commun. 242, 1-9 (1998).

89. Ernster, L. \& Forsmark-Andrée, P. Ubiquinol: an endogenous antioxidant in aerobic organisms. Clin. Investig. 71, S60-S65 (1993).

90. Becker, B. F. Towards the physiological function of uric acid. Free Radic. Bio. Med. 14, 615-631 (1993).

91. Niki, E., Noguchi, N., Tsuchihashi, H. \& Gotoh, N. Interaction among vitamin C, vitamin E, and beta-carotene. Am. J. Clin. Nutr. 62, 1322S-1326S (1995).

92. Regoli, F. \& Winston, G. W. Quantification of total oxidant scavenging capacity of antioxidants for peroxynitrite, peroxyl radicals, and hydroxyl radicals. Toxicol. Appl. Pharmacol. 156, 96-105 (1999). 
93. Bodannes, R. S. \& Chan, P. C. Ascorbic acid as a scavenger of singlet oxygen. FEBS Lett. 105, 195-196 (1979).

94. Jackson, T. S., Xu, A., Vita, J. A. \& Keaney, J. F. Ascorbate prevents the interaction of superoxide and nitric oxide only at very high physiological concentrations. Circ. Res. 83, 916-922 (1998).

95. Stanner, S. A., Hughes, J., Kelly, C. N. M. \& Buttriss, J. A review of the epidemiological evidence for the 'antioxidant hypothesis'. Public Health Nutr. 7, 407-422 (2004).

96. Toyokuni, S. et al. Protective effect of colored rice over white rice on Fenton reactionbased renal lipid peroxidation in rats. Free Radic. Res. 36, 583-592 (2002).

97. Jang, Y., Lee, J. H., Kim, O. Y., Park, H. Y. \& Lee, S. Y. Consumption of whole grain and legume powder reduces insulin demand, lipid peroxidation, and plasma homocysteine concentrations in patients with coronary artery disease: randomized controlled clinical trial. Arteriscler. Thromb. Vasc. Biol. 21, (2001).

98. Liu, S. et al. Antioxidant effects of oats avenanthramides on human serum. Agric. Sci. China 10, 1301-1305 (2011).

99. Handelman, G. J. et al. Antioxidant capacity of oat (Avena sativa L.) extracts. 1. Inhibition of low-density lipoprotein oxidation and oxygen radical absorbance capacity. J. Agric. Food Chem. 47, 4888-4893 (1999).

100. Lásztity, R. Oat grain - a wonderful reservoir of natural nutrients and biologically active substances. Food Rev. Inter. 14, 99-119 (1998).

101. Glore, S. R., Van Treeck, D., Knehans, A. W. \& Guild, M. Soluble fiber and serum lipids: a literature review. J. Am. Diet. Assoc. 94, 425-436 (1994).

102. Van Horn, L. et al. Serum lipid response to a fat-modified, oatmeal-enhanced diet. Prev. Med. 17, (1988).

103. Banaś, A. et al. Lipids in grain tissues of oat (Avena sativa): Differences in content, time of deposition, and fatty acid composition. J. Exp. Bot. 58, 2463-2470 (2007).

104. Rytter, E. et al. Changes in plasma insulin, enterostatin, and lipoprotein levels during an energy-restricted dietary regimen including a new oat-based liquid food. Ann. Nutr. Metab. 40, (1996).

105. Martínez-Tomé, M. et al. Evaluation of antioxidant capacity of cereal brans. J. Agric. Food Chem. 52, 4690-4699 (2004). 
106. Braaten, J. T. et al. High beta-glucan oat bran and oat gum reduce postprandial blood glucose and insulin in subjects with and without type 2 diabetes. Diabet. Med. 11, 312318 (1994).

107. Anderson, J. W., Story, L., Sieling, B., Chen, W. J. \& Petro, M. S. Hypocholesterolemic effects of oat-bran or bean intake for hypercholesterolemic men. Am. J. Clin. Nutr. 40, 1146-1155 (1984).

108. Anderson, J. W., Deakins, D. A., Floore, T. L., Smith, B. M. \& Whitis, S. E. Dietary fiber and coronary heart disease. Crit. Rev. Food Sci. Nutr. 29, 95-147 (1990).

109. Anderson, J. W. et al. Lipid responses of hypercholesterolemic men to oat-bran and wheat-bran intake. Am. J. Clin. Nutr. 54, 678-683 (1991).

110. Anderson, J. W. et al. Oat-bran cereal lowers serum total and LDL cholesterol in hypercholesterolemic men. Am. J. Clin. Nutr. 52, 495-499 (1990).

111. Tappy, L., Gügolz, E. \& Würsch, P. Effects of breakfast cereals containing various amounts of $\beta$-glucan fibers on plasma glucose and insulin responses in NIDDM subjects. Diabetes Care 19, 831-834 (1996).

112. Leadbetter, J., Ball, M. J. \& Mann, J. I. Effects of increasing quantities of oat bran in hypercholesterolemic people. Am. J. Clin. Nutr. 54, 841-845 (1991).

113. Braaten, J. T. et al. Oat gum lowers glucose and insulin after an oral glucose load. Am. J. Clin. Nutr. 53, 1425-1430 (1991).

114. Braaten, J. T. et al. Oat beta-glucan reduces blood cholesterol concentration in hypercholesterolemic subjects. Eur. J. Clin. Nutr. 48, (1994).

115. Wood, P. J., Weisz, J., Fedec, P. \& Burrows, V. D. Large-Scale Preparation and Properties of Oat Fractions Enriched in (1-3)(1-4)-Beta-D- Glucan. Cereal Chem. 66, 97-103 (1989).

116. Furlan, G. et al. Oat protection against the oxidative stress induced in rats by exercise. J. Food Biochem. 34, 611-624 (2010).

117. Kofuji, K. et al. Antioxidant Activity of $\beta$-Glucan. ISRN Pharmaceutics 2012, 1-5 (2012).

118. PETERSON, D. M. \& QURESHI, A. A. Genotype and environment effects on tocols of Barley and oats. Cereal Chem. 70, 157-162 (1993).

119. Horwitt, M. K. The promotion of vitamin E. J. Nutr. 116, 1371-1377 (1986). 
120. Sosulski, F., Krygier, K. \& Hogge, L. Free, Esterified, and insoluble-Bound Phenolic Acids. 3. Composition of Phenolic Acids in Cereal and Potato Flours. J. Agric. Food Chem. 30, 337340 (1982).

121. Chen, C.-Y. O., Milbury, P. E., Collins, F. W. \& Blumberg, J. B. Avenanthramides are bioavailable and have antioxidant activity in humans after acute consumption of an enriched mixture from oats. J. Nutr. 137, 1375-1382 (2007).

122. Zhu, K., Zhou, H. \& Qian, H. Antioxidant and free radical-scavenging activities of wheat germ protein hydrolysates (WGPH) prepared with alcalase. Process Biochem. 41, 12961302 (2006).

123. Nam, S. H., Choi, S. P., Kang, M. Y., Kozukue, N. \& Friedman, M. Antioxidative, antimutagenic, and anticarcinogenic activities of rice bran extracts in chemical and cell assays. J. Agric. Food Chem. 53, 816-822 (2005).

124. Bamdad, F. \& Chen, L. Antioxidant capacities of fractionated barley hordein hydrolysates in relation to peptide structures. Mol. Nutr. Food Res. 57, 493-503 (2013).

125. Fischer, M. A. \& Avorn, J. Economic implications of evidence-based prescribing for hypertension: can better care cost less? JAMA 291, 1850-1856 (2004).

126. Wu, J. \& Ding, X. Hypotensive and physiological effect of angiotensin converting enzyme inhibitory peptides derived from soy protein on spontaneously hypertensive rats. J. Agric. Food Chem. 49, 501-506 (2001).

127. Park, S. Y., Lee, J.-S., Baek, H.-H. \& Lee, H. G. Purification and characterization of antioxidant peptide from soy protein hydrolysate. J. Food Biochem. 34, 120-132 (2010).

128. Jia, J. et al. The use of ultrasound for enzymatic preparation of ACE-inhibitory peptides from wheat germ protein. Food Chem. 119, 336-342 (2010).

129. Cho, S.-J., Juillerat, M. A. \& Lee, C.-H. Cholesterol lowering mechanism of soybean protein hydrolysate. J. Agric. Food Chem. 55, 10599-10604 (2007).

130. Cheung, I. W. Y., Nakayama, S., Hsu, M. N. K., Samaranayaka, A. G. P. \& Li-Chan, E. C. Y. Angiotensim-I converting enzyme inhibitory activity of hydrolysates from oat (Avena sativa) proteins by in silico and in vitro analyses. J. Agric. Food Chem. 57, 9234-9242 (2009).

131. Kong, B. \& Xiong, Y. L. Antioxidant activity of zein hydrolysates in a liposome system and the possible mode of action. J. Agric. Food Chem. 54, 6059-6068 (2006). 
132. Mochida, T., Hira, T. \& Hara, H. The corn protein, zein hydrolysate, administered into the ileum attenuates hyperglycemia via its dual action on glucagon-like peptide-1 secretion and dipeptidyl peptidase-IV activity in rats. Endocrinology 151, 3095-3104 (2010).

133. Kannan, A., Hettiarachchy, N., Johnson, M. G. \& Nannapaneni, R. Human colon and liver cancer cell proliferation inhibition by peptide hydrolysates derived from heat-stabilized defatted rice bran. J. Agric. Food Chem. 56, 11643-11647 (2008).

134. Nakurte, I. et al. Detection of the lunasin peptide in oats (Avena sativa L). J. Cereal Sci. 57, 319-324 (2013).

135. Lumen, B. O. Lunasin: A Cancer-Preventive Soy Peptide. Nutr. Rev. 63, 16-21 (2005).

136. Cao, G., Alessio, H. M. \& Cutler, R. G. Oxygen-radical absorbance capacity assay for antioxidants. Free Radic. Biol. Med. 14, 303-311 (1993).

137. Ghiselli, A., Serafini, M., Maiani, G., Azzini, E. \& Ferro-Luzzi, A. A fluorescence-based method for measuring total plasma antioxidant capability. Free Radic. Biol. Med. 18, 2936 (1995).

138. Benzie, I. F. \& Strain, J. J. The ferric reducing ability of plasma (FRAP) as a measure of 'antioxidant power': the FRAP assay. Anal. Biochem. 239, 70-76 (1996).

139. Liu, R. H. \& Finley, J. Potential cell culture models for antioxidant research. J. Agric. Food Chem. 53, 4311-4314 (2005).

140. López-Alarcón, C. \& Denicola, A. Evaluating the antioxidant capacity of natural products: A review on chemical and cellular-based assays. Anal. Chim. Acta. 763, 1-10 (2013).

141. Wolfe, K. L. \& Rui, H. L. Cellular antioxidant activity (CAA) assay for assessing antioxidants, foods, and dietary supplements. J. Agric. Food Chem. 55, 8896-8907 (2007).

142. Foldbjerg, R., Dang, D. A. \& Autrup, H. Cytotoxicity and genotoxicity of silver nanoparticles in the human lung cancer cell line, A549. Arch. Toxicol. 85, 743-750 (2011).

143. Maduh, E. U., Borowitz, J. L. \& Isom, G. E. Cyanide-induced alteration of the adenylate energy pool in a rat neurosecretory cell line. J. Appl. Toxicol. 11, 97-101 (1991).

144. Manna, C. et al. The protective effect of the olive oil polyphenol (3,4-dihydroxyphenyl)ethanol counteracts reactive oxygen metabolite-induced cytotoxicity in Caco-2 cells. J. Nutr. 127, 286-292 (1997).

145. Faria, A. et al. Flavonoid transport across RBE4 cells: A blood-brain barrier model. Cell. Mol. Biol. Lett. 15, 234-241 (2010). 
146. Forbes, B. \& Ehrhardt, C. Human respiratory epithelial cell culture for drug delivery applications. in European Journal of Pharmaceutics and Biopharmaceutics 60, 193-205 (2005).

147. Bailey, C. A., Bryla, P. \& Malick, A. W. The use of the intestinal epithelial cell culture model, Caco-2, in pharmaceutical development. Adv. Drug Deliv. Rev. 22, 85-103 (1996).

148. Bort, R., Ponsoda, X., Jover, R., Gómez-Lechón, M. J. \& Castell, J. V. Diclofenac toxicity to hepatocytes: a role for drug metabolism in cell toxicity. J. Pharmacol. Exp. Ther. 288, 6572 (1999).

149. Wardman, P. Fluorescent and luminescent probes for measurement of oxidative and nitrosative species in cells and tissues: Progress, pitfalls, and prospects. Free Radic. Bio. Med. 43, 995-1022 (2007).

150. Ahn, C. B. \& Je, J. Y. Antioxidant activity of traditional korean fermented soybean (damdusi) extract on free radical-mediated oxidative systems. J. Food Biochem. 35, 1242-1256 (2011).

151. Roy, M. K., Juneja, L. R., Isobe, S. \& Tsushida, T. Steam processed broccoli (Brassica oleracea) has higher antioxidant activity in chemical and cellular assay systems. Food Chem. 114, 263-269 (2009).

152. Sessa, M., Tsao, R., Liu, R., Ferrari, G. \& Donsì, F. Evaluation of the stability and antioxidant activity of nanoencapsulated resveratrol during in vitro digestion. J. Agric. Food Chem. 59, 12352-12360 (2011).

153. Ziberna, L. et al. Transport and bioactivity of cyanidin 3-glucoside into the vascular endothelium. Free Radic. Biol. Med. 52, 1750-1759 (2012).

154. Valavanidis, A., Vlachogianni, T. \& Fiotakis, C. 8-hydroxy-2' -deoxyguanosine (8-OHdG): A critical biomarker of oxidative stress and carcinogenesis. J. Environ. Sci. Health. C. Environ. Carcinog. Ecotoxicol. Rev. 27, 120-139 (2009).

155. Nielsen, F., Mikkelsen, B. B., Nielsen, J. B., Andersen, H. R. \& Grandjean, P. Plasma malondialdehyde as biomarker for oxidative stress: Reference interval and effects of lifestyle factors. Clin. Chem. 43, 1209-1214 (1997).

156. Steffen, Y., Gruber, C., Schewe, T. \& Sies, H. Mono-O-methylated flavanols and other flavonoids as inhibitors of endothelial NADPH oxidase. Arch. Biochem. Biophys. 469, 209219 (2008).

157. González-Reyes, S., Guzmán-Beltrán, S., Medina-Campos, O. N. \& Pedraza-Chaverri, J. Curcumin pretreatment induces Nrf2 and an antioxidant response and prevents hemin- 
induced toxicity in primary cultures of cerebellar granule neurons of rats. Oxid. Med. Cell. Longev. (2013).

158. Eggler, A. L., Gay, K. A. \& Mesecar, A. D. Molecular mechanisms of natural products in chemoprevention: Induction of cytoprotective enzymes by Nrf2. Mol. Nutr. Food Res. 52, (2008).

159. Marina, R., Gonzï̈ ¿1/2lez, P., Ferreras, M., Costilla, S. \& Barrio, J. Hepatic Nrf2 expression is altered by quercetin supplementation in X-irradiated rats. Mol. Med. Rep. (2014).

160. Aden, D. P., Fogel, A., Plotkin, S., Damjanov, I. \& Knowles, B. B. Controlled synthesis of HBsAg in a differentiated human liver carcinoma-derived cell line. Nature 282, 615-616 (1979).

161. Knowles, B., Howe, C. \& Aden, D. Human hepatocellular carcinoma cell lines secrete the major plasma proteins and hepatitis B surface antigen. Science 209, 497-499 (1980).

162. Knasmüller, S. et al. Use of metabolically competent human hepatoma cells for the detection of mutagens and antimutagens. Mut. Res-Fund Mol. Mech. Mut. 402, 185-202 (1998).

163. Lee, Y.-Y. et al. Activities of antioxidant and redox enzymes in human normal hepatic and hepatoma cell lines. Mol. Cells 14, 305-311 (2002).

164. Ghattas, M. H., Chuang, L. T., Kappas, A. \& Abraham, N. G. Protective effect of HO-1 against oxidative stress in human hepatoma cell line (HepG2) is independent of telomerase enzyme activity. Int. J. Biochem. Cell Biol. 34, 1619-1628 (2002).

165. Murakami, C., Hirakawa, Y., Inui, H., Nakano, Y. \& Yoshida, H. Effect of tea catechins on cellular lipid peroxidation and cytotoxicity in HepG2 cells. Biosci. Biotechnol. Biochem. 66, 1559-1562 (2002).

166. Bak, M.-J., Jun, M. \& Jeong, W.-S. Antioxidant and Hepatoprotective Effects of the Red Ginseng Essential Oil in H2O2-Treated HepG2 Cells and CCl4-Treated Mice. International Journal of Molecular Sciences 13, 2314-2330 (2012).

167. Tsopmo, A., Jodayree, S. \& Abizaid, A. Oat bran protein hydrolysates affect oxidative stress markers in dietary induced obese mice. Free Radic. Bio. Med. 53, S88 (2012).

168. Huang, D., Ou, B., Hampsch-Woodill, M., Flanagan, J. A. \& Prior, R. L. High-throughput assay of oxygen radical absorbance capacity (ORAC) using a multichannel liquid handling system coupled with a microplate fluorescence reader in 96-well format. J. Agric. Food Chem. 50, 4437-4444 (2002). 
169. Liu, Y. \& Nair, M. G. An efficient and economical MTT assay for determining the antioxidant activity of plant natural product extracts and pure compounds. J. Nat. Prod. 73, 1193-1195 (2010).

170. Paglia, D. E. \& Valentine, W. N. Studies on the quantitative and qualitative characterization of erythrocyte glutathione peroxidase. J. Lab. Clin. Med. 70, 158-169 (1967).

171. Beers, R. F. \& Sizer, I. W. A spectrophotometric method for measuring the breakdown of hydrogen peroxide by catalase. J. Biol. Chem. 195, 133-140 (1952).

172. Spitz, D. R. \& Oberley, L. W. An assay for superoxide dismutase activity in mammalian tissue homogenates. Anal. Biochem. 179, 8-18 (1989).

173. Tietze, F. Enzymic method for quantitative determination of nanogram amounts of total and oxidized glutathione: applications to mammalian blood and other tissues. Anal. Biochem. 27, 502-522 (1969).

174. Markwell, M. A., Haas, S. M., Bieber, L. L. \& Tolbert, N. E. A modification of the Lowry procedure to simplify protein determination in membrane and lipoprotein samples. Anal. Biochem. 87, 206-210 (1978).

175. Maebuchi, M. et al. Improvement in the Intestinal Absorption of Soy Protein By Enzymatic Digestion to Oligopeptide in Healthy Adult Men. Food Sci. Tech. Res. 13, 45-53 (2007).

176. Cavazos, A. \& Gonzalez de Mejia, E. Identification of bioactive peptides from cereal storage proteins and their potential role in prevention of chronic diseases. Compr. Rev. Food Sci. Food Saf. 12, 364-380 (2013)

177. Klose C. \& Arendt, E.K. Proteins in oats; their synthesis and changes during germination: A review. Food Sci. Nutr. 52, 629-639 (2012).

178. Jodayree, S., Smith, J. C. \& Tsopmo, A. Use of carbohydrase to enhance protein extraction efficiency and antioxidative properties of oat bran protein hydrolysates. Food Res. Int. 46, 69-75 (2012).

179. Ranathunga, S., Rajapakse, N. \& Kim, S. K. Purification and characterization of antioxidative peptide derived from muscle of conger eel (Conger myriaster). Eur. Food Res. Technol. 222, 310-315 (2006).

180. Chen Jiun-rong, Suetsuna, K. \& Yamauchi, F. Isolation and characterization of immunostimulative peptides from soybean. J. Nutr. Biochem. 6, 310-313 (1995). 
181. Ngo, D.-H. \& Kim, S.-K. Marine Bioactive Peptides as Potential Antioxidants. Curr. Protein Pept. Sci. 14, 189-198 (2013).

182. Wu, H.-C., Chen, H.-M. \& Shiau, C.-Y. Free amino acids and peptides as related to antioxidant properties in protein hydrolysates of mackerel (Scomber austriasicus). Food Res. Int. 36, 949-957 (2003).

183. Udenigwe, C. C. \& Aluko, R. E. Chemometric analysis of the amino acid requirements of antioxidant food protein Hydrolysates. Int. J. Mol. Sci. 12, 3148-3161 (2011).

184. Byun, H. G., Lee, J. K., Park, H. G., Jeon, J. K. \& Kim, S. K. Antioxidant peptides isolated from the marine rotifer, Brachionus rotundiformis. Process Biochem. 44, 842-846 (2009).

185. Chen, H., Muramoto, K., Yamauchi, F., Fujimoto, K. \& Nokihara, K. Antioxidative Properties of Histidine-Containing Peptides Designed from Peptide Fragments Found in the Digests of a Soybean Protein. J. Agric. Food Chem. 46, 49-53 (1998).

186. Hernández-Ledesma, B., Dávalos, A., Bartolomé, B. \& Amigo, L. Preparation of antioxidant enzymatic hydrolysates from $\alpha$-lactalbumin and $\beta$-lactoglobulln. Identification of active peptides by HPLC-MS/MS. J. Agric. Food Chem. 53, 588-593 (2005).

187. Li, Y. W. \& Li, B. Characterization of structure-antioxidant activity relationship of peptides in free radical systems using QSAR models: Key sequence positions and their amino acid properties. J. Theor. Biol. 318, 29-43 (2013).

188. Lee, J. Y., Chun, B. H., Lee, J. H., Ahn, J. \& Chung, N. Influence of Mixed Protein Hydrolysates on the Growth and Viability of Chinese Hamster Ovary Cells. J. Korean Soc. Appl. Biol. Chem. 52, 612 (2009).

189. Kuzuya, M. et al. Antioxidants stimulate endothelial cell proliferation in culture. Artery 18, 115-124 (1991).

190. Noguchi, N. et al. 2,2'-azobis (4-methoxy-2,4-dimethylvaleronitrile), a new lipid-soluble azo initiator: Application to oxidations of lipids and low-density lipoprotein in solution and in aqueous dispersions. Free Radic. Biol. Med. 24, 259-268 (1998).

191. Gupta, A., Mandal, D., Ahmadibeni, Y., Parang, K. \& Bothun, G. Hydrophobicity drives the cellular uptake of short cationic peptide ligands. Eur. Biophys. J. 40, 727-736 (2011).

192. Ziegler, A. E. \& Seelig, J. Contributions of glycosaminoglycan binding and clustering to the biological uptake of the nonamphipathic cell-penetrating peptide WR 9. Biochemistry 50, 4650-4664 (2011). 
193. Nakase, I. et al. Cellular uptake of arginine-rich peptides: Roles for macropinocytosis and actin rearrangement. Mol. Ther. 10, 1011-1022 (2004).

194. Bougatef, A. et al. Antioxidant and free radical-scavenging activities of smooth hound (Mustelus mustelus) muscle protein hydrolysates obtained by gastrointestinal proteases. Food Chem. 114, 1198-1205 (2009).

195. Rajapakse, N., Mendis, E., Byun, H. G. \& Kim, S. K. Purification and in vitro antioxidative effects of giant squid muscle peptides on free radical-mediated oxidative systems. J. Nutr. Biochem. 16, 562-569 (2005).

196. Peña-Ramos, E. A., Xiong, Y. L. \& Arteaga, G. E. Fractionation and characterisation for antioxidant activity of hydrolysed whey protein. J. Sci. Food Agric. 84, 1908-1918 (2004).

197. Carrasco-Castilla, J. et al. Antioxidant and metal chelating activities of peptide fractions from phaseolin and bean protein hydrolysates. Food Chem. 135, 1789-1795 (2012).

198. García-Nebot, M. J., Cilla, A., Alegría, A. \& Barberá, R. Caseinophosphopeptides exert partial and site-specific cytoprotection against $\mathrm{H} 20$ 2-induced oxidative stress in Caco-2 cells. Food Chem. 129, 1495-1503 (2011).

199. Rajapakse, N., Mendis, E., Jung, W. K., Je, J. Y. \& Kim, S. K. Purification of a radical scavenging peptide from fermented mussel sauce and its antioxidant properties. Food Res. Int. 38, 175-182 (2005).

200. Fukumoto, L. R. \& Mazza, G. Assessing antioxidant and prooxidant activities of phenolic compounds. J. Agric. Food Chem. 48, 3597-3604 (2000).

201. Lambert, J. D. \& Elias, R. J. The antioxidant and pro-oxidant activities of green tea polyphenols: A role in cancer prevention. Archives of Biochemistry and Biophysics 501, 65-72 (2010).

202. Galati, G. \& O'Brien, P. J. Potential toxicity of flavonoids and other dietary phenolics: Significance for their chemopreventive and anticancer properties. Free Radical Biology and Medicine 37, 287-303 (2004).

203. Azmi, A. S., Bhat, S. H. \& Hadi, S. M. Resveratrol-Cu(II) induced DNA breakage in human peripheral lymphocytes: Implications for anticancer properties. FEBS Lett. 579, 31313135 (2005).

204. Kim, S. Y., Je, J. Y. \& Kim, S. K. Purification and characterization of antioxidant peptide from hoki (Johnius belengerii) frame protein by gastrointestinal digestion. J. Nutr. Biochem. 18, 31-38 (2007). 
205. Altman, S. A. et al. tert.-Butyl hydroperoxide-mediated DNA base damage in cultured mammalian cells. Mutat. Res. - Fundam. Mol. Mech. Mutagen. 306, 35-44 (1994).

206. He, R. R. et al. A New Oxidative Stress Model, 2,2-Azobis(2-Amidinopropane) Dihydrochloride Induces Cardiovascular Damages in Chicken Embryo. PLoS One 8, (2013).

207. Terao, K. \& Niki, E. Damage to biological tissues induced by radical initiator 2,2'-azobis(2amidinopropane) dihydrochloride and its inhibition by chain-breaking antioxidants. J. Free Radic. Biol. Med. 2, 193-201 (1986).

208. Martín, M. A. et al. Protection of human HepG2 cells against oxidative stress by cocoa phenolic extract. J. Agric. Food Chem. 56, 7765-7772 (2008).

209. Kim, G. N., Kwon, Y. I. \& Jang, H. D. Protective mechanism of quercetin and rutin on 2,2'azobis(2-amidinopropane)dihydrochloride or Cu2+-induced oxidative stress in HepG2 cells. Toxicol. Vitr. 25, 138-144 (2011).

210. Wang, H. \& Joseph, J. A. Quantifying cellular oxidative stress by dichlorofluorescein assay using microplate reader. Free Radic. Biol. Med. 27, 612-616 (1999).

211. Scott, J. A., Homcy, C. J., Khaw, B. A. \& Rabito, C. A. Quantitation of intracellular oxidation in a renal epithelial cell line. Free Radic. Biol. Med. 4, 79-83 (1988).

212. Takamatsu, S. et al. Antioxidant effect of flavonoids on DCF production in HL-60 cells. Phyther. Res. 17, 963-966 (2003).

213. Ngo, D. H., Qian, Z. J., Ryu, B., Park, J. W. \& Kim, S. K. In vitro antioxidant activity of a peptide isolated from Nile tilapia (Oreochromis niloticus) scale gelatin in free radicalmediated oxidative systems. J. Funct. Foods 2, 107-117 (2010).

214. Qian, Z. J., Jung, W. K., Byun, H. G. \& Kim, S. K. Protective effect of an antioxidative peptide purified from gastrointestinal digests of oyster, Crassostrea gigas against free radical induced DNA damage. Bioresour. Technol. 99, 3365-3371 (2008).

215. Ko, J. Y., Lee, J. H., Samarakoon, K., Kim, J. S. \& Jeon, Y. J. Purification and determination of two novel antioxidant peptides from flounder fish (Paralichthys olivaceus) using digestive proteases. Food Chem. Toxicol. 52, 113-120 (2013).

216. Ko, S. C., Kim, D. \& Jeon, Y. J. Protective effect of a novel antioxidative peptide purified from a marine Chlorella ellipsoidea protein against free radical-induced oxidative stress. Food Chem. Toxicol. 50, 2294-2302 (2012). 
217. Yarnpakdee, S., Benjakul, S., Kristinsson, H. G. \& Bakken, H. E. Preventive effect of Nile tilapia hydrolysate against oxidative damage of HepG2 cells and DNA mediated by $\mathrm{H} 2 \mathrm{O} 2$ and AAPH. J. Food Sci. Technol. (2015).

218. Pigeolet, E. et al. Glutathione peroxidase, superoxide dismutase, and catalase inactivation by peroxides and oxygen derived free radicals. Mech. Ageing Dev. 51, 283297 (1990).

219. Meilhac, O., Zhou, M., Santanam, N. \& Parthasarathy, S. Lipid peroxides induce expression of catalase in cultured vascular cells. J. Lipid Res. 41, 1205-1213 (2000).

220. Roig, R., Cascón, E., Arola, L., Bladé, C. \& Salvadó, M. J. Procyanidins protect Fao cells against hydrogen peroxide-induced oxidative stress. Biochim. Biophys. Acta - Gen. Subj. 1572, 25-30 (2002).

221. Kamoun, Z. et al. Efficacy of sardinelle protein hydrolysate to alleviate ethanol-induced oxidative stress in the heart of adult rats. J. Food Sci. 77, (2012).

222. Bhattacharya, S. K., Bhattacharya, A., Kumar, A. \& Ghosal, S. Antioxidant activity of Bacopa monniera in rat frontal cortex, striatum and hippocampus. Phyther. Res. 14, 174179 (2000).

223. Kim, J., Park, J., Kang, H., Kim, O. \& Lee, J. Beneficial effects of Korean red ginseng on lymphocyte DNA damage, antioxidant enzyme activity, and LDL oxidation in healthy participants: a randomized, double-blind, placebo-controlled trial. Nutrition Journal 11, 47 (2012).

224. Mendis, E., Rajapakse, N. \& Kim, S. K. Antioxidant properties of a radical-scavenging peptide purified from enzymatically prepared fish skin gelatin hydrolysate. J. Agric. Food Chem. 53, 581-587 (2005).

225. Lee, S. E., Hwang, H. J., Ha, J.-S., Jeong, H.-S. \& Kim, J. H. Screening of medicinal plant extracts for antioxidant activity. Life Sci. 73, 167-179 (2003).

226. Wijeratne, S. S., Cuppett, S. L. \& Schlegel, V. Hydrogen peroxide induced stress response. J Agric Food Chem 53, 8768-8774 (2005).

227. Liao, W. et al. Intracellular Antioxidant Detoxifying Effects of Diosmetin on 2,2-Azobis(2amidinopropane) Dihydrochloride (AAPH)-Induced Oxidative Stress through Inhibition of Reactive Oxygen Species Generation. J. Agric. Food Chem. 62, 8648-8654 (2014).

228. Park, M.-J. \& Han, J.-S. Fucoidan protects LLC-PK1 cells against AAPH-induced damage. J. Food Sci. Nutr. 13, 259-265 (2008). 
229. Epp, O., Ladenstein, R. \& Wendel, A. The refined structure of the selenoenzyme glutathione peroxidase at 0.2-nm resolution. Eur. J. Biochem. 133, 51-69 (1983).

230. Symonyan, M. A. \& Nalbandyan, R. M. Interaction of hydrogen peroxide with superoxide dismutase from erythrocytes. FEBS Lett. 28, 22-24 (1972).

231. Johnson, M. A. \& Macdonald, T. L. Accelerated CuZn-SOD-mediated oxidation and reduction in the presence of hydrogen peroxide. Biochem. Biophys. Res. Commun. 324, 446-450 (2004).

232. Shi, Y., Kovacs-Nolan, J., Jiang, B., Tsao, R. \& Mine, Y. Peptides derived from eggshell membrane improve antioxidant enzyme activity and glutathione synthesis against oxidative damage in Caco-2 cells. J. Funct. Foods 11, 571-580 (2014).

233. Shashoua, V. E., Adams, D. S., Volodina, N. V. \& Li, H. New synthetic peptides can enhance gene expression of key antioxidant defense enzymes in vitro and in vivo. Brain Res. 1024, 34-43 (2004).

234. Spanier, G. et al. Resveratrol reduces endothelial oxidative stress by modulating the gene expression of superoxide dismutase 1 (SOD1), glutathione peroxidase 1 (GPx1) and NADPH oxidase subunit (Nox4). J. Physiol. Pharmacol. 60 Suppl 4, 111-116 (2009).

235. Robb, E. L., Page, M. M., Wiens, B. E. \& Stuart, J. A. Molecular mechanisms of oxidative stress resistance induced by resveratrol: Specific and progressive induction of MnSOD. Biochem. Biophys. Res. Commun. 367, 406-412 (2008).

236. Vidyashankar, S., K Mitra, S. \& Nandakumar, K. S. Liv.52 protects HepG2 cells from oxidative damage induced by tert-butyl hydroperoxide. Mol. Cell. Biochem. 333, 41-48 (2010).

237. Jiménez, I., Aracena, P., Letelier, M. E., Navarro, P. \& Speisky, H. Chronic exposure of HepG2 cells to excess copper results in depletion of glutathione and induction of metallothionein. Toxicol. Vitr. 16, 167-175 (2002).

238. Wu, G., Fang, Y.-Z., Yang, S., Lupton, J. R. \& Turner, N. D. Glutathione metabolism and its implications for health. J. Nutr. 134, 489-492 (2004).

239. Lima, C. F., Fernandes-Ferreira, M. \& Pereira-Wilson, C. Phenolic compounds protect HepG2 cells from oxidative damage: Relevance of glutathione levels. Life Sci. 79, 20562068 (2006).

240. Kang, K. H. et al. Antioxidant peptides from protein hydrolysate of microalgae navicula incerta and their protective effects in Hepg2/CYP2E1 cells induced by ethanol. Phyther. Res. 26, 1555-1563 (2012). 
241. Tapiero, H., Mathé, G., Couvreur, P. \& Tew, K. D. II. Glutamine and glutamate. Biomedicine and Pharmacotherapy 56, 446-457 (2002).

242. Myhrstad, M. C. W., Carlsen, H., Nordström, O., Blomhoff, R. \& Moskaug, J. Ø. Flavonoids increase the intracellular glutathione level by transactivation of the $\gamma$-glutamylcysteine synthetase catalytical subunit promoter. Free Radic. Biol. Med. 32, 386-393 (2002).

243. Urata, Y. et al. Melatonin induces $\gamma$-glutamylcysteine synthetase mediated by activator protein-1 in human vascular endothelial cells. Free Radic. Biol. Med. 27, 838-847 (1999). 